University of San Diego

Digital USD

2001-07-09

\title{
The Relative Importance of Academic Achievement in Determining the Self-Esteem of Students in Rural British Columbia: An Empirical Examination of Students in Grades 6, 8, 10 and 12
}

Scott E. Bergstrome EdD

University of San Diego

Follow this and additional works at: https://digital.sandiego.edu/dissertations

Part of the Leadership Studies Commons

\section{Digital USD Citation}

Bergstrome, Scott E. EdD, "The Relative Importance of Academic Achievement in Determining the SelfEsteem of Students in Rural British Columbia: An Empirical Examination of Students in Grades 6, 8, 10 and 12" (2001). Dissertations. 670.

https://digital.sandiego.edu/dissertations/670

This Dissertation: Open Access is brought to you for free and open access by the Theses and Dissertations at Digital USD. It has been accepted for inclusion in Dissertations by an authorized administrator of Digital USD. For more information, please contact digital@sandiego.edu. 


\section{THE RELATIVE IMPORTANCE OF ACADEMIC ACHIEVEMENT IN DETERMINING THE SELF-ESTEEM OF STUDENTS IN RURAL BRITISH COLUMBIA: AN EMPIRICAL EXAMINATION OF STUDENTS \\ IN GRADES 6, 8, 10 AND 12.}

Scott E. Bergstrome

A dissertation submitted in partial fulfillment of the requirement for the degree of Doctor of Education

University of San Diego

July 9,2001

Dissertation Committee

Dr.Paula Cordeiro, Ed.D., Chair Dr. Fred Galloway, Ed.D., Member Dr. Robert Donmoyer, Ph.D., Member 


\begin{abstract}
As school systems across North America struggle to redefine themselves, educators everywhere are seeking a balance between academic achievement and the human and social needs of their students. The purpose of this correlational study was to quantitatively assess the construct of the school experience, as determined by academic achievement, as measured by GPA, and the level of involvement in school activities, from the perspective of four measures of student self-esteem. Data were collected from 263 students in grades $6,8,10$, and 12 in a small district in southwestern Canada.

The first part of this study explored the relationship between student self-esteem and four independent variables: GPA, level of involvement, grade level, and gender. The Coopersmith Self-Esteem Inventory was used to measure self-esteem on four scales. As a result of multiple regression analysis it was found that the $R^{2}$ values were very low in all cases (ranging from 0.20 to 0.36 ), which indicates that the factors studied were poor indicators of self-esteem and that there was a great deal unexplained variation associated with the data. GPA, level of involvement, grade and GPA:grade were significant at .05 level of significance. Gender was not a significant factor in this study. It appears that selfesteem is linearly related to GPA, with the intercept depending on the grade, level of involvement, and gender and the slope depending on the grade. The relationship between GPA and self-esteem was strongest at Grade 6. Self-esteem was found to be strongest for students who were heavily involved in school-related or extra-curricular activities.

Eleven survey questions regarding the school experience were analyzed using logistical regression analysis, which showed that the importance of getting good grades and participating in school activities varied according to grade and gender. Academic
\end{abstract}


achievement was most important to Grade 6 students, good grades were more important to girls, than boys, and the association between getting good grades and self-esteem was strongest at Grade 6.

This study suggests the current focus on intellectual development in most schools may not have the desired effect on social and human development, more specifically, the development of healthy self-esteem. 


\section{DEDICATION}

I would like to dedicate this project to my best friend and partner in marriage and life, my wonderful wife Moira, for her unwavering support and encouragement, without which I fear this adventure would not have been possible. Additionally, I would like to dedicate my work to my five children, Alana, Jeffrey, Laura, Jennifer, and Erik, for their patience and support over the last several years. I also wish to dedicate this study to my grandson, Sebastian, whose appreciation of life inspires me. Finally, although yet unborn, I would like to dedicate my efforts to any future grandchildren I may have. The miracle and mystery of children is the true essence of what motivates me to do this study. 


\section{ACKNOWLEDGEMENTS}

I wish to express my appreciation to Dr. Paula Cordiero, the Dean of the School of Education at the University of San Diego and the Chair of my Dissertation Committee, for her encouragement and guidance throughout the writing of this document. Dr. Cordeiro personifies Educational Leadership in the truest sense.

I also wish to thank Dr. Fred Galloway and Dr. Robert Donmoyer, both members of my Dissertation Committee, for challenging me to strive for understanding and perfection.

In addition, I would like to thank my statistical analysis mentor team, Rachel Mackay of the Statistical Consulting and Research Lab at the University of British Columbia; Dr. Rod Matheson, statistics instructor and Director of the West Vancouver International Education Program; Dr. John Anderson, School of Education, University of Victoria: Dr. Rick Brydges, Leadership Consultant; and my fellow doctoral students and Northern Lights, Dr. Ron Germaine, Dr. Halyna Kornuda, Dr. Doug Hoey, and doctoral candidate, Craig Code.

I also wish to thank the rest of the administrative team at Gulf Islands Secondary School, Principal Nancy Macdonald and Vice Principal Neill Armitage, for their patience and understanding. They often walked the extra mile on my behalf so that I could focus on this work.

Finally, I would like to thank the students who participated in this study. They collectively were the force behind these efforts. 


\section{TABLE OF CONTENTS}

ABSTRACT
DEDICATION
ACKNOWLEDGEMENTS
LIST OF TABLES

CHAPTER I: OVERVIEW OF THE STUDY

Introduction 1

Statement of the Problem $\quad 4$

Background of the Study $\quad 4$

Self-esteem $\quad 6$

Optimism: Confidence and positive attitudes towards the future 8

Academic achievement 9

Methods and Procedures $\quad 11$

$\begin{array}{ll}\text { Limitations } & 14\end{array}$

Definition of Terms $\quad 17$

Significance of the Study 18

$\begin{array}{ll}\text { Summary } & 19\end{array}$

CHAPTER II: THE LITERATURE REVIEW $\quad 20$

$\begin{array}{ll}\text { Introduction } & 20\end{array}$

Self-esteem $\quad 21$

What is self-esteem? $\quad 21$

$\begin{array}{ll}\text { Criticism of self-esteem } & 24\end{array}$

Self-esteem and learning $\quad 25$

$\begin{array}{ll}\text { Current research } & 27\end{array}$

$\begin{array}{ll}\text { Optimism } & 30\end{array}$

What is optimism?

Optimism and learning $\quad 34$

$\begin{array}{ll}\text { Current research } & 36\end{array}$

Academic Achievement $\quad 39$

What is academic achievement? $\quad 40$

Traditional assessment and evaluation $\quad 42$

Academic achievement $\quad 45$

Summary 51

CHAPTER III: METHODOLOGY AND DATA COLLECTION

Introduction $\quad 54$

Research Questions $\quad 54$

Sample $\quad 55$

Access and Confidentiality $\quad 57$

Instrumentation $\quad 58$

Coopersmith Self-Esteem Inventory $\quad 59$

Student Survey 61

Procedures $\quad 62$ 
Sample Analysis $\quad 67$

Limitations of the Study $\quad 69$

$\begin{array}{ll}\text { Summary } & 70\end{array}$

CHAPTER IV: ANALYSIS OF DATA

$\begin{array}{ll}\text { Introduction } & 72\end{array}$

Data Collection and Procedures $\quad 73$

Multiple Regression Analysis $\quad 74$

Survey Analysis $\quad 91$

Description of survey analysis 93

Summary of survey analysis $\quad 112$

Summary of Analysis of Data 113

CHAPTER IV: SUMMARY, CONCLUSIONS, AND RECOMMENDATIONS 115

$\begin{array}{ll}\text { Introduction } & 115\end{array}$

Findings and Discussion $\quad 115$

Statistical analysis 117

Survey analysis 121

Implications for Future Study $\quad 129$

Recommendations for future study 130

Limitations of the study $\quad 132$

Summary and Conclusions 133

REFERENCES 136

APPENDIX

A: Coopersmith Self-Esteem Inventory 146

B: Student Survey 148

C: Request for Permission to Conduct the Study 152

D: Parent Informed Consent Form 153

E: Scatter Plots 155

F: S-PLUS Analysis of Self-Esteem Data (New GPA's, Full Model) 159

G: S-PLUS Logistical Regression Survey Analysis 171

$\mathrm{H}$ : Correlation Matrices for GPA and GPAnew 176

I: Correlation Tests Using Type 1 and Type 3 ANOVA Tables 178

J: S-PLUS Comparisons of Type 1 and Type 3 ANOVA Tables 181

K: S-PLUS Comparisons of Parameter Tables 187 


\section{LIST OF TABLES}

Table 3.1 Student participation data according to grade level and gender after Lie Scale (>4) data eliminated for the statistical analysis

Table 4.1 ANOVA table for Total self-esteem and the independent variables, GPAnew, Involvement, Gender, Grade, and GPAnew:Grade

Table 4.2 Parameter estimates, $t$-values, and significance of the independent variables to Total self-esteem

Table 4.3 ANOVA table for School-Academic self-esteem and the independent variables, GPAnew, Involvement, Gender, Grade, and GPAnew:Grade

Table 4.4 Parameter estimates, $t$-values, and significance of the independent variables to School-Academic self-esteem

Table 4.5 ANOVA table for General self-esteem and the independent variables, GPAnew, Involvement, Gender, Grade, and GPAnew:Grade

Table 4.6 Parameter estimates, $t$-values, and significance of the independent variables to General self-esteem

Table 4.7 ANOVA table for Social Self-Peers self-esteem and the independent variables, GPAnew, Involvement, Gender, Grade, and GPAnew:Grade

Table 4.8 Parameter estimates, $t$-values, and significance of the independent variables to Social Self-Peers self-esteem

Table 4.9 Student responses recorded as a percentage to survey question 1

Table 4.10 Student responses recorded as a percentage to survey question 2

Table 4.11 Student responses recorded as a percentage to survey question 3

Table 4.12 Student responses recorded as a percentage to survey question 4

Table 4.13 ANOVA table for survey question 4

Table 4.14 ANOVA table for survey question 5

Table 4.15 Number of responses according to gender to survey question 5 
Table 4.16 ANOVA table for survey question 6

Table 4.17 Number of responses according to gender to survey question $6 \quad 100$

$\begin{array}{lll}\text { Table } 4.18 & \text { ANOVA table for survey question } 7 & 100\end{array}$

Table 4.19 Number of responses according to grade and gender to survey 101 question 7

Table 4.20 Student responses according to grade to survey question $8 \quad 103$

Table 4.21 Number of responses according to gender to survey question $9 \quad 105$

Table 4.22 Student responses recorded as a percentage to survey question $10 \quad 106$

$\begin{array}{lll}\text { Table 4.23 ANOVA table for survey question 11A } & 107\end{array}$

Table 4.24 Number of responses according to gender to survey question 11A $\quad 108$

Table 4.25 Number of responses according to grade to survey question 11B 109 


\section{CHAPTER I: OVERVIEW OF THE STUDY}

Introduction

During the summer of 2000, the San Diego Union-Tribune featured a special report under the heading, A Measure of Success, which examined the success of the San Diego public schools on the Stanford Achievement Test (Ninth Edition). According to the article, "The statewide SAT 9 results are the linchpin of a public school accountability system" (p. 1). The use of the SAT 9 in California mirrors the North American trend towards standards and accountability in education. Standards and accountability have become popular political issues. As part of his television campaign for the presidency of the United States, for example, then Texas Governor, George W. Bush, promoted the implementation of standardized public school testing in his state as an example of his commitment to accountability.

The political agenda of using standardized testing as the primary measure of accountability in public education has not been without controversy. In the introduction of his book, Taking Sides: Clashing Views on Controversial Education Issues, James Noll (1997) asks two thought-provoking questions, "What is an educated person?" and "What should be the primary purpose of organized education?" (p. xv). Branden (1994) wonders, "Is the primary goal to train young people to be good citizens?" (p. 206). He suggests further:

What is needed and demanded today, in the age of the knowledge worker, is not robotic obedience but persons who can think; who can innovate, originate, and function self-responsibly; who are capable of self-management; who can remain individuals while working as members of teams; who are confident of their powers and their ability to contribute. What the workplace needs today is selfesteem. And what the workplace needs sooner or later of necessity becomes the agenda of the schools (p. 207). 
The British Columbia Graduation Program Policy (1993) states students..."should leave the public school system with the knowledge, skills and attitudes needed to become educated citizens" (p. 1). According to Year 2000: A Framework for Learning (1999), "The purpose of the British Columbia school system is to enable learners to develop their individual potential and to acquire the knowledge, skills, and attitudes needed to contribute to a healthy society and a prosperous and sustainable economy" (p. 3). The educated citizen is described as follows:

A healthy society and a prosperous and sustainable economy are achievable when educated citizens, striving to be the best they can be, are thoughtful, able to learn and to think critically, and able to communicate information from a broad knowledge base; creative, flexible, self-motivated and possessing a positive selfimage; capable of making independent decisions; skilled and able to contribute to society generally, including the world of work; productive, able to gain satisfaction through achievement and to strive for physical well-being; cooperative, principled and respectful of others regardless of differences; aware of the rights and prepared to exercise the responsibilities of an individual within the family, the community, Canada and the world (p.3).

This description of the educated citizen has much in common with Branden's view of the knowledge worker. It is also remarkably consistent with the Conference Board of Canada's three employability skill sets as identified by the British Columbia Labour Force Development Board's document, Training for What? (1995). The Conference Board, in consultation with industry and employer groups, suggests that there needs to be more emphasis on the development of academic skills, personal management skills, and teamwork skills. The Board stresses that employers need employees, who have the academic skills to communicate effectively; think critically and problem solve; use tecknology and access information; and embrace lifelong learning as a reality. Personal management skills are identified as..."the combination of skills, attitudes and behaviors 
required to get, keep and progress on a job and to achieve best results" (p. 21). More specifically, Canadian employers need employees who can demonstrate positive attitudes, including self-esteem and confidence; responsibility; adaptability; and the ability to work with others (p. 21).

Finding a balance that meets the needs of society and the workplace, and the everincreasingly demand for accountability in public education, creates some interesting problems for educators and politicians. One has to wonder if the current emphasis on academic achievement, as measured by standardized tests or grade-point averages, is likely to produce the personal management characteristics so desired of the educated citizen. While Year 2000: A Framework for Learning (1999) identifies the primary goal of the British Columbia public schools as Intellectual Development (p. 4), it also identifies a secondary goal, Human and Social Development. The learning strategies for the development of the knowledge and skills dimensions (Intellectual Development) of the educated citizen are clearly articulated throughout the Year 2000: A Framework for Learning document. The authors say very little, however, about the development strategies for the attitude dimensions, which include a positive self-image and sense of self-worth (Human and Social Development), and how this might be achieved. The underlying assumption seems to be that these personal qualities will somehow evolve out of the focus on intellectual development and academic achievement. It is the purpose of this study to investigate this assumption from the perspective of a small, semi-rural school district in southwestern British Columbia. 
Statement of the Problem

As school systems across North America struggle to redefine themselves in terms of the $21^{\text {st }}$ century, educators everywhere are seeking to create a balance between academic achievement and the human and social needs of their students. While intelligence tests, standardized assessments, and grade-point averages generally define academic achievement, the human and social dimensions are less likely to be formally evaluated and are often difficult to define. According to the Year 2000: A Framework for Learning document they are defined, at least in part, as a positive self-image and sense of self-worth. The British Columbia Labour Force Development Board (1995) defines the human and social dimensions as positive attitudes and behaviors, including self-esteem, confidence and a positive attitude toward change. The problem that needs to be addressed, at least from the perspective of the province of British Columbia and the district in question, is how to develop these human and social dimensions within a school system that defines intellectual development as its primary purpose. Will a focus on academic achievement help students develop self-esteem and positive attitudes about change? The purpose of this study is to explore this question in terms of students in grades $6,8,10$ and 12 .

\section{Background of the Study}

There is strong evidence in the literature that suggests a positive relationship between academic achievement and self-esteem (Wiggins, Schatz, \& West, 1994). The California Task Force to Promote Self-esteem and Personal and Social Responsibility collected and documented much of this evidence in the 1990 document, Toward a State of Esteem. What is less clear, however, is the direction of this relationship. It is not clear 
whether self-esteem is primarily a dependent or independent variable (Mruk, 1995).

Kitano (1989), as cited in Mruk (1995) suggests from a socio-cultural perspective, it is a

Dependent variable, that is, self-esteem is the result of a person's ethnic, social class, or gender group...Another aspect of self-esteem is that self-esteem is in progress or in process. Individuals are perceived and judge themselves in relation to yet-to-be fulfilled goals and activities...Self-esteem is also used as an independent variable - that is, as the "cause" of behavior. An individual is said to behave in a particular manner because of a high or low level of self-esteem. Through knowledge of this variable, then, we can try to predict and understand behavior (p. 318).

In this study, self-esteem is viewed as a dependent variable, as the researcher is interested in the influence of academic achievement on self-esteem. Academic achievement is viewed as an independent variable. The literature suggests significant age- and genderspecific considerations may be relevant (Gleason, 1998; Kolenik, 1993; Levinson, 1996; $\mathrm{Wu}, 1990)$ so they have been included as additional independent variables. There is also some uncertainty as to the meaning of self-esteem. According to Mruk (1995), there are at least three schools of thought on this issue. Self-esteem is defined by some as a sense of worthiness, while for others it is a sense of competence. A third group defines selfesteem as a combination of both these dimensions.

A significant relationship between self-esteem and optimism has been documented in the literature (Rambo-Chroniak, 1998). Given the emphasis on confidence and positive attitudes in this chapter, the researcher conducted exploratory research, which asked the students to consider the value of their school experience in terms of feelings of worthiness and confidence in the future. It is important to understand that during this part of the study no formal measurement of optimism was used in the data collection. The researcher was only interested in identifying themes with regard to certain aspects of the school experience and student views of the future, and believes there is no acceptable, valid, or reliable instrument currently available to adequately measure this 
intent. From the review of the literature, it was concluded that optimism is generally viewed as a sub-scale on an unrelated self-concept measurement or used as a measurement of coping strategies, explanatory style, or depression. None of these measurements adequately address the student view of the school experience and how it relates to the future. As Patton (1990) points out,

The state of the art in social science measurement is such that a number of desirable outcome measures still elude precise measurement. Where outcome measurements have not been developed and tested, it is more appropriate to gather descriptive information about what happens...than to use some scale that has the merit of being quantitative but whose validity and reality are suspect (p. 130).

While there will be no claim of significant findings regarding relationships, only potential themes for further study, it is expected that the student responses will add a valuable dimension to the study and have therefore they have been included.

Many questions need to be answered. Is it possible, for example, that a student might feel confident about his or her future without demonstrating academic success? It is possible that he or she may have a positive self-regard, yet feel negative about the future? History reminds us that many of our greatest minds have been tormented by thoughts of the future and have even engaged in self-destructive habits, which seem inconsistent with high levels of self-esteem. To help clarify some of these questions, it will be helpful to briefly discuss self-esteem, optimism and academic achievement in terms of this study.

\section{Self-esteem}

In January 1990, Toward A State of Esteem, the Final Report of the California Task Force to Promote Self-esteem and Personal and Social Responsibility, recommended, "Every school district in California should adopt the promotion of selfesteem and personal and social responsibility as a clearly stated goal" (p.65). As 
previously mentioned, there is considerable debate as to the meaning of self-esteem. For some, self-esteem is primarily a measure of competence (James, 1890; White, 1963), while others are more inclined to define self-esteem as a measure of worthiness (Coopersmith, 1967; Rosenberg, 1965). Mruk (1995) defines self-esteem as a function of both dimensions, worthiness and competence, and suggests that his definition is similar to the view of Branden (1994), who defines self-esteem as combination of self-respect and self-efficacy. These different views of self-esteem create some problems for the researcher when searching for appropriate assessment instruments.

Clearly both dimensions of self-esteem are important to the ideal of the educated citizen. A study measuring both the worthiness and competence sides of the self-esteem equation might provide valuable insight into the relationship between this broader view of self-esteem and academic achievement. Mruk (1995) reports, "There are self-esteem tests which seem to include both components in their design, such as Coopersmith's Selfesteem Inventory" (p.36). The Coopersmith Self-Esteem Inventory was originally designed for use with children, drawing on items from scales that were previously used by Carl Rogers. A widely used instrument, the Coopersmith Self-Esteem Inventory or SEI (see Appendix A) is recognized as a reliable measurement of self-esteem and is used to measure self-esteem on five scales: General Self, Social Self-Peers, School-Academic, Home-Parents and a composite score, Total Self. The SEI is frequently cited as an instrument of choice by researchers investigating self-esteem (Blascovich \& Tomaka, 1991). Coopersmith (1967) defines self-esteem as follows:

By self-esteem, we refer to the evaluation a person makes, and customarily maintains, of himor herself; that is, overall self-esteem is an expression of approval or disapproval, indicating the extent to which a person believes him- or herself to be competent, successful, significant and worthy. In shoit, self-esteem is a personal judgment of worthiness that is expressed in the attitude the individual holds toward himself [herself] (p. 5). 
For the purpose of construct validity, Coopersmith's definition of self-esteem is used to define self-esteem in this study.

Optimism: Confidence and positive attitudes towards the future

Like self-esteem, there is considerable debate as to the meaning of optimism. Webster's Ninth New Collegiate Dictionary (1987) defines optimism as an inclination to put the most favorable construction upon actions and events or to anticipate the best possible outcome. The Random House Thesaurus, College Edition (1987) offers that optimism is a sense of confidence, hopefulness, and trust in the future. Branden (1994) defines the self-efficacy dimension of self-esteem as a sense of basic confidence in the face of life's challenges; self-trust; self-reliance (p. 26). This sense of well-being implies a sense of confidence that connects the internal self with the external view one has of him- or herself. Confidence suggests a direct relationship between the sense of self-worth and the level of optimism one has regarding his or her skills, attitudes and abilities. The New Lexicon Webster's Encyclopedic Dictionary of the English Language defines confidence as a state of trust and a feeling of hope on which one relies (p.205). Internal trust and hope are key components of what Seligman (1995) defines as optimism. For the purpose of this study, the term optimism combines these elements of trust and hope as a reflection of the confidence and positive attitudes students have towards their skills and abilities and their ability to exert some control over their future.

The 1994 National Youth Survey (Van Scotter, 1994) asked a sample of 630 students, aged 10-17: "How sure are you that you will have a promising future and be able to control your life?" Over $90 \%$ of the students responded that they were either "very sure" or "somewhat sure", implying a high degree of confidence and optimism 
about the future. When asked, "How well off financially do you expect to be as an adult compared to your family?" $99 \%$ of the students indicated that they would be at least the same, or better off, financially. These results were echoed in a similar survey of Canadian youth, which reported $93 \%$ of the respondents expected to achieve happiness and prosperity during their lifetime (Kiener, 2000). Optimism is clearly a theme in both these surveys, even though at times it seems to be based on blind faith and a lack of realism. Sixty-three percent of the students participating in the 1994 National Youth Survey, for example, indicated that they expected to find future employment as professionals or managers, with $30 \%$ of this group expecting to earn at least a doctoral degree. This is interesting, given Van Scotter's observation that many of these students were generally nonchalant about their studies (p. 77). Stevenson (1992), as citied in Frase and Streshly (2000), concurs. In his study of education in Asia and the United States, he found only $10 \%$ of American students mentioned education as being very important to them; they valued money and things. Frase and Streshly suggest further..."that the trend is clear...American parents and students...lack faith in the efficacy of hard work in school" (p. 61). While the reported findings of the 1994 National Youth Survey imply that most students possess a high degree of confidence and a highly optimistic view of the future, one has to wonder on what this apparent optimism is based and if self-esteem and academic achievement are important considerations.

$\underline{\text { Academic achievement }}$

Over the past two decades the school reform movement across North America has witnessed a boom of intellectual activity designed to engage the learner in the process of learning. Despite these efforts, student success in school continues to be measured 
primarily as a function of grades and grade-point averages. Standardized tests are increasingly being used as a measurement of school effectiveness and for entry into postsecondary programs. In the past, the assumption has been that high grades in school should help students find success beyond their school experience. Certainly many of the students who excelled in school and earned the highest grades were the ones most likely to gain entry into the colleges and universities. Academic achievement is clearly recognized as important and should not be minimized, especially in terms of the knowledge-based economy. The British Columbia Labour Force Development Board (1995) reminds us, however, that this knowledge-based economy also demands strong personal management skills, such as good self-esteem, and confidence and positive attitudes, qualities generally associated with an optimistic view of life and the future. This researcher is intrigued by the obvious discrepancies between the apparent need for self-esteem programs in schools as expressed by the California Task Force to Promote Self-esteem and Personal and Social Responsibility; the high levels of optimism reported by students on the 1994 National Youth Survey; and the cited malaise towards education as a value.

This study examines these important relationships in more depth by exploring the following research questions:

1. To what extent does academic achievement influence the Total self-esteem of students in grades 6,8,10 and 12 in a small, semi-rural school district in British Columbia?

a. To what extent does academic achievement influence the School-Academic selfesteem of the students? 
b. To what extent does academic achievement influence the General-Self self-esteem of the students?

c. To what extent does academic achievement influence the Social Self-Peers selfesteem of the students?

2. Do these relationships vary by gender, grade level and participation in nonacademic and extra-curricular activities in school?

3. What attitudes, if any, do the participants in this study have with regard to their school experience, more specifically towards getting good grades, participating in school activities, and preparing for the future

4. Do these attitudes vary according to gender and grade level?

Methods and Procedures

In this quantitative study, that utilizes both correlational and descriptive designs, approximately 450 students across four different grade levels (Grade 6, 8,10 and 12) in a small rural school district in southwestern British Columbia were invited to participate. Two hundred and eighty-seven students accepted this invitation. To answer Research Questions 1 and 2, the Coopersmith Self-Esteem Inventory or SEI was administered to gain measures self-esteem on four scales: General Self, Social Self-Peers, SchoolAcademic, and a composite score, Total Self. Although a fifth measure, the HomeParents score, contributes to the composite score, it was not identified in this study as a dependent variable due to the lack of direct relevance. The other four scores were used as the dependent variables for self-esteem. These scores were modeled as functions of four independent variables: student grade point averages (GPA), as reported on the student report cards at the end of the first school term; the self-reported level of 
participation in non-academic and extra-curricular school activities; grade level; and gender.

Multiple regression analysis was used to determine the extent of the relationship between the dependent variable, self-esteem, and the four independent variables mentioned above. Dummy variables were created for level of participation, gender, and grade level. When dummy variables that represent different levels of a categorical variable are created and used as independent variables in multiple regression, the resulting $R^{2}$ is interpreted the same way (Hinkle, Wiersma \& Jurs, 1988). The multiple regression analysis included determining the coefficient of determination $R^{2}$ and testing for significance of the independent variables at the $5 \%$ level. In each case, self-esteem was modeled as a linear function of the continuous GPA data and the level of Involvement, Grade, and Gender. The main effects of these variables, along with the GPA:Grade, GPA:Involvement, and GPA:Gender interactions, were included in the original model. Since the different types of self-esteem were measured on scales with at least 17 points, it was assumed, for simplicity, that these measurements were continuous and, in particular, were normally distributed with constant variance. Further, it was assumed that the students' self-esteems were independent, that is, unrelated to one another. Multiple comparison analysis was then conducted to investigate mean differences between the different levels of the factors deemed significant to the study. Finally, comparative analysis was conducted between the participating and nonparticipating students to ascertain whether the participating students were representative of the total population. 
A descriptive research design was used to answer Research Questions 3 and 4. In the case of Research Question 3, an open-ended questionnaire was used to collect descriptive data regarding the participants' perceptions of the value of their school experience in terms of self-esteem, optimism, and their future. This second part of the study was exploratory and primarily designed to generate some hypotheses for further study. The questionnaire or Student Survey was piloted with a group of fifty-six grade 9 students as part of their Career And Personal Planning program. As a result of this pilot, several changes were made to the format of the questionnaire, including the method of self-reporting the level of participation in school-related or extra-curricular activities and the wording of several of the questions. Four additional questions were added to the original seven questions, three of which had been taken directly from the 1994 National Youth Survey, to add more depth to the student responses.

The survey questions provided the respondents with an opportunity to rate their degree of response, then to expand upon these ratings by answering related open-ended questions. For each question, the ratings were combined to get an aggregated response. In Question 1, for example, the Very sure and Somewhat sure responses and Not too sure and Not sure at all responses were combined and classified as either Sure or Not sure (an aggregated response). To answer Research Question 4 logistical regression was used to analyze the relationship between the response and the independent variables: Grade, Gender, and the interaction between Grade and Gender. Logistical regression is a type of regression procedure used when there is one binary dependent variable. The response in a logistical regression is the log odds of the probability of "success". In the example above, the probability of success is probability of a students being Sure. By modeling the 
response in this way, we can deal with the problem of binary (rather than continuous) data. As before, the independent variables, which are categorical, were coded as dummy variables.

Given the reported difficulty some of the students in the pilot study experienced estimating the actual number of hours they spent on average each week engaged in school-related non-academic and extra-curricular activities, students were now asked to rate the level of participation as none, minimal (one hour or less), moderate (more than one hour, but less than three) or heavy (more than three). A checklist of activities was included under specific headings to help promote more accurate responses. Student scores on the Student Survey were tallied and reported according to grade, number, and gender, when Gender was found to be a significant factor. The descriptive data were coded and the responses grouped according to theme. Any reporting of student responses to the open-ended questions is speculative and not intended to be statistically significant. The decision to include these typical responses was made because this researcher believes they add a human dimension to the reporting of the statistical analysis related to the survey.

\section{Limitations}

This study should only be considered a glimpse in time. Time constraints limit the ability to conduct a longitudinal study, which would measure the variables over time. It is also important to remember that the findings are based solely on the collection of data from students in a small, predominantly white and middle class, semi-rural school district in southwestern British Columbia. Additional research needs to be conducted to discover whether the findings are generalizable across other populations or to other areas of the 
province or to larger communities. While some effort has been made to compare at least the GPA, gender, and grade level of participating and non-participating students, it may be difficult to generalize the findings across the overall school population in this district, given the rate of non-response was relatively high at $36 \%$. Comparative data on the level of involvement for the non-participating students was not available, yet this independent variable was considered to be an important factor in this study. It seems some students were excluded because their parents were less supportive of the project and simply refused or neglected to return the parent consent forms. This may have resulted in some response bias, that is, the students self-selected to participate in this study, thus the sample may not have been a random sample and therefore, the results may not accurately reflect the total population.

Although a generally respected measurement of self-esteem, many of the items in the Coopersmith Self-Esteem Inventory are context-bound, that is, the respondents are instructed to respond to the item within a specific context; rather than context-free, where the there is no reference to context. There is some evidence to suggest that results associated with gender or ethnic/racial differences may differ when the self-esteem measure is context-free or context-bound (Osbourne \& Le Gette, 1982). When dealing with general populations, it is possible that some students may not complete all of the 58 items on the Coopersmith Self-Esteem Inventory. Depending on the level of omission, this problem, should it occur, will be addressed using the zero-order correction technique, that is, the calculation of the mean scores of the other students in the same grade and gender group, then substituting this value for the missing response. If the number of items omitted is considered beyond this unbiased correction procedure, in this case, more 
than one of the eight items in the Social Self-Peers and School-Academic scales or more than three of the twenty-six items in the General Self scale, the inventories will be excluded from the study. In addition, the Lie Scale (0-8), which is associated with the Coopersmith Self-Esteem Inventory, reveals the probability that some students may respond to the items on the inventory either defensively or in a manner in which they think they were expected to answer. According to the Coopersmith Self-Esteem Inventory manual, high scores on the Lie Scale may render the inventory invalid and require additional study, so it was determined that scores $>4$ would not be included in the statistical analysis. Further investigation of these respondents, however, might add valuable insight to the study.

When self-reporting measures are employed in the collection of data, the responses may not accurately reflect the thoughts, feelings, or actions of the respondents. The fact that over $8 \%$ of the respondents had a score $>4$ on the SEI Lie-Scale seems to support this point. Perhaps the greatest limitation of all measures of self-esteem is their susceptibility to socially desirable responding. Most measures are self-report, and it is difficult to obtain non-self-report measures of such a personal and subjective construct. Also, scores tend to be skewed toward high self-esteem, with even the lowest scorers on most tests scoring above the mean and exhibiting fairly high levels of self-esteem (Adler, 1997). In addition, grading inconsistencies, including the calculation of GPA, are commonplace throughout education, even with the individual teacher. The reporting of grades seems to be an imprecise science at best. To add to the confusion, sometimes grades are reported as percentages, while in other cases, they are more subjective and percentages are less visible. 
The use of the Student Survey has several strengths including accuracy, generalizability, and convenience, but as Marshall and Rossman point out, "The strengths of surveys can also be weaknesses. While controlling for accuracy, a survey cannot assure without further evidence that the sample represents a broader universe" (p.85). This statement suggests accuracy may be at a cost of generalizability. As reported above, self-reported measures such as the estimation of involvement in extra-curricular are susceptible to socially desirable responses, which may or may not reflect more longitudinal trends. Another survey limitation is potential researcher bias. The researcher must ensure that the descriptive data are reported as written. A written survey or questionnaire may lose some of the depth of the communication process as it misses language beyond the written word. It is also possible that some students may have experienced difficulty interpreting some of the questions, even though the researcher attempted to address this problem as the survey was being administered.

\section{Definition of Terms}

For the purpose of this study self-esteem, academic achievement, and optimism are defined as follows:

Self-Esteem: Self-esteem, according to Coopersmith (1967), is..."the evaluation a person makes, and customarily maintains, of him- or herself; that is, overall self-esteem is an expression of approval or disapproval, indicating the extent to which a person believes him- or herself to be competent, successful, significant and worthy. In short, self-esteem is a personal judgment of worthiness that is expressed in the attitude the individual holds toward himself [herself]" (p. 5). 
Academic Achievement: Academic achievement is a measurement of academic success, as reported through grade-point averages.

Optimism: For the purpose of this study, the term optimism is defined as the combination of self-trust and hope that results in the confidence and positive attitudes that students have regarding their skills and abilities, and their ability to exert some control over their future.

\section{Significance of the Study}

Although only reflective of a small and somewhat unique school district in south western British Columbia, this study is significant in the sense that it explores the relationship between academic achievement and the human and social dimension: student self-esteem. As pointed out earlier in this chapter, self-esteem is recognized as central to development of the educated citizen and the knowledge worker of the $21^{\text {st }}$ century. As the person responsible for the coordination of the Career and Personal Development program in the district under investigation, this study provides the researcher with an opportunity to investigate how well the participating schools are helping students develop these important human and social dimensions. The study spans the general school population over four grade levels and seeks to address issues related to gender. Some concern has been expressed locally and provincially that boys are somehow falling behind intellectually and socially. This study might provide valuable insight regarding these allegations. Student attitudes toward their school experience should provide some additional insight into how the students view the relevance of school in terms of their future. Finally, this study should contribute to the current literature on self-esteem and academic achievement by attempting to address the stated problem: How do we, as 
educators, address the human and social needs of our students, in a system that identifies academic achievement as its primary purpose?

\section{Summary}

To conduct a study which encompasses all the variables suggested in the Graduation Program and the Conference Board of Canada's employability skill sets would be a monumental task and difficult to achieve. The notion of the educated citizen is intriguing, however, and worthy of study. The educated citizen, as defined by the British Columbia Graduation Program, is one who has mastered his or her academic skills through Intellectual Development, as well as developed their personal management and teamwork skills through Human and Social Development. This study attempted to narrow the focus by concentrating on the relationship between academic skills, in terms of academic achievement, and two important personal management skills, self-esteem and optimism in a small school district in semi-rural British Columbia. 


\title{
CHAPTER II: THE LITERATURE REVIEW
}

\author{
Introduction
}

A great deal of emphasis has been placed on the promotion of self-esteem programs in schools across North America over the past decade. In January 1990, Toward A State of Esteem, the Final Report of the California Task Force to Promote Self-esteem and Personal and Social Responsibility recommends, "Every school district in California should adopt the promotion of self-esteem and personal and social responsibility as a clearly stated goal" (p.65). The Task Force presented convincing "expert" evidence that low self-esteem is related to low academic achievement, especially in at-risk populations. Less clear, however, is the relationship between high levels of selfesteem and academic achievement.

The 1994 National Youth Survey: Attitudes Regarding Society, Education, and Adulthood, conducted by the Gallup Organization for Junior Achievement, Inc., revealed several conflicting observations. While $91 \%$ of the students surveyed expressed confidence in their futures ( $55 \%$ very sure and $36 \%$ somewhat sure), interview data also revealed unrealistic career expectations and a general malaise towards learning (Van Scotter, 1994). It seems there may be some merit in investigating the discrepancies associated with self-esteem, optimism (confidence in the future), and academic achievement. This chapter will first examine the current literature on self-esteem, especially in terms of learning. Next, the literature on optimism and its relationship with learning will be summarized. Finally, the construct of academic achievement as it relates to accepted measurement practices will be reviewed. 


\section{Self-Esteem}

The Final Report of the California Task Force to Promote Self-esteem and Personal and Social Responsibility (1990) concludes, "Education and the schoolexperience greatly influence a child's psychology and social well-being, character, and productive potential as an adult" (p.64). The Task Force recommends teacher education programs include course work on self-esteem. According to the Task Force self-esteem is

Appreciating my own worth and importance and having the character to be accountable for myself and to act responsibility toward others (p.18).

Nathaniel Branden (1994) expresses concern in his book, The Six Pillars of Self-Esteem, however, that this definition is problematic due to its lack to specificity and wonders what the Task Force means by the terms "worth and importance". "Concerning what?" he asks. Branden is also highly critical of the insertion into the definition of what he suggests is obviously meant to be a basic source of healthy self-esteem (that is, being accountable for oneself and acting responsibly towards others). According to Branden, "A definition of a psychological state is meant to tell us what a state is, not how one gets there" (p.307).

\section{What is self-esteem?}

Many definitions of self-esteem exist in the literature, and are sometimes synthesized into meaning the way a person thinks and feels about him- or herself and how he or she does things that are important to him or her. Branden (1994) defines this state as feeling confidently appropriate to life. Self-esteem, according to Branden, is a function of self-efficacy, the confidence in our ability to think, learn, choose, make decisions, and understand; and self-respect, the assurance of our own personal value (p.4). Mruk (1995) also sees self-esteem as having two similar dimensions: competence 
and worthiness, and suggests Branden's view of self-efficacy implies competence (p. 18).

Bandura (1997) expands on this idea of self-efficacy and suggests:

There is a causal relationship between beliefs of personal efficacy and outcome expectations. Perceived self-efficacy is a judgement of one's ability to organize and execute given types of performances, whereas an outcome expectation is a judgement of the likely consequence such performances will produce.

A high sense of personal efficacy in a responsive environment that rewards valued accomplishments fosters aspirations, productive engagement in activities, and a sense of fulfilment. These are the conditions that enable people to exercise substantial control over their lives through self-development (p. 21).

To esteem yourself you must value yourself. Certain attitudes toward self result from this value assessment. These attitudes have several psychological components, including beliefs, emotions and behaviours. The evaluation one makes of one's self goes beyond feelings.

Although sometimes defined in slightly different terms, self-esteem is generally seen as an integration of both the cognitive and feeling dimensions. William James (1890) identified four aspects of the self: the physical self, the social self, the cognitive self, and spiritual self. Steinem (1993) suggests self-esteem is personal, contagious, selfdiscovery, physical, cosmic, love. Self-esteem is a concept, an attitude, a feeling, a selfimage, and it is represented by behavior. It is the ability to value one's self and to treat the self with dignity, love, and reality (Satir, 1988). Self-esteem is that gap between our self-concept or self-image and our self-ideal.

While self-esteem resists change (Coopersmith, 1967), it is changeable and reflects an individual's natural striving for superiority through achievement of goals (Adler, 1969). Self-esteem is continually evolving and constitutes the totality of our perceptions we hold of ourselves at any given moment (Reasoner \& Dusa, 1991). Our self-esteem is the very core of our personality and it affects every aspect of our human 
behavior - how we act; how we relate to others; our ability to learn; our capacity to grow and change; our choice of friends, mates and careers (LaMeres, 1990). Self-esteem is our sense of well-being, our comfort zone, our oneness with the universe, all of which collectively help us create meaning and purpose in our lives.

Our self-esteem is shaped by our beliefs. Challenging our beliefs is often difficult and can create a certain degree of discomfort. It is this very discomfort, however, that pushes us to move forward. Coopersmith (1967) contends high self-esteem is contingent on two conditions: setting high goals, and finding some success in reaching those goals. Self-esteem is about doing something; it is about assuming responsibility for our choices and having more control over our lives. The beliefs we hold of ourselves impact on the choices we make, which in turn determine the experiences we have. There is a continuous feedback loop between our actions in the world and our self-esteem.

The level of our self-esteem influences how we act, and how we act influences the level of our self-esteem (Branden, 1994). Reasoner and Dusa (1991) define self-esteem as the degree of satisfaction we feel about ourselves, the appreciation of personal worth or the value of our endeavors, and confidence in our potential. This sense of satisfaction is consistent with finding peace with our place in the world relative to others, our public reality. Self-esteem is having confidence in who and what we are and faith in our capabilities. In recognition of the apparent two dimensions to self-esteem, worthiness and confidence, this study focuses on these combined dimensions as defined by Coopersmith (1967).

By self-esteem, we refer to the evaluation a person makes, and customarily maintains, of himor herseif; that is, overall self-esteem is an expression of approval or disapproval, indicating the extent to which a person believes him- or herself to be competent, successful, significant and worthy. In short, self-esteem is a personal judgment of worthiness that is expressed in the attitude the individual holds toward himself [herself] (p. 5). 


\section{Criticism of self-esteem}

The relationship between some groups in society and the self-esteem movement has at times been quite stormy. The pursuit of high esteem has been seen by some as detrimental to learning, narcissistic, and even contrary to the teachings of the Bible. Gloria Steinem (1993) offers the idea of an inner authority may be upsetting to those accustomed to looking outside for orders - and certainly to those accustomed to giving them. Some critics of self-esteem suggest the concept has become a pop-culture phenomenon, more of an end unto itself. For others, self-esteem is seen as being selfcentred and selfish. Some Christian groups believe a person who has a relationship with Christ already has an enormous basis for good self-esteem. They believe further that the plague of low self-esteem, which seems to be affecting so many youth people today, is based primarily on their pre-occupation with self. Low self-esteem is a natural human condition and if you have low self-esteem, it only proves you are honest and understand your relationship with Christ.

Not all Christians, however, share this negative view of self-esteem. Pugh (1985) quotes Norman Vincent Peale, one of the fathers and key promoters of the self-esteem gospel, an unholy mixture of modern psychology and the Bible, as saying:

There is a deep tendency in human nature ultimately to become precisely what you visualize yourself as being. If you see yourself as tense and nervous and frustrated, if that is your image of yourself, that assuredly is what you will be. If you see yourself as inferior in any way, and you hold that image in your conscious mind, it will presently by the process of intellectual osmosis sink into the unconscious, and you will be what you visualize. If, on the contrary, you see yourself as organized, controlled, studious, a thinker, a worker, believing in your talent and ability and yourself, over a period of time, that is what you will become (p.1).

For some, it is possible to have proper self-esteem if one is rightly related to the creator, God. They believe we were created with deep needs for personal security and 
significance, and God designed the way to meet these needs. God's unconditional love provides us with the courage to retrain our thinking about ourselves and to discover who we really are (Walker, 1995). One related qualitative study of ninth graders in a Catholic school, for example, determined that there was a positive relationship between the development of self-esteem and the atmosphere of a Catholic high school (Mullin, 1998).

\section{Self-esteem and learning}

There is considerable debate about the relationship between self-esteem and academic achievement in many education circles. Is self-esteem a prerequisite of academic achievement or does academic success foster high levels of self-esteem?

Despite the controversy, the relationship between self-esteem and academic achievement has been well documented in the literature (Aspinwall \& Taylor, 1992; Beane \& Lipka, 1984; Brookover, 1965; Wylie, 1974). Some critics of the self-esteem movement, however, have made claims that the emphasis on self-esteem has actually been responsible for student failure in learning. Concern has been voiced that self-esteem has become a goal of the public schools, rather than being recognized as a result of achievement. There is evidence to support the claim that some current self-esteem building programs in schools are not working as well as intended and this has led some critics to conclude that the concept of self-esteem is at fault (Kohn, 1993). Wiggins, Schatz, and West (1994) concur and suggest that few schools do more than..."employ sporadic hit or miss procedures with selected students in helping in the affective domain" (p. 239). Frase and Streshly (2000) agree and state further that it is..."silly myopic thinking" [and a myth to suggest] "students must feel good about themselves before they can learn" (p.58). 
Despite this criticism, the Final Report of the California Task Force to Promote Self-esteem and Personal and Social Responsibility (1990), reported a direct correlation between self-image or self-esteem and learning potential. Learning something successfully reportedly makes one feel good about oneself and creates positive attitudes about school and class work. A student with good self-esteem is considered to be an active rather than passive learner and is eager to try new things without fear of failure. According to the Task Force, a student afraid to risk failure inevitably stops trying to learn. Students will not develop self-esteem overnight because it's a building process, but each small step to improved confidence will ultimately impact all their future choices or goals. In this case, goals are defined as an end we strive to attain, something to live for, to guide us, to keep us healthy, to give our life meaning and a sense of connection with our world. Mihaly Csikszentmihalyi (1997) cautions us, however, that goal setting may not produce the desired results. A student may develop low self-esteem, for example, as a result of setting goals too high, or because he or she achieves too few successes. He states further, "Contrary to popular wisdom, increasing children's self-esteem is not always a good idea - especially if it is achieved by lowering their expectations" (p.24).

Despite the critics, Reasoner and Dusa (1991) advise, "It is no exaggeration to say that building self-esteem is the best possible preparation for life" (p.3). According to the supporters of self-esteem, people with positive self-esteem feel good about who they are and as a result are more effective and productive. They feel proud of their accomplishments, act independently, assume responsibility, and are more likely to be successful in school, their jobs and even their personal relationships. Once a self-image 
has been formed, an individual begins to perceive circumstances and respond to them in a way that reinforces that self-mage (Renchler, 1992).

\section{Current research}

Much of the research on self-esteem in schools has been focused on at risk students or minority groups (Bottenfield, 1999; Castro, 1998; Faltz, 1996; Kirk, 1995; Rosario, 1999). One exploratory study, utilizing descriptive data analysis, consisting of correlation statistics, $t$-tests and a student survey, was conducted to identify the demographic, socio-emotional and cognitive characteristics of 276 adolescents identified as at-risk (McGill, 1999). The students in this study were identified as either completing or dropping out of a 5-month long military-style residential intervention program. Additional data was collected on the demographic, socio-emotional and cognitive factors associated with the students who completed the program achieving a GED diploma. The achievement of a GED diploma was determined to be the measure of academic success. Finally, this analysis attempted to specify significant changes in the cognitive and socioemotional functioning of adolescents who completed the program, regardless of whether they achieved the GED diploma or not. Although factors such as parent's level of education and participant cognitive skill levels before entering the program were strongly related to student success, self-esteem was reported as being correlated with this success.

Another correlational study, which employed muitiple regression and structural equation processes, surveyed 500 Chinese vocational school students about their views and opinions concerning the values of receiving a vocational education $(\mathrm{Mu}, 1999)$. This quantitative study was designed to examine the relationship between educational success and psychological achievement. The research revealed a very strong association between 
educational engagement and psychological achievement. Educational engagement was measured as having educational goals and motivation, and was seen as a predictor of optimism, self-esteem and self-efficacy (confidence). Parental and teacher support were identified as factors strongly associated with the student's perception of the utility of their educational program, while the level of parent education showed minimal association, and cognitive abilities negatively impacted on education engagement.

A number of studies have investigated the relationship between self-esteem and school success (Weisman, 1998; Long, 1995). One quantitative study of 100 high school age students enrolled in a full-time vocationaì high school examined the differences between academic achievement, self-esteem, and behavior for educable mentally retarded adolescents and learning disabled adolescents in a mainstream vocational shop placement and those in a special class vocational shop placement (Segal, 1980). The study reported that the fifty students who were placed in the special class vocational shop placement scored higher than the students did in the mainstream shop placement in academic achievement and self-esteem. Academic achievement was determined using two standardized tests, one in reading and one in mathematics. Self-esteem was measured using the Coopersmith Self-Esteem Inventory. The researcher reports that random assignment into the mainstream and special needs vocational shop placements was not possible, so one might question the validity of the conclusions. Were the students equally capable of understanding and processing the standardized tests and self-esteem measurement? Even though sample size is relatively small, it is interesting to note that the girls in the study scored significantly lower than the boys in self-esteem, yet scored 
higher in academic achievement. This finding is consistent with a number of other studies (Kolenik, 1993; Levinson, 1996; Wu, 1990) and is worthy of further investigation.

Maehr and Braskamp (1986) suggest that people do what they believe they can do and what they believe is worth doing, both functions of a healthy self-esteem. In the academic arena, one might logically infer that high levels of self-esteem could reasonably predict the accomplishment of student goals, including academic achievement. Research such as a longitudinal investigation of the impact of individual differences and coping on college adjustment and performance, for example, suggests self-esteem and control predict greater motivation and higher grades, controlling for college entrance exam scores (Aspinwall \& Taylor, 1992). These finding were substantiated in a similar study of the determinants of freshman year coping and adjustment (Rambo-Chroniak, 1998). Research on motivational aspects and academic performance suggests self-esteem, achievement motive, hope of success, perseverance, future time orientation, and locus of control significantly influence academic performance (Pereda, del-Carmen-Menendez, Mori, \& Meneez, 1990).

Not all studies see self-esteem as a major factor in academic success. One study, for example, suggests that student success is more a function of school policy and practice (Nieto, 1994). Based on interview data, the researcher concludes policies and practices related to curriculum, pedagogy, tracking, ability grouping, grades, student expectations, racism and discrimination play a primary role in determining student success. Tracking, ability grouping, grading practices and student expectations often lead to student achievement being pre-determined and the labeling of students. Racism and discrimination attack the self worth of the students being discriminated against and are 
often responsible for many of these students dropping out of school. Sadly lacking in these reflections, however, are any significant data regarding the specifics as to why the students in the sample were able to rise above the obstacles and find success in their particular educational experience. Although there were a few generalized statements about setting goals and pursuing them with a personal commitment, there was virtually no discussion about how this was possible.

It is clear from the literature that a relationship between self-esteem and academic achievement exists in some populations. What is not clear, however, is the direction of this relationship. The degree to which self-esteem predicts academic achievement or academic achievement predicts improved levels of self-esteem needs further investigation. Also unclear is the relationship between self-esteem and academic achievement in general student populations. Most of studies found in the literature seem to target specific groups, such as students-at-risk, ethnic groups, or students with special needs. In addition, most studies seem to target college students and middle school populations and few studies cross the grade boundaries between secondary grade levels and middle school grade levels. No studies on the relationship between self-esteem and academic achievement were found that specifically considered the broader school experience from perspective of student involvement in non-academic or extra-curricular activities. Finally, there seems to be some evidence suggesting that self-esteem may differ according to gender. More research in this area is clearly warranted.

\section{Optimism}

Martin Seligman's (1995) work on what he refers to as an individual's "explanatory style" proposes the intervening variable connecting self-esteem and 
achievement is not specific expectations in a particular subject, but rather the student's level of "optimism" or the tendency to see the world as benevolent (good things will probably happen) or malevolent (bad things will probably happen). Many young people today report having negative feelings about their educational experiences. For these students education is often seen as an obstacle, something they need to overcome before they can get on with their lives. They have resisted learning and been unwilling or unable to seek relevance or meaning in what they have learned. It is the meaning of the situation to the person that determines personal investment (Maehr \& Brascamp, 1986). Meaning involves three interrelated categories of cognition: personal incentives, sense of self, and perceived options (Renchler, 1992). The way these students feel about themselves determines the core of their personalities - the way they think, the way they relate to people, the manner in which they learn, and the choices and decisions they make. As mentioned earlier, the 1994 National Youth Survey: Attitudes Regarding Society, Education, and Adulthood reported that more than 9 out of 10 students surveyed expressed a positive degree of confidence in the future. A survey of 1,003 Canadian teenagers in the spring of 2000 produced similar results (Keiner, 2000). On the surface one might interpret this to mean young people are generally optimistic about the future. Drug abuse, youth violence, teenage pregnancies, teen depression, and suicide seem to indicate otherwise, however. If there is a direct positive relationship between optimism and self-esteem, and the reported levels of optimism are so high, then why is there so much emphasis on self-esteem building in North American schools today? Careful consideration of the wording of the findings associate with these surveys might suggest a completely different interpretation. While the young people surveyed might have 
expressed a level of confidence in the future, it does not necessarily follow that it was their future they are confident about.

The teenage years are full of doubt. According to Erikson (1997) it is a time marked by an adolescent "struggle for identity", both in terms of the existential self and the self as seen by others. Young people often struggle to create a balance between who they think they are and who they think they should be, especially in terms of others. The need for relationships as they begin to seek independence often produces confusing and conflicting issues related to roles and personal identity.

There may be a number of explanations for the unusually high level of optimism expressed by the students in the 1994 National Youth Survey: Attitudes Regarding Society, Education, and Adulthood A review of 1970's study by Alloy and Abramson, as cited in Seligman (1995), offered one possible explanation. Students were given different levels of control over the turning a light on and off. Some students were given direct control, while others had no control at all. The light would simply turn on and off without student input. The students were then asked to judge how much control they had. Students judged to possess depressive symptoms were very accurate about their level of control during the experiment and were able to articulate clearly when they had control and when they did not. To the surprise of Alloy and Abramson, the students without depressive symptoms expressed a level of control regardless of the circumstances. It mattered little to them whether they were in the group with control over the light button or the group who had no control. It seems then, that the students with depressive symptoms were more accurately able to assess their level of control, while the students without these symptoms either ignored their lack of control or were more likely to create 
the illusion of control. Although this experiment did not compare people who are severely depressed with those who are not, the findings are still relevant in terms of the way in which many people choose to see the world around them.

What is optimism?

In his book, The Optimistic Child Martin Seligman (1995) is clear about what optimism is not. He writes:

Optimism is not chanting happy thoughts to yourself. Vacuous slogans of the sort "I am a special person," "People like me," and "My life will get better and better" may make you feel warm and fuzzy for a moment, but they will not help you to achieve your goals. Optimism is not blaming others when things go wrong. Dodging responsibility for problems will serve only to exacerbate them. Optimism is not the denial or avoidance of sadness or anger. Negative emotions are part of the richness of life and they are usually healthy responses that encourage us to understand or change the things that upset us (p.297).

Seligman is highly critical of the "Pollyannaish purveyors of you are special selfesteem", choosing instead to teach young people realism. He believes accurate optimism can be taught and cautions his readers to be mindful of the tendency for the concept of optimism to drift towards "self-serving illusions" (p.298). He explains further:

Optimism, then, is not a cure-all. It will not substitute for good parenting. It will not substitute for a child's developing strong moral values. It will not substitute for ambition and a sense of justice. Optimism is just a tool, but a powerful tool. In the presence of strong values and of ambition, it is the tool that makes both individual accomplishment and social justice possible (p.299).

The basis of optimism, according to Seligman, lies not in positive self-talk or affirmations, but how we choose to think about the causes behind the events in our lives. This cognitive process is described as our "explanatory style". Our explanatory style is influenced by life events, much like our level of self-esteem. Depending on how we have been conditioned to think, we may see these events as temporary or permanent; global or specific; and internal or external. Optimism is defined as the ability to view life events or obstacles as temporary, specific and external. The key is avoiding blame and accepting 
responsibility for making the appropriate choices (Covey, 1989; Frankl, 1984; Quinn, 1996; Rabbin, 1998).

Optimism and learning

In his book, Learned Optimism, Martin Seligman (1990) suggests optimism can be learned, just as helplessness or pessimism can also be learned. He points out life begins in a helplessness state and depending on our circumstances either stays that way or moves toward having a sense of control over the events in our lives. Our support systems and learning environments play a major role in determining which direction we will take. He also acknowledges that some of us are more or less genetically predisposed towards optimism or pessimism, but despite this predisposition we still have the ability to determine our direction.

Concerned over what they saw as an over-emphasis on feeling good, as opposed to doing well, Seligman and colleagues designed the keystone Penn Prevention Program (Seligman, 1995). This anti-depression program was aimed at developing cognitive and social skills in fifth- and sixth-graders in an effort to help them deal with identity issues such as rejection and puberty. In the winter of 1990,70 students with the greatest risk of depression were offered spots in the twelve-week program. The 70 students were divided into six smaller groups. Three researchers each taught the course material to two of the six groups. To ensure consistency, an instruction manual, complete with a minute-byminute script, was developed. During the course of the program the children were encouraged to share their life experiences.

This study was designed to assess whether the Penn Prevention Program would have lasting anti-depressive effects. Pre-program assessment indicated that $24 \%$ of the 
children in both the experimental group and the control group had moderate-to-severe depressive symptoms. Post-program assessment revealed a significant drop to $13 \%$ in the experimental group, while the control group remained virtually the same at $23 \%$. A follow-up assessment two years later indicated that the number of students experiencing strong depressive symptoms had been reduced by $100 \%$. The researchers concluded that their anti-depressive program not only prevented depression, but also increased optimism. Of particular note is the observation that the program helped these young people... "undercut their tendency to attribute their problems to permanent causes (p.129)." This shift from a permanent view of problems, to a more temporary view, provided the students in the study with hope.

Reflecting on his horrific experiences as a Jewish prisoner-of-war at Auschwitz during the Second World War, Victor Frankl $(1946,1984)$ writes in his book, Man's Search for Meaning, that a prisoner who had lost his faith in the future was doomed. "With his loss of belief in the future, he also lost his spiritual hold, he let himself decline and became subject to mental and physical decay" (p.82). Robert Quinn (1996) refers to this state as "slow death, [a time when] people join the legions of the walking dead, [and] begin to live their lives of quiet desperation" (p.21). Dramatic words to be sure, but for many young people perhaps an accurate reflection of how they often feel as they try to make sense of their lives.

Susan Jeffers (1987) advises her readers in her book, Feel the Fear and Do It Anyway, that, "The only way to feel better about myself is to go out and do it" (p.25). She states further, "Pushing through the fear is less frightening than living with the underlying fears that comes from a feeling of helplessness" (p.28). So it is with learning. 
As Seligman and colleagues demonstrated during their Penn Prevention Program study, moving beyond a state of helplessness to a sense of hope can be learned. According to Seligman (1990),

Whether or not we have hope depends on two dimensions of our explanatory style: pervasiveness and permanence. Finding temporary and specific causes for misfortune is the art of hope: Temporary causes limit helplessness in time; and specific causes limit helplessness to the original situation. On the other hand, permanent causes produce helplessness far into the future, and universal causes spread helplessness through all your endeavors. Finding permanent and universal causes for misfortune is the practice of despair (p.48).

Much of the literature on optimism supports the notion that there is a positive relationship between learning and optimism, but like the literature on self-esteem most of these studies focus on specific groups, rather than general school populations. It is difficult, then, to make any general predications about the relationship between optimism and academic achievement or optimism and self-esteem.

\section{Current research}

Self-esteem and optimism are often linked as independent variables in studies related to student achievement and levels of happiness. The suggestion being that they work in tandem. In one study, fifty-one middle school students volunteered to participate in an after-school program designed to increase self-esteem (Gleason, 1998). Children were assigned to one of three treatment groups. The first group underwent explanatory style training, generally associated with teaching optimism. A second group participated in relaxation training, while the third was designated as the control group. The explanatory style and relaxation groups received five hours (one hour weekly) of training to foster optimistic explanatory style or to promote relaxation skills, whereas students in the no-contact group received no training during this phase. The no-contact group was later provided with the explanatory style training. At first glance the results seem to 
support the findings of the Penn Prevention Program study, with the depressed children in all three groups experiencing a reduction of depressive symptoms at post-test. It must be remembered; however, that one group did not receive the explanatory style training, receiving instead, relaxation training. It is possible then that simply receiving the attention associated with the study, perhaps suggesting the Hawthorne Effect, might have produced similar results. It is not clear whether any of the treatments affected the students who were not identified as depressed in any significant way.

Another correlational study surveyed 245 minority male and female adolescents ranging in age from 14 to 20 and registered in grades 9 through 12 in an urban high school. Regression analysis explored the relationship between learned helplessness and urban adolescent problem behaviors, which linked such problem behaviors such as school failure, criminality, early sexual behavior, and substance abuse with five learned helplessness factors identified as optimism, depression, acceptance of family and self, worry and fear of negative consequences, and low self-esteem (Stephens, 1997). Optimism and self-esteem were seen as being closely related. According to this study, school failure was found to be positively related to the factor depression, and negatively related to the factors worry and fear of negative consequences and optimism. The data reveal further that relatively low internal consistencies were calculated for the factors worry and fear of negative consequences and low self-esteem. While these findings are probably not that surprising, it is interesting to note that the students who exhibited the learned helplessness characteristics, including low self-esteem and lack of optimism, did not appear to be too worried or afraid of negative consequences. It seems individuals develop preconceived notions about their chances for success or failure based on their 
level of self-confidence (Renchler, 1992). Experiments by Weiner $(1979,1983,1984)$, as cited by Renchler (1992), demonstrated that when individuals possessing low levels of self-confidence and pessimistic explanatory styles succeed they often dismissed this success to luck or lack of difficulty, rather than to skill level. On the other hand, studies on coping also suggest an optimistic explanatory style helps young people deal with issues such as deprivation and adversity (Egger, 1998; Litten, 1998; Stephens, 1997).

As previously mentioned, there is some concern that many young people may not be as optimistic as they report themselves to be. They may have simply created the illusion of being comfortable with their environment and their thoughts of the future, what Seligman (1995) refers to as depressive realism, as opposed to accurate optimism. One related study examined the generalized future expectancies for personal life success and failure of 583 Grade 4 to 6 students (Fischer \& Leitenberg, 1986). The results of this study indicated an overwhelming majority of the students were more optimistic than pessimistic, with no significant sex or age differences being observed. It is interesting to note, however, the negative association between pessimism and self-esteem was stronger than the positive association between optimism and self-esteem. Another quantitative study of the coping and adjustment skills of sixty-nine college freshman at a Midwestern university, however, found a significant relationship between self-esteem and optimism, linking them together as a single coping variable: dispositional resilience (RamboChroniak, 1998). A follow-up qualitative study of 26 of the students originally surveyed showed that the variables related to academic preparedness, socio-demographic fit, and developmental role readiness did not effectively predict adjustment, but the dispositional resilience variables of hope (optimism) and self-esteem did. These findings might suggest 
a changing relationship between the two variables over time. There is also some evidence that suggests perceptions of competence significantly impact the academic readiness of students during the transition from elementary school to junior high school (Riddle, 1986). Academic success, however, appears to be less determined by personal factors and more determined by "powerful others". These findings seem to indicate an imbalance between feelings of competence and a sense of control as students enter junior high school.

There appears to be minimal evidence linking optimism directly to academic achievement in the literature. In some cases self-esteem and optimism are linked together as like variables in studies related to at-risk or minority student success. More often than not, however, optimism is associated with studies related to coping strategies, goal setting, transitions, or explanatory styles, rather than academic achievement. The association between a positive explanatory style and high levels of self-esteem seems self-evident. Given the links between self-esteem and optimism and the confusing reports of high levels of optimism in young people, who reportedly have little regard for the value of education, further study in this area is not only timely; it is important.

Academic Achievement

During the California Task Force to Promote Self-esteem and Personal and Social Responsibility (1990) hearings, evidence was presented suggesting a strong relationship between a healthy self-concept and positive education outcomes. In the Task Force's final report, Jones and Grieneeks (1970) are quoted as stating, "Self-concept is the most effective and consistent predictor of academic achievement, even better than test scores" (p.61). A study of kindergarten students, designed to determine whether self-esteem is a 
good predictor of future reading success, concludes self-esteem is a better predictor of reading success than I.Q. (Canfield \& Wells, 1976, as cited by Brock, Bialozor, \& McLaughlin, 1993). While much of the research clearly indicates a positive relationship between self-esteem and academic achievement, the directional relationship between selfesteem and academic achievement is not as clear. Also in need of clarification is the meaning of academic achievement and how it is measured.

What is academic achievement?

Traditionally academic achievement is a measurement of student success that is reported as grades, grade point averages, or test scores. Students are generally treated more or less alike, and evaluated according to grade level and age. Sizer (1999) observes grade level counts, socially and academically, and the norm has been "one-size fits all". He suggests, "Success at high school is measured by an accretion of scores in subjects taught largely in isolation from one another" (p.8). Sternberg (1997) reminds his readers, however, "Success is a relative term [and] like beauty, ... may be in the eye of the beholder" (p.251). Successful people tend to have what he refers to as successful intelligence, something not generally taught in schools or measured by most intelligence tests. Sternberg suggests further, “Conventional intelligence tests only measure a small part of intelligence and focus on inert academic intelligence and not active successful intelligence" (p.47). Successful intelligence is more than just the analytical aspects, the basis of inert intelligence; it also includes the creative and practical aspects. While it is one thing to identify and solve problems, it is quite another to decide whether or not the problem needs solving in the first place or whether or not the solution is, in fact, 
effective. Conventional intelligence testing is one-dimensional and focuses exclusively on the academic domain.

Like Sternberg, a number of scholars, including James (1996), Gardner (1993) and Goleman (1995), have been struggling with the meaning of academic achievement and academic success. James (1996) stresses, "We must teach our children to increase their intelligence, to cooperate, to think in new ways [and the key is] to think in the future tense" (p.24). She identifies eight skills necessary for thinking in the future tense: Perspective, pattern recognition, cultural awareness, flexibility, vision, energy, intelligence and global values. James defines intelligence as the integration of..."the right brain of images and creativity with the left brain of words and calculations, in the context of the social environment" (p.179). In this sense, she agrees with Sternberg that the analytical and creative aspects of his successful intelligence are important components to the emerging view of intelligence.

James (1996), and to a lesser degree Sternberg (1997), regard Howard Gardner's work on multiple intelligence as an important consideration in the study of academic achievement and intelligence. According to James, Gardner devised a list of eight levels of intelligence: Linguistic intelligence, logical-mathematical intelligence, spatial intelligence, musical intelligence, bodily-kinesthetic intelligence, interpersonal intelligence, intrapersonal intelligence, and spiritual intelligence (p.182). While Sternberg (1997) virtually ignores interpersonal, intrapersonal, or spiritual intelligence in his own work, James (1996) is much more receptive to the possibilities associated with additional dimensions of intelligence, even to the point of adding a ninth dimension, practical intelligence, ironically the third aspect of Sternberg's successful intelligence. 
The interpersonal and intrapersonal dimensions of intelligence closely relate to Goleman's (1995) work on emotional intelligence. While Sternberg (1997) makes brief reference to Goleman in the introduction to his book, Successful Intelligence, he effectively dismisses his work by stating that..."he will focus on the kind of intelligence that matters to everone in reaching important life goals, and that's successful intelligence" (p.13)." James (1996), on the other hand, considers the emotional quotient, or measure of emotional intelligence, as an exciting and refreshing view of what it means to be human. She states, "New brain research suggests that emotional intelligence, or emotional quotient (EQ), not IQ, may be the truest predictor of success" (p.195).

Goleman (1993) recognizes the difficulties associated with challenging the traditional meanings of intelligence and suggests the emotional aspect or domain of intelligence has been largely ignored due to a preoccupation over the last few decades with the cognitive-science model of the mind. Rather than exploring the role of feelings as a measurement of intelligence, researchers have tended to focus more on the cognitive aspects of feelings. According to Goleman, this focus..."leaves unexplored the rich sea of emotions that makes the inner life and relationships so complex, so compelling, and so often puzzling" (p.40). Finding a meaningful definition of academic achievement remains a challenge. Measurement beyond the traditional measurements of academic achievement also remains a challenge.

Traditional assessment and evaluation

Despite the efforts of the provincial government in British Columbia to create a new framework for learning for the $21^{\text {st }}$ century, the evaluation and assessment of students has remained much the same as it was in the past. Even the progressive move to 
eliminate letter grades in the primary grades has met resistance from parents. Three guiding principles about learning and the learner have helped to provide a framework for curriculum development and assessment in the province: (1) Learning requires the active participation of the learner; (2) People learn in a variety of ways and at different rates; and (3) Learning is both an individual and a social process. Teachers have been encouraged to employ a wide range of assessment methods to ensure the best picture possible of each student's learning. According to the Year 2000: A Framework for Learning document, "The central aim of assessment and evaluation is to help the child to learn [and] assessment methods [should] include all the formal and informal techniques used by the classroom teacher to collect information about the progress of student learning" (p.8). At the middle school and secondary school levels this assessment is recorded as letter grades on the student report card. There are consistency issues, of course, associated with the assessment and grading practices of the classroom teacher. Classroom grades often include other subjective aspects, including the relationship between the teacher and the members of his or her class. Classroom grading also reflects the individual teaching style and educational philosophy of the teacher with respect to testing, student assessment, and evaluation.

While discouraging testing as the primary measure of student success in the classroom, the provincial government reinstated provincial examinations for academic graduation courses, worth $40 \%$ of the final mark in examinable subjects. A series of province-wide British Columbia Performance Standards assessments in grade specific reading, writing, numeracy, and social responsibility have also been implemented on a voluntary basis. These assessments have been designed to supplement the non-voluntary 
subject and grade-specific Provincial Learning Assessment Program recently mandated by the government. Resistance from the teachers' union and a lack of concern over the results by the students has led many to question the relevance of such test scores.

Testing as a means of assessment continues to be a controversial topic in many educational circles. The need for more accountability in education has led many legislators to push for standardized testing. As pointed out by Noll (1997), "In recent years a large number of national reports appear to have placed economic reconstruction and growth firmly in the driver's seat when it comes to reconsidering educational objectives and making curricular decisions" (p.118). Establishing national goals and standardized assessment plays a major role in this reconsideration. Kennedy (1994) concurs and shares the following observation:

Few topics are more important that academic content standards for what we want graduates to know and be able to do. These standards will represent our vision of the future, a vision we can achieve only by effective coordination at every level [of government] (p.120).

The issue of standardized testing has led Scherer (2000) to ask the following questions:

When we use standardized tests as the major criterion for judging the abilities and fates of children, are we likely in the long run to get the results we want? If the tests do not measure a given school's curriculum but instead present a blend of what has been taught across the [province, state, or] nation, are the tests fair? If the tests change from time to time, can the scores still assess progress? At what point will students [or teachers] get excited about mastering a skill or learning facts that are not on the test? Do the 175 items on a typical multiple-choice test limit the curriculum? Does the emphasis on testing improve teaching (p.7)?

Geocaris and Ross (1999) urge teachers to create more meaningful and relevant tests by giving students options to demonstrate what they know and how they learn best. This is an interesting idea and challenges the notion that tests should measure the same thing in order to be valid. Dissatisfied with the reliance on short-answer tests, Geocaris and Ross borrowed from the work of Lowery (1998), Schlecty (1994), and Wiggins and 
McTighe (1998) to develop a model for learning-compatible testing. They counsel further that students should be allowed to "... actively seek assistance from their notes, textbooks, or friends" and suggest further..."any test that inspires students to actively seek knowledge on their own is certainly not a tragedy!" (p.32). Caine and Caine (1994) recognize formal tests for specific performance and memory may be useful to some extent, but remind us that tests of this nature often interfere with a student's ability to understand the work that they are doing because they do not allow for complexity of thought.

Academic achievement

According to the previously mentioned National Youth Survey: Attitudes Regarding Society, Education, and Adulthood (1994), young people generally feel school is adequately preparing them for the world of work and a healthy lifestyle. The researchers were alarmed, however, to find that a general nonchalance towards learning seems to exist for many of the young people surveyed. Even more alarming is the attitude of the parents. Van Scotter (1994) reports, "By and large, parents today are not eager for their children to be too studious" (p.72). School is expected to be fun, often at the expense of high expectations. Renchler (1992) reports similar findings in his review of a survey of 1,879 students listed in Who's Who Among American High School Students. Although $75 \%$ of the students surveyed eamed an " $A$ " average, most indicated their level of motivation was not particularly high and that they studied less than seven hours per week. The majority of these students also reported they would not increase their study time even if the government implemented a national achievement test. The publisher of 
the Who's Who asks, “What is wrong with our educational system that our best and brightest students are so unmotivated?" (Column One, 1991).

Raffini (1988) suggests students who are doomed by the system to intellectual failure often direct their motivation towards behaviors that cover up the failure and thus protect their sense of self-worth:

Apathy is a way for many students to avoid a sense of failure. Those behaving from this motive approach each new learning experience with apprehension and fear - often masked with apathy, aloofness, or indifference. Their philosophy becomes "Nothing ventured, nothing failed". Teachers and parents worry that they are unmotivated. In reality, they are highly motivated to protect their sense of self-worth. As they get older they begin to reject education completely. If they state publicly that school is a valueless, boring waste of time, then their self-worth is protected when they received a failing grade. These students have discovered that it is less painful to reject school than to reject themselves (p.12).

Lynch (1998) found that people [students] who are unsure about their own level of competence, but wish to appear as competent to others, often employ one of two strategies, self-handicapping or over-achievement. Self-handicapping is defined as the creation of obstacles or the withdrawal of effort on a task. Over-achievement, on the other hand, means expending excessive effort to accomplish the task. Both strategies are designed to protect the self-worth of a self-doubting individual.

This is a most curious phenomenon and closely parallels the work of Low (2000), who suggests we have a schooling system, not an education system. The learning process, according to Low, is an evolution of skill building, starting with the development of certain basic skills through practice and drill. He suggests most school curricula never get beyond this level. The next level is developing integrated skills sets, followed by applied judgment and skill building as a means of developing task or challenge integrated skills. The next step concerns the development of situation-integrated skills and ultimately selfintegration through the development of life integrated skills. 
Low has identified two types of learning - conventional and adaptive.

Conventional learning is a continuous, successive approximation leading toward an expected outcome. Failure to realize that outcome generally is defined as a problem with the teacher or the learner. Learning at this level is seen as routine and the learners are characterized as being either compliant, that is, they will not do anymore than necessary, or resistant, those students who reject learning. Adaptive learning, on the other hand, involves doing things where there are no established patterns. Learning becomes more complex, negotiated, and innovative. Learners who enjoy excelling at the task, yet fall into the category of complying, are found at one end of the adaptive learning continuum, while students who are determined to create their own learning and to make the most of the learning experience, can be found at the other. These students transcend the learning opportunity. Bennis (1989) reminds us that unlearning must often precede true learning. Low believes human beings are wired to be useful and if we cannot be useful we lose our spirit, direction and purpose. Wisdom is defined as the ability to see what needs to be done, then doing it without being told what to do. Ignorance, on the other hand, is the absence of learning what would be helpful. Regrettably, Low suggests we are all more ignorant than we are wise. Wisdom requires an evolution of discipline that moves from character discipline, to self-knowledge, to adaptive learning discipline, then to selfauthorization discipline or the ability to author one's own actions or story.

The progression of discipline is often seen as a matter of personal control. Being in control is closely related to resiliency. Students who are described as resilient seem to have the ability to project their circumstances into the future and to envision how their decisions will impact on them in the future. A qualitative study using case studies of 
disadvantaged or "at-risk" minority students who were college-bound, for example, found that these students had formed an image of their college-bound future selves (Shih, 1998). They were not only motivated by the potential for better career opportunities; they also possessed the self-knowledge to recognize what might become of them if they did not pursue a college education. They were able to rationalize the negative peer pressure to abandon their college dreams by comparing their future prospects with those who were not likely to go on to college. While these results are encouraging, they are based on the observations of a very small sample of four students. Like other studies of this nature, the answer to deeper human question; "What is it specifically about students like this that helps them paint such positive pictures of their future, when so many others seem incapable of the doing so?" remains a mystery. Explanatory styles, coping mechanisms, levels of self-esteem, confidence, and optimism are part of the answer, but something seems to be missing, something deeper. Two other studies (Billings, 1997; Witty, 1992) produced similar findings about students who were able to "beat the odds". Key to the success of these students were factors that created a positive perception of self and the school experience, including feelings of independence, support, sense of responsibility, adoption of achievement behaviors, lessons learned, and sense of achievement. Again the findings fail to fully explore the important internal processes that have taken place within the individual, which resulted in them feeling independent, being able to appreciate support, accepting responsibility, embracing achievement behaviors, understanding the lessons they had learned, and being able to find success. The concept of "beating the odds" needs to be examined. While the student accomplishment in both studies was admirable, in the Billings study it was defined as thirteen at-risk girls either graduating 
from school or making the graduation list, while simply achieving passing grades was considered "academic success" for eighty inner-city African American male seventh grade students in the Witty study. It is quite possible that graduating from school or achieving passing grades had very little to do with having a positive perception of self or the school experience for some to the students in these studies.

Many studies cite family support as a major contributor to academic success (Aalborg, 1998; Billings, 1997; Valenzuela, 1990; and Witty, 1992). Other studies conclude school atmosphere, policies, and practices are often influential in determining academic achievement (Cazenave, 1993; Bumbary, 1991; Forsythe, 1994; Mullin, 1998; Smith, 1997). School attachment is also a significant factor in determining the success or failure of students (Mouton, 1995). Low-attached students report being lonely, isolated, and alienated from the school community. A reason often given by at-risk students for dropping out of school is the feeling that no one cares whether they attend school. Belonging is absolutely crucial to the development of healthy self-esteem (Reasoner \& Dusa, 1991).

Social-economic status is also a primary factor in determining academic achievement. (Nurmi, 1990; Rawlins, 1991). Family socioeconomic status seems particular relevant to academic achievement in the Asian community. A correlational study of 339 seventh, eighth, and ninth grade Chinese-American students was designed to explore the role socioeconomic status, before and after immigration, along with several other variables, played in academic achievement (Bao, 1996). Grade-point averages and standardized math percentile scores were defined as academic achievement. Multiple regression analysis determined that family social-economic was superior to all the other 
independent variables in accounting for academic achievement. Generalizing these findings across other cultural groups, however, may be misleading. Stevenson (1992), as cited in Frase and Streshly (2000), found during his study of education in Asia and the United States, for example, that Asian students placed a great deal more value on the educational experience and academic achievement than the American students.

There is some evidence that academic achievement and motivation may be related to grade level and age. The research indicates children's confidence in their academic achievement generally declines with age (Stipek, 1984; Erickson, 1994). Gender differences have also been identified as a major factor in studies related to academic achievement (Bottenfield, 1999; Rizza, 1997; Wu, 1990). Girls are reported to value academic achievement more than boys, yet continue to find math and the sciences challenging (Daggy, 1994). Pollina (1995) submits the issue could be addressed more effectively if educators spent more time studying how girls learn, rather than trying to change the way female students approach math, science and technology, which she refers to as "remedial masculinity". "Is it any wonder", she asks, "that many girls lack selfesteem?" (p.30). Girls are also more likely to lack self-confidence (Kolenik, 1993), but as Stein (1999) points out in her description of girls today:

There is no one representative girl or homogenous girl culture. Girls are too varied and vibrant for labeling, and as soon as you think you have one pegged, she changes. Their resilience, their resistance, and their ability to find altemative narratives to inspire them to persevere are powerful qualities (p.18).

In British Columbia, girls are out-performing boys in graduation rates, average school marks, honors graduation status, winning provincial scholarships, Foundation Skills Assessment results in reading and writing, and being designated as gifted. The British Columbia Teachers' Federation recently released a report, entitled G.I. Joe Meets 
Barbie, Software Engineer Meets Caregiver: Males and Females in B.C.'s Public Schools

and Beyond (November, 2000), which addressed issues related to gender in education, especially from the perspective of the boys. According to this report:

The data examined in this report reveal that a stunning amount of gender stereotyping remains in British Columbia's public education system, from Kindergarten through graduate school and beyond. Males still dominate in the "hard" sciences, technology, and engineering, while females dominate in the arts and the helping professions. There is no evidence that this situation is imposed, caused, or condoned by public schools... [and] given the range of factors that reflect, define and describe our lives, it would be an oversimplification to say that our schools are failing boys (p.72).

It is imperative that schools and teachers be sensitive to both boys' and girls' achievement and self-esteem needs. It is too easy to overlook a student's mental health status when he or she is doing well at school. Teachers and parents would do well to ask themselves the cost of high achievement (p.75).

Despite the multitude of issues related to academic achievement the research clearly indicates the measurement of academic achievement continues to rely mostly on standardized achievement tests (Bao, 1996; Rosario, 1999; Smith, 1997); cognitive intelligence tests (Frost, 1996; Levinson, 1996); and grade point averages (Daggy, 1994; Hair, 1999). Unfortunately standardized tests or measures of intelligence may not motivate students to take these tests seriously. Grade point averages probably provide a more accurate reflection of global academic achievement, especially if the grades are based on a variety of assessment activities.

\section{Summary}

The "educated citizen" is by definition a person who possesses a positive selfimage (self-esteem), self-motivated and capable of making independent decisions . (confidence and optimism), and thoughtful, able to learn and to think critically, and able to communicate information from a broad knowledge base (academic achievement). Selfesteem is a cognitive and feeling response to our circumstances and a confidence that we can achieve the goals we determine are important to us. Optimism, too, is an expression 
of confidence, confidence in our abilities and confidence in the future. In that sense, selfesteem and optimism are closely related personality traits. It would seem logical that a positive relationship should exist between self-esteem, optimism, and academic achievement. This relationship assumes, of course, that academic achievement is a goal deemed important to most of our students. From the literature it appears this is not always the case, at least given the current definition of academic achievement. In British Columbia this obviously should be of great concern to educators, given the primary goal of the education system is intellectual development.

The relationship between self-esteem, optimism, and academic achievement is not as clear as it appears to be. The literature has tended to focus on at-risk students, minority groups, gender, transitions, treatment programs or coping strategies. There appears to be little evidence in the literature of studies that focuses on the general student population and span late elementary, or entry into middle school, through to high school graduation. This analytical study proposes to collect data, including formal measures of self-esteem, less formal indicators of optimism and academic achievement, from all students in grades $6,8,10$ and 12 in a rural community. This community is well known for its attachment to the arts and its "laid-back" lifestyle. The population is well educated, over $90 \%$ white, and middle class. There is no evidence in the literature of studies with similar demographics.

Much has been made of the gender differences in many of the studies on selfesteem and academic achievement. Many studies indicate girls have a stronger attachment to academic achievement, with the possible exception of mathematics and the sciences, while their self-esteem levels tend to be lower than boys. Current debate in the 
schools, however, indicates a concern for the boys as they struggle to find an identity in a school system that many say caters to the feminine side of their personalities. This certainly is a contentious issue, yet clearly worthy of further study.

It is not the intent of this study to debate the issues related to measures of academic achievement. For now, that will be left to the scholars and the politicians. Intelligence, as Sternberg (1997), James (1996), Gardner (1993) and Goleman (1995) point out, seems to wear many faces. Despite the controversy, academic achievement continues to be measured by intelligence tests, standardized tests, grade point averages and letter grades. The purpose of this study is to explore the relationship between academic achievement, self-esteem, and optimism. Recent tragic events, (1998) such as the student massacre at Littleton, Colorado and more recently, San Diego (2001), clearly demonstrate that bright children are often lonely and feel isolated, two traits not normally associated with self-esteem or optimism. It is possible that individuals such as Eric Harris and Dylan Kiebold may have produced high scores on these measurements, but did they feel confidently appropriate to life or confident in their future, as short as it was? This is an interesting question and clearly a scary thought that begs an answer to the questions: What does self-esteem, optimism, and academic achievement really mean and what, then, are the implications for the school system and the "educated citizen"? 


\section{CHAPTER III: METHODOLOGY AND DATA COLLECTION}

\section{Introduction}

The purpose of Chapter III is to present the methodology that was used in this study. The first part of the study employed quantitative methodology that utilized multiple regression analysis and a correlational research design as described in Huck, Cormier, and Bounds (1974) and Hinkle, Wiersma, and Jurs (1988). The second part of the study utilized an open-ended questionnaire, which was designed to collect descriptive data from the participants regarding the value of the school experience from the perspective of self-esteem and optimism, including their thoughts and feelings towards academic achievement and involvement in school activities. Although the questionnaire responses were also analyzed using logistical regression methodology, the primary purpose for collecting these data was to add some additional depth to the study and to generate hypotheses and recommendations for further study. Specifically, how this methodology was used in this study is described under the following headings: Research Questions, Sample, Access and Confidentiality, Instrumentation, Procedure, and Limitations of the Study.

\section{Research Questions}

1. To what extent does academic achievement influence the Total self-esteem of students in grades $6,8,10$ and 12 in a small, semi-rural school district in British Columbia?

a. To what extent does academic achievement influence the School-Academic selfesteem of the students? 
b. To what extent does academic achievement influence the General Self self-esteem of the students?

c. To what extent does academic achievement influence the Social Self-Peers selfesteem of the students?

2. Do these relationships vary by gender, grade level and participation in non-academic and extra-curricular activities in school?

3. What attitudes, if any, do the participants in this study have with regard to their school experience, more specifically towards getting good grades, participating in school activities, and preparing for the future?

4. Do these attitudes vary according to gender and grade level?

\section{Sample}

Approximately four hundred and fifty students across four grade levels $(6,8,10$ and 12), from a small, semi-rural school district in soutbwestern British Columbia were invited to participate in this study. All of the grade 6 and 8 students attend the district's Middle School, while the grade 10 and 12 students attend the only secondary school in the district. All students at each of the four grade levels were invited to participate, however some data were not included in the statistical analysis because of the problem of calculating grade-point averages for the Special Needs students where no grades were reported. Two hundred and eighty-seven students, or $64 \%$ of the invited students, accepted the invitation to participate by returning their Informed Consent forms, which had been distributed through homeroom classes at the middle school grade level or mailed to the parents of the secondary school students. Of these 287 students, 24 students were dropped from the first part of the study because of high scores (>4) on the Lie Scale. 
The data collected from the remaining 263 participants were entered into a computer database and analyzed using the statistical software program, S-PLUS. (see Table 3-1). Table 3.1

Student participation data according to grade level and gender after the Lie Scale $(>4)$ is eliminated from the statistical analysis.

\begin{tabular}{|c|c|c|c|c|c|}
\hline \multirow{2}{*}{ Grade } & \multicolumn{2}{|c|}{ Original Participants } & \multicolumn{2}{|c|}{ Lie Scale Score $>4$} & \multirow{2}{*}{ Total } \\
\hline & $M$ & $F$ & $\mathrm{M}$ & $\mathrm{F}$ & \\
\hline Six & 40 & 30 & 5 & 3 & 62 \\
\hline Eight & 36 & 40 & 3 & 5 & 68 \\
\hline Ten & 30 & 42 & 2 & 2 & 68 \\
\hline Twelve & 33 & 36 & 4 & 0 & 65 \\
\hline Total & 139 & 148 & 14 & 10 & 263 \\
\hline
\end{tabular}

The school district involved in this study is over $90 \%$ Caucasian, generally well educated, and middle class. Results on provincial examinations and standardized tests are usually above the provincial average. Academic achievement is valued in the district, with the student performance on the provincial Foundational Skills Assessments in Reading placing near the top in the province, while the secondary school has the highest transition rate between grades and the highest grade-point average of graduating students in British Columbia. The participation rate in school and community events, especially those to related to music, drama and athletics, is high. Many professional artists, writers, and musicians are attracted to this part of British Columbia and this focus on creativity and the arts is reflected within the schools. The collective community is considered a safe place to raise children, with one of the lowest crime rates in the province, and the schools are well supported by parents and the community. There is growing concern, however, over an increase in the use of drugs and alcohol by teenagers and some teenagers 
complain that there is little to do outside of the school setting or beyond organized community events.

\section{Access and Confidentiality}

The treatment of the students participating in this study was in accordance with the ethical practices and procedures as identified by the Protection of Human Subjects Committee of the University of San Diego, which included securing permission from the Superintendent of Schools to conduct this study (see Appendix C) and the return of the signed Informed Consent forms (see Appendix D). Before the Informed Consent forms were distributed to the students and the parents, notice of the study was posted in the newsletters at both schools and informational letters were inserted into the Interim report card packages at the secondary school. As detailed in the Informed Consent form, participation in this study was optional, and either the parents or the students could choose to opt out of the process at any time. All data collected were strictly confidential and used only as collective data for the purpose of statistical analysis. All students were assigned a numerical code and information was reported anonymously.

Once formal approval was granted, the Informed Consent forms were mailed to the parents of the secondary students, along with a stamped return envelope addressed to the researcher. The decision to mail the Informed Consent forms to the parents of the secondary school students was made to help expedite the return process and in recognition of the problems traditionally associated with getting information home at the secondary school level. A mail-out at the middle school level was not considered necessary given the school's expectation that information not only get home, but that the parents respond to requests for information. This expectation was reinforced by the 
school's Personal Planning program which awards credit to the students for successfully facilitating the school-home communication process. It might be of interest to note that the return rate for the middle school students was higher than that of the secondary students despite the direct mail-out to the parents of the secondary students ( 74 percent for Grade 6, 73 percent for Grade 8, 59 percent for Grade 10, and 60 percent for Grade 12). Access to all the participating students was facilitated through the district's Career and Personal Planning program, which with the exception of the grade 9 students at the secondary school, has been integrated into other curricular areas or facilitated through class seminars or special presentations. A schedule for classroom visits was organized. In some cases, classes were combined, while non-participating students were either excused from the class to work in the library or were given other work to do by their teachers.

The students were walked through the instructions to the Coopersmith SelfEsteem Inventory or SEI, as outlined by the publisher, then led through the various sections of the Student Survey. They were instructed to seek clarification at any time should they need it. As the person responsible for the Career and Personal Planning program at the secondary level, the researcher experienced minimal difficulty scheduling the collection of data. The researcher enjoys a positive relationship with the teachers and administration at both of the participating schools.

Instrumentation

Two instruments were used for data collection during this study. The first of these instruments, the Coopersmith Self-Esteem Inventory or SEI (see Appendix A) was used to measure student self-esteem. The second instrument, a Student Survey (see Appendix B) was used to collect data regarding student involvement in school-related non-academic 
and extra-curricular activities and to gather information regarding the perceptions of the participating students towards their school experience from the perspective of feelings of worth (self-esteem) and levels of optimism.

\section{Coopersmith Self-Esteem Inventory}

The Coopersmith Self-Esteem Inventory measures self-esteem on five different scales: General Self, Social Self-Peers, Home-Parents, School-Academic, as well as a combined score, Total Self. The Home-Parents score was not included in this study due to the lack of direct relevance. It should be noted, however, that the Home-Parents score contributes to the Total Self score. According to Mruk (1995):

The strengths of this instrument include the fact that it is consistent with Coopersmith's (1967) model and research on self-esteem (construct validity); the presence of some content validity in terms of how the questions relate to what we know about self-esteem (especially in terms of worthiness); and the relative ease of administering, scoring, and interpreting it in both individual and group settings (p. 83).

Acceptable reliability (internal consistency and test-retest) and validity (convergent and discriminant) information exists for the Coopersmith Self-Esteem Inventory (see Blascovich \& Tomaka, 1991). Adair (1984), as cited in Keyser and Sweetland (1987), reports that the SEI may be used with the confidence that their development has been well thought out and researched (p. 109). Adair reports further:

The manual reports several studies demonstrating the reliability of this test at several grade levels. To estimate the internal consistency of the instrument Spatz \& Johnson (1973) administered the School Form to over 600 students in Grades 5, 9, and 12. With an $\mathrm{N}=600$ they randomly selected 100 subjects from each grade level and calculated Kuder-Richardson reliability estimates (KR-20). At all three levels they obtained coefficients in excess of .80 , considered adequate for the instrument (p. 108).

The School Form consists of 58 items, 50 of which measure self-esteem and an 8-item

Lie Scale. The Lie Scale items are scored separately and not included in any of the selfesteem scales associated with this measurement. The scores on the Lie Scale range from 
0 to 8. According to the Coopersmith Self-Esteem Inventory manual, high Lie Scale scores may suggest defensiveness in the responses of the students or indicate that the examinee thought he or she understood the intention of the inventory and was attempting to respond positively to all items (p.9). In such cases, the inventory may be invalid, especially if supplementary observations indicate contradictory evidence of either low or high levels of self-esteem. Given the relatively large sample, the collection of this supplementary data was not deemed practical, so in the absence of specific guidelines, it was determined for simplicity that only those surveys with a Lie Scale score $<5$ would be included in the analysis. The researcher wished to avoid the potential limitation that the responses to the Coopersmith Self-Esteem Inventory items might not be accurate.

Students were asked to respond to each of the Coopersmith Self-Esteem Inventory items, such as "I never worry about anything" or "I'm pretty sure of myself", by indicating whether or not the statement was "Like Me" or "Unlike Me". A pilot study of fifty-four grade 9 students revealed that some students experienced difficulty generating an "either-or" response. This potential problem was discussed with the students in the study during the instruction stage and they were encouraged to answer each item according to the response that best describes them most of the time. In the case of students failing to respond to all the items on the inventory, it was determined that depending on the number of missed items, the researcher would employ the zero-order correction technique. A small number of students did, in fact, fail to respond to a large number of items, but their level of non-response was considered to be so great that zeroorder correction did not seem appropriate and these observations were deleted from the 
statistical analysis. It seems they either lost interest or became frustrated with the inventory for some reason.

Due to the relative short timelines associated with the collection of the data, it was not possible to give any of the students who either missed the inventory or failed to respond to any of the questions a second opportunity to complete it. The short timelines could partially explain the somewhat disappointing response rate, given all data were collected during the two-week period preceding the Christmas Break. It should be noted as well that the collection of data was conducted during the flu season, so any students who were absent from school due to sickness or an extension of the holiday season were unable to participate. Lack of participation, however, did not necessarily indicate that the students or their parents were not willing to participate. Only one parent expressed any direct concern about the instruments that would be used in the study and requested a copy of the Coopersmith Self-Esteem Inventory. This parent later determined that the questions relating to Home-Parent Self-Esteem were too personal and directed that her two sons only participate in the Student Survey. Two other parents returned the Informed Consent forms unsigned and indicated that their sons would not be participating. It was later determined that these students would be away from school during the collection of data. A few parents added words of encouragement to the Informed Consent forms and the project was generally well received by the participating students.

\section{Student Survey}

The Student Survey was designed to be used as part of the Career and Personal Planning program as a self-awareness exercise and to stimulate interest and discussion. In the first section of the survey, the students were asked to identify the school-related non- 
academic and extra-curricular activities in which they participated and to indicate their average level of involvement engaged in these activities. In the original survey, the students were asked to estimate the average number of hours per week involved in these activities, but according to feedback from the pilot study of grade 9 students, many of the students reported that they experienced some difficulty with this task. Reported hours were changed to levels of involvement: no involvement; minimal involvement (one hour or less per week); moderate involvement (more than 1 hour, but less than 3 hours per week); and heavy involvement (more than 3 hours per week). Also as a result of the pilot study, four additional questions were added to the original seven survey questions; three of which had be taken from the 1994 National Youth Survey. The eleven questions were designed specifically to gather descriptive data regarding the feelings of the students towards the future and the value of the school experience, primarily from the perspective of getting good grades and/or level of involvement in school activities. The students were asked, for example, to rate that following question: "How well does school prepare you for life after graduation?" They were then asked to expand upon their ratings by answering open-ended questions related to the survey question. The demographic information included in the questionnaire was used to provide the required grade level and gender data. Grade level and gender were included in this study because the literature suggested they might be significant.

\section{Procedures}

All participating students were given the Coopersmith Self-Esteem Inventory and the Student Survey according to a prearranged timetable for classroom visits. In the first part of this study, the Coopersmith Self-Esteem Inventory was scored according to the 
directions of the publisher and the scores on the four scales: General Self, Social SelfPeers, School-Academic, and the composite score, Total Self, were entered into a database according to a coded number. In addition, the Lie-Scale scores were also calculated and added to the database. Grade point averages (GPA) at the end of the first term, that is, the November reporting session, were calculated as follows: $A=4, B=3, C$ $=2, P=1$, and $F=0$. It should be noted that in British Columbia, the GPA scale includes $\mathrm{C}+=2.5$, but for the purpose of this study and the ease of reporting statistical significance, all $C+$ grades were calculated as $C=2$. It should also be noted that $P=1$ is generally reported as $\mathrm{C}-=1$ on student report cards until the grades are formally entered into the Student Permanent Records, when a $C$ - is reported as $P$. The grades $D$ and $E$ are no longer used in British Columbia.

As pointed out earlier in this study, there are potential problems associated with the use of GPA as a measurement of academic achievement, especially when letter grades are converted to GPA. In British Columbia, education policy states that in Grades 4 to 12 letter grades will be used to indicate students' levels of performance in relation to the learning outcomes for each course or subject and grade. Provincial policy dictates these letter grades will be converted to a 4-point GPA scale. The 4-point GPA scale seems to be the standard for most post-secondary institutions although the way in which they are interpreted sometimes varies. A national survey of trends in college grading practices gathered data from 1,601 universities and colleges and reported 97 percent of respondents indicated their institutions used some form of a letter grading system and 90 percent used a 4.0 grading scale (Riley \& Others, 1992). 
Grade point averages are imprecise measurements and consistency may be an issue. Chickering (1983) reports there are a number of problems regarding student evaluation. First of all, each institution and teacher establishes private performance norms. Secondly, the criteria for performance are seldom clearly articulated, and thirdly, grades awarded depend primarily upon one student's performance relative to another. While this may be true, it is also true that an " $A$ " grade in one Grade 4 to 12 classroom in British Columbia numerically means the same thing in every Grade 4 to 12 classroom across the province.

Huck and Cormier (1996) remind us the basic idea of reliability is summed up by the word consistency. It can be stated with confidence that consistency in treatment is evident in this case and that GPA is a reliable measurement of academic achievement for the purposes of this study. In terms of validity, more specifically, content validity, a grade of " $\mathrm{A}$ " numerically means a range of $86 \%$ to $100 \%$, which is then represented by 4.0 on the GPA scale. An "A" or 4.0 GPA are both meaningful values representing continuous data, that is, the percentage scale from which they were calculated. If the same conversion system is used across all schools in the province, including the schools in this study, that is, percentages are converted to letter grades and GPA, then the GPA values make perfect sense. The fact that letter grades are discrete just translates into a loss of information. The GPA value is not a meaningless value, just an imprecise one. This likelihood has been identified as a limitation of this study. The analysis is still valid as presented and considered acceptable in the Social Sciences. What is really important is that the GPAs are meaningful. In this case, the analysis is valid because the numbers assigned to GPA make sense and are consistent with provincial education policy. Grade 
point averages were entered into the database according to the coded numbers assigned to the students. Levels of involvement, as reported in the Student Surveys, were also added into the database, as were student gender and grade levels.

To answer the first research question, "To what extent does academic achievement influence the Total Self self-esteem of students in grades 6,8,10 and 12 in a small, semi-rural school district in British Columbia?, the composite or Total Self score on the Coopersmith Self-Esteem Inventory was used as the dependent variable measure of self-esteem. The scores on the General Self, Social Self-Peers, and the School-Academic Self scales were used as the dependent variable measures of self-esteem for Research Questions $1 \mathrm{a}, 1 \mathrm{~b}$ and $1 \mathrm{c}$. Four independent variables were entered into these models, reported grade-point averages, the self-reported average level of weekly involvement spent engaged in school-related non-academic or extracurricular activities, gender, and grade level. F-tests were used to evaluate the significance of the independent variables. The S-PLUS statistical software program was used for the purpose of analyzing the data. As reported in Chapter I, multiple regression analysis was used to determine the extent of the relationship between the dependent variables (the four measures of selfesteem) and the four independent variables mentioned above. Dummy variables were created for Involvement or the level of participation, Gender, and Grade. The main effects of these variables, along with the GPA:Grade, GPA:Involvement, and GPA:Gender interactions, were included in the original model. For each one of the four models, the coefficient of determination $R^{2}$ was calculated and the effects of the independent variables were estimated and tested for significance at the $5 \%$ level. In each case, self-esteem was modeled as a linear function of the continuous GPA data and the 
levels of participation, grade level, and gender. For each response, ANOVA tables showed the simultaneous significance of the factors studied. Multiple comparison analysis was then conducted to investigate mean differences between the different levels of the factors deemed significant to the study. In addition, the parameter estimate tables showed the individual t-tests of significance.

The survey questions were grouped and coded for analysis to answer Research Question 3, "What attitudes, if any, do the participants in this study have with regard to their school experience toward regard to their school experience, more specifically towards getting good grades, participating in school activities, and preparing for the future?" Student responses to the open-ended questions associated with each survey question were grouped by theme according to grade level. For example, the analysis of the Grade 6 responses to survey question 1, "How sure are you that you will have a promising or bright future?", revealed several common responses, including the importance of good grades and a positive self-image. Although the responses from the older students, especially the Grade 12 students, were often more descriptive and diverse, and hence more challenging to analyze, typical responses clearly emerged from the data. For example, many different courses were reported as one of the "best things about school", yet they were collectively grouped as "diversity of learning opportunities". Student responses to the open-ended questions were analyzed and grouped according to theme. Some of the more common or typical responses were included in Chapter IV to add a human dimension to the reporting of the statistical analysis and, as such, should not be interpreted as implying formal qualitative analysis. 
The ratings given by the students to each of the questions were tallied according to number of students responding, their grade level and gender, and were reported as percentages when deemed appropriate to the question. To answer Research Question 4, "Do these attitudes vary according to gender and grade level?" the ratings were grouped into one of two responses to get an aggregated response and analyzed using a logistical regression model (see Appendix G). For example, in the case of the first survey question which asked, "How sure are you that you will have a promising or bright future?", the responses "Very sure" and "Somewhat sure" were combined, as were "Not too sure" and "Not sure at all" and classified as either "Sure" or "Not sure", an aggregated response. In the case of logistical regression, a "Sure" response would be considered a "success". Gender, Grade, and the interaction of Gender and Grade were tested for significance at the $5 \%$ level. The combining of the responses was consistent with the descriptive reporting of these data.

To deal with the issues of potential selection bias and generalizability, the participating and non-participating groups were compared according to gender and GPA. Chi-square tests were used to determine whether the probability of participating was dependent on grade or gender. A 2-sample t-test compared the GPA of participating and non-participating students. Similarly, the students who had a Lie Scale score $<5$ and Lie Scale score $>4$ on the Coopersmith Self-Esteem Inventory were compared using the same tests and effects.

\section{Sample Analysis}

A comparison of the participating and non-participating students, and the students with Lie Scale score $<5$ and Lie Scale scores $>4$ on the Coopersmith Self-Esteem 
Inventory, revealed that both groups were the same, except that the probability of participation varied by grade.

In the case of participating and non-participating students, a 2-sample t-test comparing GPA's of the two groups resulted in the p-value of 0.127 , which implies that there is no evidence against the null hypothesis that the two groups have the same mean GPA. A Chi-square test of whether the probability of participating depends on gender resulted in a p-value of 0.3677 , which implies that there is no evidence against the null hypothesis that the probability of participation is the same for both genders. A Chi-square test of whether the probability of participating depends on grade resulted in a p-value of 0.0004 , which implies there is strong evidence that the probability of participation is different for different grades.

In the case of the Lie Scale scores $<5$ and Lie Scale scores $>4$, a two sample t-test comparing the GPA's of students resulted in a p-value 0.8357 , which implies there is no evidence against the null hypothesis that the two groups have the same mean GPA. A Chi-square test of whether the probability that "lying" depends on gender resulted in a pvalue 0.4324 , which implies there is no evidence against the hypothesis that the probability of lying is the same for both genders. Finally, a Chi-square test of whether the probability of lying depends on grade resulted in a p-value 0.4478 , which implies there is no evidence against the null hypothesis that the probability of lying is the same for all grades. The assumption that the sample is a representative sample of the total population is thus reasonable. Although the tests are approximate, they should be valid given the relatively large sample size. 


\section{Limitations of the Study}

Due to time constraints this study only provided a snapshot in time with results that only reflected generalized trends of a specific population. It might be argued that the results apply only to the students participating in the study, given the need for an Informed Consent form. In this sense, each participating student was self-selecting, which meant that they might not have been representative of the other students in their grade or gender. It should be noted, as well, that this study was further delimited because it was reliant on data collected from students in a small, rural district in British Columbia. The community in which the study was conducted is generally middle class, white, and well educated. Although a strong sense of community exists, many people have been attracted to this area of the province because of their creative talents or perceived need to "get away from it all". Additional research needs to be conducted to ascertain whether the findings of the study are generalizable to other student populations or other areas of the province or to larger communities.

A longitudinal study tracking the same group of students from the time they were in Grade 6 through to graduation would likely produce more meaningful results, but that is beyond the scope of this particular study. The literature also reveals that there are many variables, some school related, some not, that a researcher might wish to use to predict self-esteem beyond the ones used in this study. The academic achievement construct is also open to interpretation. Grading is often subjective and inconsistencies in measurement are commonplace. It is generally assumed that a grade in one course or from one teacher means the same thing, yet the method of teaching or the content of the course is likely to vary from class to class or from teacher to teacher. Grading by its very 
nature is an imprecise science at best. Reporting academic achievement according to defined clusters of academic and/or elective courses or by student enrolment might be worthy of additional study, especially considering the current interest in Multiple Intelligence.

In the second part of the study, the researcher was looking for themes related to self-esteem, academic achievement, and positive or optimistic views of the future. This research was exploratory and while relevant to the intent of this study, the open-ended responses were open to interpretation, speculation, and researcher bias. This awareness, however, should reduce the potential for any problems associated with these limitations. Finally, it is possible that a number of factors influenced the responses of the students to the survey questions or the self-esteem inventory items, including being swayed by the opening discussion, the perception that the participating students were part of a select group, or even the presentation style of the researcher. As reported in Chapter One, over $8 \%$ of the participating students had scores $>4$ on the 8-point Lie-Scale. This seems to indicate that some students may not have answered the items in the Coopersmith SelfEsteem Inventory in a manner that reflected their true feelings.

Summary

This correlational study investigates the relationship between self-esteem and academic achievement, as defined by grade-point averages. It also investigates the relationship between self-esteem and level of involvement in school related or extracurricular activities. In addition, this study attempts to survey a general school population across four grade levels (Grades 6, 8, 10 and 12) and looks for significant variation according to gender. Certain aspects of optimism, self-esteem, academic 
achievement, and involvement in school activities are explored from the perspective of the total school experience. The findings of this study should provide some additional insight into the complexities of developing the educated citizen. 


\title{
CHAPTER IV: ANALYSIS OF DATA
}

\author{
Introduction
}

This chapter discusses the statistical analysis of the factors affecting four measures of school children's self-esteem in a small, semi-rural school district in southwestern British Columbia. The students who participated in this study were registered in grades $6,8,10$ and 12 . The measures of self-esteem were modeled as linear functions of the variables: grade point averages (GPA) of the students at the end of the first term, Grade level, Gender, and Involvement in school related and extra-curricular activities. The main effects of these variables, along with the interactions of GPA and Grade, GPA and Involvement, and GPA and Gender, were also included. Diagnostic plots were created to test the assumptions about the data, namely that self-esteem could be approximated as normally distributed with constant variance. The assumption of constant variance appeared to be reasonable in all cases. The normality assumption was somewhat violated, however, this assumption is not critical because the sample size is large, and hence the results are still valid. Further, it was assumed that the students' selfesteem were independent and unrelated to one another. The correlations between the effect estimates associated with different factors were quite low, and thus the significance of these can be interpreted essentially independently of one another.

Student rating responses to eleven survey questions were then aggregated to form binary responses and analyzed for significance. The factors studied included Grade, Gender, and the interaction of Gender and Grade level. Only the independence of observations was assumed in this case. ANOVA tables are included in the survey analysis 
when the factors are deemed significant. Additional descriptive data gathered from the open-ended questions associated with each survey question were collected and analyzed according to dominant themes. Although the inclusion of these data provides the study with a certain contextual richness and helps support recommendations for further study, the results should not be considered statistically significant.

Data Collection and Procedures

In the first part of this study, self-esteem scores on the Coopersmith Self-Esteem Inventory (CEI) were tabulated on four scales: General Self, Social Self-Peers, SchoolAcademic, as well as a combined score, Total Self, and entered into a database. As per the instructions of the publisher the scores on each one of these scales were multiplied by two, with totals ranging from 16 on the Social Self-Peers and School-Academic scales, to 52 on the General Self scale, and 100 on the Total Self scale. Lie Scale scores, with a range of 0 to 8 , were also calculated and entered into the database. The publishers of the CEI suggest high Lie Scale scores may render the inventory invalid, so it was determined that cases with scores $>4$ on the Lie Scale would not included in the statistical analysis. Grade levels, gender, and levels of involvement in school related or extra-curricular activities were gathered from the participating students and entered into the database. The four self-esteem measures were identified as the dependent variables in this study, with grade point average, grade level, gender, and level of involvement serving as the independent variables. Multiple regression analysis included determining the coefficient of determination $R^{2}$ and testing for significance of the independent variables at the 5 percent level. In each case, self-esteem was modeled as a linear function of the 
continuous GPA data and Involvement, Grade, and Gender. F-tests were used to evaluate the significance of the independent variables.

The second part of the study was exploratory and descriptive by design. A Student survey asked the participants to respond to 11 questions, which combined ratings and open-ended responses, and addressed issues pertaining to self-esteem, optimism, and academic achievement. The ratings given to the survey questions, which are reported, were aggregated to form binary responses and analyzed using logistical regression methodology. Three additional open-ended questions explored the value of the school experience. The student responses to the open-ended survey questions were analyzed for content and theme. As detailed in Chapter III, comparative analysis, including Chi-square tests and t-tests, was used to compare the GPA, Grade level and the Gender of the participating and non-participating students and students with Lie Scale scores $<5$ and $>4$.

$$
\text { Multiple Regression Analysis }
$$

In the first part of the study data were analyzed to answer Research Questions 1 and 2 , that is:

1. To what extent does academic achievement influence the Total self-esteem of students in grades $6,8,10$ and 12 in a small, semi-rural school district in British Columbia?

a. To what extent does academic achievement influence the SchoolAcademic self-esteem of the students?

b. To what extent does academic achievement influence the General Self self-esteem of the students? 
c. To what extent does academic achievement influence the Social Self-Peer self-esteem of the students?

2. Do these relationships vary by gender, grade level and participation in school related and extra-curricular activities in school?

Self-esteem was defined as the score on the total or composite scale on the Coopersmith Self-Esteem Inventory in Research Question 1. Research Questions 1 and 2 generated the following null hypotheses which will be addressed in this Chapter:

1. Grade point averages (GPA), level of involvement in school-related or extracurricular activities, gender, and grade level have no effect on Total self-esteem.

2. Grade point averages (GPA), level of involvement in school-related or extracurricular activities, gender, and grade level have no effect on Academic-School self-esteem.

3. Grade point averages (GPA), level of involvement in school-related or extracurricular activities, gender, and grade level have no effect on General Self selfesteem.

4. Grade point averages (GPA), level of involvement in school-related or extracurricular activities, gender, and grade level have no effect on Social Self-Peer self-esteem.

\section{$\underline{\text { Regression Model }}$}

The original model contained the terms GPA, Involvement, Gender, Grade and the interactions of GPA and Grade, GPA and Involvement, and GPA and Gender. Since this study was interested in the relationship between GPA and self-esteem, as well as whether this relationship varies with Involvement, Grade, and Gender, AVOVA tables 
displaying the significance of these variables were generated for each measure of selfesteem.

A high correlation among some of the parameter estimates was noted when the interaction effects were included in this model. The correlation matrix (see Appendix $\mathrm{H}$ ) shows that the interaction effects corresponding to GPA:Involvement, GPA:Grade, and GPA:Gender are relatively uncorrelated, which means the significance of each effect can be assessed individually. It should be noted, however, that the correlation between the estimated effects of GPA:Gender and Gender is very high, thus these effects cannot be interpreted separately. Similarly the estimated effect of the interaction of GPA and Involvement is highly correlated with the effects of Involvement and GPA. When two or more independent variables are highly correlated, a condition known as multicollinearity, these variables are essentially measuring the same phenomenon. Under these circumstances, there is less precision associated with estimated coefficients, and, more importantly, the effects of these variables cannot be interpreted individually. Thus, multicollinearity can weaken the analysis.

Schroeder, Sjoquist, and Stephen (1986) suggest, "There is no single preferable technique for overcoming multicollinearity, since the problem is due to the form of the data" (p.72). When the regression model involves an interaction term, such as the interaction between GPA and Grade, one suggested method is to use a centred score regression model. Centring GPA to get GPAnew substantially reduced the correlation among the parameter estimates. GPAnew was calculated by subtracting the mean (GPA) from the GPA scores, that is, the difference between a student's GPA and the overall mean GPA. A comparison of the Type 1 and Type 3 ANOVA tables for each measure of 
self-esteem shows centring GPA substantially reduced the correlations between the effects so that they could tested for significance individually (see Appendices I and J). As a result of these individual tests the interactions of GPAnew and Involvement, and GPAnew and Gender, were found to be insignificant in all cases and dropped from the model. Because Gender was an important factor in this study and has been associated with self-esteem and academic achievement, it was retained in the regression model. In formal studies, it is not proper to exclude a variable when the theory indicates that the variable should be included (Schroeder, Sjoquist, \& Stephan, 1986). The reduced model, then, contained the factors, GPAnew, Involvement, Grade, Gender, and the interaction effect of GPAnew and Grade.

For each response, an ANOVA table and list of parameter estimates are provided. Note that both tables result from the same analysis, but have different uses. The ANOVA table is useful for assessing the significance of categorical variables with more than 2 levels. For example, the F-test for Involvement tests whether self-esteem is the same for all levels of Involvement simultaneously. The table of parameter estimates shows the individual t-tests of significance, and thus is not appropriate for multiple tests. Specifically, each p-value corresponds to the test of whether that parameter is equal to zero. When alpha is equal to .05 , the probability of Type I error at 5 percent is controlled for each test individually, but the overall probability of Type I error, that is, making a Type I error in any of these tests, will be higher than this. Note that for continuous variables, such as GPAnew, or categorical variables with 2 levels, such as Gender, the ttest and F-test are equivalent (Huck \& Cormier, 1996), therefore the ANOVA table is sufficient for displaying all the necessary information about testing. 
For factors or interactions with more than 2 levels that were deemed significant, in this case, Involvement, Grade, and the interaction of GPAnew and Grade, it may be of interest to determine which levels are significantly different from the others. Multiple comparison tests were conducted to address this question while properly controlling the Type I error. The multiple comparison tests control the overall probability of Type I error, keeping it at 5 percent.

\section{Total Self-Esteem}

In the case of Total self-esteem, the $R^{2}$ value of .24 indicates that the independent variables in this model explain approximately 24 percent of the variation in the Total selfesteem scores. Clearly the independent variables in the model are relatively weak predictors of total self-esteem and at least one important variable is missing. There is a great deal of unexplained variance associated with total self-esteem.

Table 4.1 shows the results of the regression, implying the significance of GPAnew, Involvement, Grade, and the interaction of GPAnew and Grade. Gender was not a significant factor in this case.

Table 4.1

ANOVA table for Total self-esteem and the independent variables GPAnew, Involvement, Gender, Grade, and the GPAnew:Grade interaction

\begin{tabular}{lccccc}
\hline & Df & Sum of Squares & Mean Square & F-value & $\operatorname{Pr}(\mathrm{F})$ \\
\hline GPAnew & 1 & 7778.76 & 7778.76 & 35.86 & 0.00 \\
Involvement & 3 & 3869.36 & 1289.79 & 5.95 & 0.00 \\
Gender & 1 & 349.79 & 349.79 & 1.61 & 0.21 \\
Grade & 3 & 1105.92 & 368.64 & 1.70 & 0.17 \\
GPAnew:Gra & 3 & 4895.39 & 1631.80 & 7.52 & 0.00 \\
de & & & & & \\
Residuals & 251 & 54448.24 & 216.93 & & \\
\hline
\end{tabular}


Based on the evidence shown in Table 4.2 we can partially reject Hypothesis 1 , that states GPA, Involvement, Gender, and Grade have no effect on Total self-esteem.

When the $F$ statistic exceeds the critical value and the null hypothesis is then rejected, we can conclude some difference among the means exists. Hinkle, Wiersma, and Jurs 1988) write, "Using ANOVA, this hypothesis is tested while maintaining the Type I error rate at the pre-established level. After the hypothesis is rejected, we are still faced with the problem of deciding which pairs or combinations of means are not equal" (p.367). According to Huck and Cormier (1996), "Planned comparisons typically allow researchers to answer precise research questions that caused their studies to be carried out and to test null hypotheses with a lower probability of Type II error" (p.452).

Additionally these authors report, "Post hoc analysis helps researchers in their effort to understand the true pattern of the population means" (p.324).

Post Hoc Multiple Comparison tests were conducted to determine which means differed significantly after a significant $F$ statistic had been found in the ANOVA table. Cormier and Huck (1996) suggest, "The researcher's objective is to better understand why the ANOVA yielded a significant $F^{\prime \prime}$ (p.324). In this case, the S-PLUS statistical analysis revealed Involvement 3, that is, being heavily involved in school-related or extra-curricular activities, was significantly different from the other levels of Involvement, and Grade and the interaction of GPAnew and Grade were significantly different between Grade 6 and Grades 10 and 12.

Table 4.2 shows the parameter estimates of the same model, indicating the degree to which each of the independent variables contribute, on average, to the Total selfesteem scores. It should be noted that for any subsequent analysis the term "on average" 
is implied. The reported figures do not apply to the students individually, but rather to the group as a whole.

The GPAnew coefficient of 19.15 indicates that a change of one point in GPA at the Grade 6 level results in a change of almost 19.2 percent in Total self-esteem score (the maximum total self-esteem score is 100). A one-unit change in GPAnew is equivalent to a one-unit change in GPA in this particular case. In comparison, Table 4.2 also shows a one-point change in GPA results in an increase in the Total self-esteem scores of 3.3 percent $(19.15-15.90)$ at the Grade 10 level and 1.9 percent $(19.15-$ 17.27) at the Grade 12 level.

Table 4.2

Parameter Estimates, $t$-values, and significance of the independent variables to total selfesteem

\begin{tabular}{lcccc}
\hline & Value & Standard Error & $t$ value & $\operatorname{Pr}(>|t|)$ \\
\hline Intercept & 70.67 & 3.34 & 21.15 & 0.00 \\
GPAnew & 19.15 & 3.39 & 5.65 & 0.00 \\
Involvement 1 & 1.70 & 3.32 & 0.51 & 0.61 \\
Involvement 2 & 2.05 & 3.06 & 0.67 & 0.50 \\
Involvement 3 & 10.19 & 3.12 & 3.27 & 0.00 \\
Gender & 2.43 & 1.91 & 1.27 & 0.21 \\
Grade 8 & -5.07 & 2.63 & -1.92 & 0.06 \\
Grade 10 & -5.28 & 2.65 & -1.99 & 0.05 \\
Grade 12 & -4.40 & 2.77 & -1.59 & 0.11 \\
GPAnew:Grade 8 & -7.86 & 4.64 & -1.69 & 0.09 \\
GPAnew:Grade 10 & -15.90 & 4.07 & -3.90 & 0.00 \\
GPAnew:Grade 12 & -17.27 & 4.03 & -4.28 & 0.00 \\
\hline
\end{tabular}

The Grade parameter estimates refer to the difference in self-esteem between the grades at the mean of GPA. Since there is an interaction between Grade and GPA, the effect of Grade cannot be discussed without specifying the level of GPA, so the main effects of Grade (i.e. the parameter estimates) represent the effect of Grade for students 
with the mean GPA, in this case, GPA $=2.76$. It can be seen that the Total self-esteem scores at the mean value of GPA are greater at the Grade 6 level than they are at the Grade 10 or Grade 12 levels. The Grade 6 scores were 5.3 percent higher than the scores of the Grade 10 students and 4.4 percent higher than the scores of the Grade 12 students.

Although Gender was not a significant factor in this model, the positive coefficient means the total self-esteem scores were 2.4 percent higher for boys (coded 1 ) than the scores of the girls (coded 0 ). Although a difference was observed in this sample, there is no statistical evidence to show that a difference exists in the population.

Table 4.2 also shows that Involvement 3 , that is, three or more hours per week engaged in school-related or extra-curricular activities, is associated with higher total self-esteem scores. Specifically, Level 3 Involvement represents an increase of about 10.2 percent in the Total self-esteem scores between the students with no involvement in school activities and those who are heavily involved. These students have Total selfesteem scores about 8.5 percent $(10.19-1.70)$ higher than students with Level 1 Involvement (minimal involvement) and 8.1 percent $(10.19-2.05)$ higher than students with Level 2 Involvement (moderate involvement in school-related or extra-curricular activities).

\section{School-Academic Self-Esteem}

A relatively stronger relationship exists between the predictor variables and School-Academic self-esteem scores. The $R^{2}$ value of .36 indicates the model containing GPAnew, level of involvement in school-related or extra-curricular activities, gender, grade level, and the GPAnew:Grade interaction explains 36 percent of the variation in these scores. Table 4.3 shows the results of the regression, implying the significance of 
GPAnew, Involvement, Grade, and the GPAnew:Grade interaction. Gender was not a significant factor in the case of School-Academic self-esteem. Based on the evidence shown in Table 4.3, we can partially reject Hypothesis 2, that is: GPA, Involvement, Gender, and Grade have no effect on School-Academic self-esteem.

Multiple comparison analysis showed Involvement 3 was significantly different from the other levels of school involvement. Grade 6 was significantly different from the other three grades and there were no statistical differences between the GPAnew:Grade interactions, despite the $F$-test showing GPAnew:Grade as significant. A review of the confidence intervals shows that the lower bounds for grades 6 and 12 is close to zero at -0.277 and the lower bounds for grades 8 and 12 is close to zero at -0.185 , which suggests they might have been significant had the level of significance been slightly increased from .05 .

Table 4.3

ANOVA table for School-Academic self-esteem and the independent variables GPAnew, Involvement, Gender, Grade, and the GPAnew:Grade interaction

\begin{tabular}{lccccc}
\hline & Df & Sum of Squares & Mean Square & F-value & $\operatorname{Pr}(\mathrm{F})$ \\
\hline GPAnew & 1 & 558.34 & 558.34 & 56.41 & 0.00 \\
Involvement & 3 & 238.38 & 79.46 & 8.03 & 0.00 \\
Gender & 1 & 18.99 & 18.99 & 1.92 & 0.17 \\
Grade & 3 & 242.27 & 80.76 & 8.16 & 0.00 \\
GPAnew:Gra & 3 & 84.81 & 28.27 & 2.86 & 0.04 \\
Residuals & 251 & 2484.52 & 9.90 & & \\
\hline
\end{tabular}

Table 4.4 reveals that a one-unit increase in GPAnew at Grade 6 results in an $18.9 \%(3.18 / 16)$ increase in the School-Academic self-esteem scores. This compares to a 12.3 percent (1.96/16) increase at the Grade 10 level and a 7.4 percent $(1.19 / 16)$ at the Grade 12 level. As was the case with Total self-esteem, the positive coefficient for 
Gender means that the School-Academic self-esteem scores in this sample for the boys were 3.6 percent $(1.7 / 16)$ greater than the scores of the girls, although gender was not found to be a significant factor in the overall population.

It can also be seen from Table 4.4 that involvement in school-related and extracurricular activities has a positive relationship to School-Academic self-esteem. A heavy level of involvement, Level 3 Involvement, is associated with an increase of about 2.65 or 16.6 percent in the School-Academic self-esteem scores of these students as compared to the students with Level 0 Involvement (no involvement), 2.30 or 14.3 percent $(2.3 / 16)$ over students with Level 1 Involvement (minimal involvement), and 1.65 or 10.3 percent over students with Level 2 Involvement (moderate involvement).

Grade was also a significant factor. The Grade 6 self-esteem scores at the mean value of GPA were 1.78 or 11.1 percent $(1.78 / 16)$ greater than the Grade 10 students and 2.84 or 17.8 percent $(2.84 / 16)$ greater than the Grade 12 students.

Table 4.4

Parameter estimates, $t$-values, and significance of the independent variables to schoolacademic self-esteem

\begin{tabular}{lcccc}
\hline & Value & Standard Error & $t$-value & $\operatorname{Pr}(>|t|)$ \\
\hline Intercept & 9.72 & 0.71 & 13.62 & 0.00 \\
GPAnew & 3.18 & 0.72 & 4.39 & 0.00 \\
Involvement 1 & 0.35 & 0.71 & 0.49 & 0.62 \\
Involvement 2 & 1.00 & 0.65 & 1.53 & 0.13 \\
Involvement 3 & 2.65 & 0.67 & 3.98 & 0.00 \\
Gender & 0.57 & 0.41 & 1.39 & 0.17 \\
Grade 8 & -1.07 & 0.56 & -1.90 & 0.06 \\
Grade 10 & -1.78 & 0.57 & -3.15 & 0.00 \\
Grade 12 & -2.84 & 0.59 & -4.81 & 0.00 \\
GPAnew:Grade 8 & 0.03 & 0.99 & 0.04 & 0.97 \\
GPAnew:Grade 10 & -1.22 & 0.87 & -1.40 & 0.16 \\
GPAnew:Grade 12 & -1.99 & 0.86 & -2.31 & 0.02 \\
\hline
\end{tabular}




\section{General-Self Self-Esteem}

The $R^{2}$ value of .195 indicates the independent variables in this model explain almost 20 percent of the variation in the General-Self self-esteem scores. There is a great deal of unexplained variance associated with General-Self self-esteem.

Table 4.5 shows that GPAnew, Involvement, Grade, and the GPAnew:Grade interaction were all significant factors in the case of General Self self-esteem. Although the main effect of Grade was not significant with a p-value of 0.13 , the interaction of GPAnew and Grade was, which suggests Grade was a significant factor. Gender was not a significant factor. On this basis, Hypothesis 3, that is, GPA, Involvement, Gender and Grade have no effect on General-Self self-esteem, is rejected in part. Multiple comparisons for Involvement found significant differences between a heavy level of involvement or Involvement Level 3, and Levels 1 and 2. In addition, significant differences were found between the GPAnew:Grade interactions between Grade 6 and Grades 10 and 12.

\section{Table 4.5}

ANOVA table for General self-esteem and the independent variables GPAnew, Involvement, Gender, Grade, and GPAnew:Grade

\begin{tabular}{lccccc}
\hline & Df & Sum of Squares & Mean Square & F-value & $\operatorname{Pr}(\mathrm{F})$ \\
\hline GPAnew & 1 & 1467.61 & 1467.61 & 21.34 & 0.00 \\
Involvement & 3 & 888.23 & 296.08 & 4.31 & 0.00 \\
Gender & 1 & 226.78 & 226.78 & 3.30 & 0.07 \\
Grade & 3 & 395.40 & 131.80 & 1.91 & 0.13 \\
GPAnew:Grade & 3 & 1770.90 & 590.30 & 8.58 & 0.00 \\
Residuals & 251 & 17259.07 & 68.76 & & \\
\hline
\end{tabular}

Table 4.6 shows the parameter estimates of the independent variables in the case of General-Self self-esteem. A one-unit increase in GPAnew results in a 9.97 or 19.1 
percent $(9.98 / 52)$ increase in General Self self-esteem scores at the Grade 6 level. This compares to an increase of $0.17(9.98-9.81)$ or 0.3 percent $(0.17 / 52)$ in these scores at the Grade 10 level and a decrease of $-0.13(9.98-10.11)$ or 0.025 percent $(-0.13 / 52)$ at the Grade 12 level.

Multiple comparison analysis also found Involvement 3 significantly different from Involvement 1 and 2 . Table 4.6 shows a 3.75 or 7.2 percent (3.75/52) difference in General self-esteem scores between the students with a Level 1 (minimal level of involvement) and Level 3 Involvement (those students who were heavily involved) and a 3.56 or 6.8 percent (3.56/52) difference in these scores between Level 2 Involvement (a moderate level of involvement) and Level 3 Involvement. Although Gender was not a significant factor in the case of General-Self self-esteem, the positive coefficient associated with Gender once again suggests the scores for the boys were 3.8 percent higher that they were for the girls in this sample.

Table 4.6

Parameter Estimates, $t$-values, and significance of the independent variables to general self-esteem

\begin{tabular}{lcccc}
\hline & Value & Standard Error & $\mathrm{t}$ value & $\operatorname{Pr}(>|\mathrm{t}|)$ \\
\hline Intercept & 38.28 & 1.88 & 20.35 & 0.00 \\
GPAnew & 9.98 & 1.91 & 5.23 & 0.00 \\
Involvement 1 & -0.27 & 1.87 & -0.14 & 0.89 \\
Involvement 2 & -0.19 & 1.73 & -0.11 & 0.91 \\
Involvement 3 & 4.02 & 1.75 & 2.29 & 0.02 \\
Gender & 1.95 & 1.08 & 1.82 & 0.07 \\
Grade 8 & -3.15 & 1.48 & -2.12 & 0.03 \\
Grade 10 & -3.08 & 1.49 & -2.06 & 0.04 \\
Grade 12 & -2.43 & 1.56 & -1.56 & 0.12 \\
GPAnew:Grade 8 & -4.55 & 2.61 & -1.74 & 0.08 \\
GPAnew:Grade 10 & -9.81 & 2.29 & -4.28 & 0.00 \\
GPAnew:Grade 12 & -10.11 & 2.27 & -4.45 & 0.00 \\
\hline
\end{tabular}


Table 4.6 also suggests the scores for the Grade 6 students on the General Self self-esteem measure at the average GPA value of 2.76 were 5.9 percent (3.08/52) and 4.7 percent $(2.4 / 52$ higher than the scores of the Grade 10 and 12 students.

\section{Social Self-Peers Self-Esteem}

In the case of Social Self-Peers self-esteem, an $R^{2}$ value of .22 indicates approximately $22 \%$ of the variation in the self-esteem scores can be explained by the predictor variables. The factors in the model are very weak predictors of the self-esteem scores and once again, at least one important variable is missing from the model.

Table 4.7 shows the results of the regression, implying the significance of GPAnew, Involvement, Grade, and the interaction effect of GPAnew:Grade. Although the main effect of GPAnew was not significant with a p-value of .07 , the interaction of GPAnew and Grade was, which implies GPAnew is a significant factor. Gender was not a significant factor in this case. Based on the evidence shown in Table 4.7, we can partially reject Hypothesis 4, that is: GPA, Involvement, Gender, and Grade have no effect on Social Self-Peers self-esteem.

Table 4.7

ANOVA table for social self-peers self-esteem and the independent variables GPAnew, Involvement, Gender, Grade, and GPAnew:Grade

\begin{tabular}{lccccc}
\hline & Df & Sum of Squares & Mean Square & F-value & $\operatorname{Pr}(\mathrm{F})$ \\
\hline GPAnew & 1 & 34.31 & 34.31 & 3.38 & 0.07 \\
Involvement & 3 & 274.43 & 91.48 & 9.02 & 0.00 \\
Gender & 1 & 8.49 & 8.49 & 0.84 & 0.36 \\
Grade & 3 & 3876.81 & 1292.27 & 5.96 & 0.00 \\
GPAnew:Grade & 3 & 184.69 & 61.56 & 6.07 & 0.00 \\
Residuals & 251 & 2545.74 & 10.14 & & \\
\hline
\end{tabular}


Multiple comparison analysis of the significant factors Involvement, Grade, and the interaction of GPAnew:Grade revealed significant differences between Level 3 Involvement (a heavy level of involvement) and Level 0 Involvement (no involvement) and Level 1 Involvement (a minimal level of involvement), as well as between Level 2 (a moderate level of involvement) and Level 0 Involvement (no involvement). Significant differences were also found between Grade 6 and Grades 10 and 12 and the interactions of GPAnew:Grade between Grade 6 and Grades 8, 10 and 12.

It can be seen in Table 4.8 that a change of one unit of GPAnew results in a 2.99 or 18.7 percent $(2.99 / 16)$ increase in the Grade 6 Social Self-Peers self-esteem scores. This compares to an increase of only 0.27 or 1.7 percent (2.7/16) at Grade 8, a decrease of -0.51 or minus 3.2 percent $(-0.51 / 16)$ at Grade 10 , and a decrease of -0.38 or minus 2.3 percent $(-0.38 / 16)$ at the Grade 12 level.

Table 4.8

Parameter Estimates, $t$-values, and significance of the independent variables to social self-peers self-esteem

\begin{tabular}{lcccc}
\hline & Value & Standard Error & $t$ value & $\operatorname{Pr}(>|t|)$ \\
\hline Intercept & 10.25 & 0.72 & 14.19 & 0.00 \\
GPAnew & 2.99 & 0.73 & 4.08 & 0.00 \\
Involvement 1 & 0.79 & 0.72 & 1.09 & 0.27 \\
Involvement 2 & 1.87 & 0.66 & 2.82 & 0.00 \\
Involvement 3 & 3.06 & 0.67 & 4.55 & 0.00 \\
Gender & -0.38 & 0.41 & -0.91 & 0.36 \\
Grade 8 & -0.003 & 0.57 & -0.01 & 0.995 \\
Grade 10 & 1.34 & 0.57 & 2.34 & 0.02 \\
Grade 12 & 1.90 & 0.60 & 3.18 & 0.00 \\
GPAnew:Grade 8 & -2.72 & 1.00 & -2.72 & 0.01 \\
GPAnew:Grade 10 & -3.50 & 0.88 & -3.97 & 0.00 \\
GPAnew:Grade 12 & -3.37 & 0.87 & -3.86 & 0.00 \\
\hline
\end{tabular}


Gender was not a significant factor in the case of Social Self-Peers self-esteem, but the negative coefficient of -.38 indicates the self-esteem scores in this sample for the girls were 2.4 percent $(.38 / 16)$ higher than the scores of the boys.

Table 4.8 shows that students who are heavily involved in school activities, that is, Level 3 Involvement, have Social Self-Peers self-esteem scores that are 3.06 or 19.1 percent (3.06/16) higher than the students with Level 0 Involvement (no involvement) and 2.27 or 14.2 percent (2.27/16) higher than the students with Level 1 Involvement (minimal involvement). In this case, it can also be seen that students with a Level 2 Involvement (moderate level of involvement or more than one hour, but less than three hours per week), score 1.87 or 11.7 percent (1.87/16) higher on the Social Self-Peers selfesteem measure than the students with Level 0 Involvement (no involvement).

In the case of Social Self-Peers self-esteem, the regression analysis found Grade was a significant factor. Multiple comparison analysis reported significant differences between the mean scores of Grade 6 and the Grade 10 and 12 students. Table 4.8 shows the estimated difference in the self-esteem scores at the average value for GPA between Grade 6 and Grade 10 was 1.34 and 1.90 between Grade 6 and Grade 12. This suggests the Social Self-Peers self-esteem scores were 8.3 percent (1.34/16) higher for Grade 10 students and 11.9 percent (1.90/16) higher for Grade 12 students when compared to the scores of the Grade 6 students at the mean value of GPA.

\section{Summary of the Regression Analysis}

The $R^{2}$ values were very low in all cases (ranging from 0.20 to 0.36 ), which indicate the factors studied were poor indicators of self-esteem and that there was a great deal of unexplained variation associated with the data. A review of the ANOVA tables 
shows Involvement and the interaction of GPAnew and Grade were significant in all cases. Although the main effect of Grade was shown to be insignificant ( $p=.13$ ), in the case of General-Self self-esteem, the significance of the interaction of GPAnew and Grade implies Grade was a significant factor. The same reasoning applies in the case of Social Self-Peers self-esteem, when the main effect of GPAnew was found to be not significant ( $p=.07$ ), while the interaction of GPAnew and Grade was. Gender was not a significant factor in any of the cases studied. On the evidence presented above, Hypotheses 1, 2, 3, and 4 were all partially rejected.

The multiple comparison analysis revealed significant differences between the means of Level 3 Involvement (a heavy level of involvement in school-related or extracurricular activities) and other levels of Involvement. In the case of Total self-esteem and School-Academic self-esteem, these significant differences applied to all levels of Involvement, but were limited to Level 1 Involvement (minimal) and Level 2 Involvement (moderate involvement) in the case of General Self self-esteem, and Level 0 Involvement (no involvement) and Level 1 Involvement (minimal involvement) in the case of Social Self-Peers self-esteem. Further investigation of the parameter estimate tables revealed that when compared to Level 0 Involvement (no involvement), Level 3 Involvement (a heavy level of involvement) resulted in a 10.2 percent increase in Total self-esteem scores, a 16.6 percent increase in School-Academic self-esteem scores, and a 19.3 percent increase in the Social Self-Peers self-esteem scores. In the case of General Self self-esteem, Level 3 Involvement resulted in a 7.2 percent in the self-esteem scores when compared to Level 1 Involvement. 
Multiple comparison analysis also showed significant differences in all cases, except School-Academic self-esteem, between the relationship of GPAnew and selfesteem in Grade 6 and that in Grades 10 and 12. Significant differences were also reported between Grade 6 and Grade 8 in the case of Social Self-Peers self-esteem. A review of the parameter estimates shows an increase of one-point in GPAnew, or GPA, resulted in a 19.5 percent increase in Total self-esteem scores as compared to an increase of 3.3 percent and 1.9 percent at the Grade 10 and Grade 12 levels. This compares to an 18.9 percent increase at the Grade 6 level in the School-Academic self-esteem scores 12.3 percent and 7.4 percent increases in these scores at the Grade 10 and Grade 12 levels. In the case of General Self self-esteem a one-point increase in GPAnew resulted in a 19.1 percent increase in self-esteem scores at the Grade 6 level, which compares to an increase of 0.3 percent at the Grade 10 level and a decrease of 0.025 percent at the Grade 12 level. The same increase in GPAnew resulted in an 18.7 percent increase in the Grade 6 scores, an increase of 1.7 percent in the Grade 8 scores, a decrease of 3.2 percent in the Grade 10 scores, and a decrease 2.3 percent in the Grade 12 scores in the case of Social Self-Peers self-esteem.

Although Gender was not statistically significant the positive coefficients in the parameter estimates for Total self-esteem, School-Academic self-esteem, and General Self self-esteem suggest the scores for the boys were respectively 2.4 percent, 3.6 percent, and 3.8 percent higher than the scores for the girls. In the case of Social SelfPeers self-esteem, however, the scores of the girls were 2.4 percent higher than the scores for the boys. It is important to note that while differences were observed in this sample, there is no statistical evidence to show that a difference exists in the population. 
Significant differences at the average value of GPA (2.76) for Grade were found between Grade 6 and Grades 10 and 12. For Total self-esteem, School-Academic selfesteem, and although not statistically significant, General Self self-esteem, the scores were higher at the Grade 6 level than they were at the Grade 10 or Grade 12 levels. In the case of Total self-esteem, the Grade 6 scores were 5.3 percent higher than the scores of the Grade 10 students and 4.4 percent higher than the scores of the Grade 12 students. The Grade 6 scores were 11.1 percent higher than the Grade 10 students and 17.8 percent than the Grade 12 students in the case of School-Academic self-esteem. Table 4.6 suggests the scores for the Grade 6 students on the General Self self-esteem measure were 5.9 percent higher than the Grade 10 students and 4.7 percent higher than the Grade 12 students. The Grade 6 scores on the Social-Peers self-esteem measure, however, were 8.4 percent lower than the Grade 10 scores and 11.9 percent lower than the Grade 12 scores.

It appears that self-esteem is linearly related to GPA, with the intercept depending on the grade, level of involvement, and gender and the slope depending on the grade. The slope was steepest for the grade 6 students indicating the strongest relationship between GPA and self-esteem at that grade level, while the other grades tended to be similar to one another. Self-esteem was found to be the strongest for students who were heavily involved in school-related or extra-curricular activities.

\section{Survey Analysis}

In the second part of the study, survey data were analyzed in reference to Research Question 3, which asked, "What attitudes, if any, do the participants in this study have with regard to their school experience, more specifically towards getting good 
grades, participating in school activities, and preparing for the future?" Eleven survey questions were analyzed according to the ratings given by the students at each of the four grade levels. Dominant or recurring themes, which emerged from the analysis of these data, were noted. Some reference to these themes is made in the following survey analysis, but it should be noted that no statistical significance is implied. Student comments are added only because in the opinion of this researcher they seem to "humanize" the reported findings. This is not intended to appear as a qualitative research and should not be interpreted that way. Three reflective questions, which asked the students to identify the things or circumstances that made them feel good about themselves (self-esteem); to identify the things or circumstances that gave them confidence in the future (optimism); and to identify the best and worst things about their school experience (the relative importance of academic achievement and involvement in school activities) were also analyzed according to theme.

A logistical regression model with Gender, Grade, and the Gender:Grade interaction term coded as dummy variables was used to answer Research Question 4, which asked. "Do these attitudes vary according to gender and grade level?" Only the independence of the observations was assumed in this case. For each question, responses were aggregated to get a binary response, for example, the responses "Very sure" and "Somewhat sure" were grouped together as a "Sure" response. The combining of responses was consistent with the way in which the data was interpreted. Using the SPLUS statistical software, ANOVA tables were generated for each question, which reported the significance of each factor. 


\section{Description of the Survey Analysis}

Question 1 of the survey asked the students, "How sure are you that you will have a promising or bright future?" Table 4.9 shows how each grade level responded to this question.

Table 4.9

Student responses recorded as a percentage to the survey question 1

\begin{tabular}{cccc}
\hline N & Grade level & Sure & Not sure \\
\hline 73 & 6 & 80.8 & 18.2 \\
77 & 8 & 81.8 & 17.2 \\
75 & 10 & 88.0 & 12.0 \\
69 & 12 & 71.0 & 29.0 \\
\hline
\end{tabular}

The combining of the "Very sure" and "Somewhat sure" responses as a "Sure" response and the "Not that sure" and "Not sure not all" as a "Not Sure" response showed that Gender, Grade and the interaction of Gender and Grade were not statistically significant in explaining the responses to this question. In other words, the probability of being "Sure" did not depend on these factors. Although not statistically significant it is of interest to note that 29 percent of the Grade 12 students reported that they were unsure about a promising future, as compared to 18.2 percent of Grade 6 students, 17.2 percent of Grade 8 students, and 12 percent of Grade 10 students.

When queried to expand upon their ratings typical responses from the Grade 6 or 8 students included getting good grades as being important to a bright future. Confidence and determination emerged as recurring themes with the Grade 10 students. The following statements by two of the Grade 10 students seem to summarize the sentiments of many of their classmates, "I am very confident in myself and the goals that I have set 
for myself," and "I have good grades, I know what I want, and I like to succeed". These sentiments were shared by many of the Grade 12 students. One student wrote, for example, "I know I can do anything that I put my mind to. Success is in the eye of the beholder and I have very big eyes".

Table 4.10 summarizes the aggregated responses to Question 2: "How much control do you think you will have over your life after you graduate from school?" Table 4.10

Student responses recorded as a percentage to the survey question 2

\begin{tabular}{cccc}
\hline N & Grade level & Control & $\begin{array}{c}\text { Minima/ No } \\
\text { Control }\end{array}$ \\
\hline & & & \\
73 & 6 & 97.3 & 2.7 \\
76 & 8 & 96.0 & 3.9 \\
75 & 10 & 93.3 & 6.7 \\
69 & 12 & 100.0 & 0 \\
\hline
\end{tabular}

These results indicate an overwhelming majority of students at all four grade levels appear to believe they will have at least some control over their lives, although there were no statistical differences between the Grade and Gender of the respondents. Once again the probability of being in control was not contingent on these factors. According to the data, 100 percent of the Grade 12 students reported they would have control over their lives, which is interesting given 29 percent of them reported being relatively pessimistic about the future in Question 1.

When asked to expand on their ratings, more than 68 percent of the Grade 6 and 8 students identified control with going to university and college or getting a good job. This common view is summarized by the words of one of the Grade 8 boys who wrote, "Good grades lead to good jobs, good jobs lead to good choices, and good choices lead to 
ultimate control." Four Grade 10 students made reference to their growing independence, which was coupled with growing responsibility and effective decision making by several of the Grade 12 students. A response typical of these Grade 12 students might be, "I know what I want and that I am going to get it, and that I have to prepare for the unexpected, but I will be in control".

Survey question number 3 asked the students, "How well off financially do you expect to be as an adult compared to your family now?" It can be seen from Table 4.11 that the majority of students from all four grade levels seemed confident that in the future they would be better off or about the same financially as their parents. In this case, the two responses, "Better off" and "About the same" were combined into a single response, "Well off," and compared with column C, "Worse off." The "Don't know" response was not included in the combining of the responses in this case, but left in the table for informational purposes. Once again, neither Grade nor Gender was found to be statistically significant to this question, that is, the probability of being well off did not depend on these factors.

\section{Table 4.11}

Level of response recorded as percentages to the survey question 3

\begin{tabular}{ccccc}
\hline N & Grade level & Well off & Worse off & Don't know \\
\hline & & & & \\
71 & 6 & 78.9 & 7.0 & 14.1 \\
77 & 8 & 88.3 & 2.6 & 9.1 \\
75 & 10 & 84.0 & 2.67 & 13.33 \\
67 & 12 & 78.1 & 6.0 & 17.9 \\
\hline
\end{tabular}

This question elicited a variety of responses from the students. A typical response from many of the students in the junior grades, including students in Grade 10, credited 
finding a good job as a primary reason for their optimism. Several students at each grade level made reference to what they saw as their parents' mistakes, which they did not wish to repeat. One of the Grade 12 girls summarized it this way, "My family is very poor and to be better off would not be that hard; actually I'm already better off than my parents". A Grade 8 boy added somewhat emphatically, "I refuse to be like my parents." Not all students, however, were concerned about being well off. The following response by one of the Grade 6 girls is typical of these responses. She wrote, "I don't expect to make very much [money], I just want to enjoy my life."

Question 4 shifted the focus of the study directly to the school experience and asked the students, "How well does school prepare you for life after graduation?" Table 4.12 shows the combined responses, "Very well" and "Quite a bit" as a "Well" response, which was then compared to the combined "Not well" responses, "Not very much" and "Not at all."

Table 4.12

Student responses recorded as percentages to the survey question 4

\begin{tabular}{cccc}
\hline $\mathrm{N}$ & Grade level & Well & Not Well \\
\hline 74 & 6 & 85.1 & 14.9 \\
76 & 8 & 70.8 & 29.2 \\
76 & 10 & 55.2 & 44.8 \\
69 & 12 & 37.6 & 62.4 \\
\hline
\end{tabular}

Table 4.13 shows that Grade was a significant factor in this case, that is, the probability of getting a "Well" response was dependent on Grade $(p=.00)$. Gender $(\mathrm{p}=.37)$ and the interaction of Gender and Grade $(\mathrm{p}=.42)$ were not found to be significant factors in this case, therefore, Gender was not reported in Table 4.12. 
Table 4.13

ANOVA table for survey question 4

\begin{tabular}{lccc}
\hline & Df & Df Residual & Pr(Chi) \\
\hline Null & & & \\
Gender & 1 & 6 & 0.37 \\
Grade & 3 & 3 & 0.00 \\
Grade:Gender & 3 & 0 & 0.42 \\
& & & \\
\hline
\end{tabular}

The student responses to the open-ended question associated with this question generated a variety of responses. The most common response from the middle school students suggested the school experience was adequately preparing them for university or college and the job market, a belief shared by almost a third of the Grade 10 students. Quite a different view is revealed in the words of a Grade 10 boy who observed, "Going to school is a sheltered existence and nobody really realizes what the real world is like." This comment effectively summarizes the most typical sentiment of the $62 \%$ of the Grade 12 students who reported that their school experience was not preparing them very well for the life after graduation.

The school experience was more narrowly defined as the importance of getting good grades (academic achievement) in survey questions 5,6, and 7. Question 5 asked, "How important do you think getting good grades is in terms of your future success after graduation?" The responses, "Very important" and "Somewhat important" were aggregated as "Important" and compared with the response column, "Not Important." Table 4.14 shows the probability of getting an "Important" response was dependent on Gender. 


\section{Table 4.14}

ANOVA table for survey question 5

Df Df Residual $\operatorname{Pr}(\mathrm{Chi})$

Null

Gender

7

Grade

16

Grade:Gender

$3 \quad 3$

0.002

30.24

$\begin{array}{lll}3 & 0 & 0.79\end{array}$

In this case, the SPLUS software determined Gender was statistically significant $(p=.002)$. Neither Grade $(p=.24)$ nor the interaction of Grade and Gender $(p=.79)$ were found to be statistically significant factors in this case.

Table 4.15 shows the aggregated responses according to Gender. It can be seen that 97.2 percent (137/141) of the girls, as compared to 87.8 percent (122/139) of the boys, reported that getting good grades was important. More than four times as many boys, than girls reported getting good grades was not that important to them. Given the current interest in boys and academic achievement in some educational circles, this is an interesting observation.

\section{Table 4.15}

Number of responses according to gender to the survey question 5

\begin{tabular}{cccccc}
\hline $\begin{array}{c}\text { Grade } \\
\text { level }\end{array}$ & $\mathrm{N}$ & Important & \multicolumn{2}{c}{$\begin{array}{c}\text { Not } \\
\text { important }\end{array}$} \\
\hline & & $\mathrm{M}$ & $\mathrm{F}$ & $\mathrm{M}$ & $\mathrm{F}$ \\
\hline & & & & & \\
6 & 67 & 35 & 30 & 2 & 0 \\
8 & 74 & 33 & 33 & 6 & 2 \\
10 & 73 & 26 & 42 & 4 & 1 \\
12 & 66 & 28 & 32 & 5 & 1 \\
Total & 280 & 122 & 137 & 17 & 4 \\
& & & & & \\
\hline
\end{tabular}


The vast majority of students, however, regardless of gender, reported getting good grades was important. Typically the students across all four grades reported getting good grades was important because they associated it with getting into college or university or finding a good job. This theme was summarized by the following comment from one of the Grade 12 girls, who wrote, "If you get good grades, you will be accepted in the better schools and have a better chance of being successful." The following statement, however, is typical of the students who did not think getting good grades was that important, "Getting good grades isn't everything."

Question 6 also queried the students about getting good grades, this time from the self-worth or self-esteem perspective. The students were asked, "How much does getting good grades contribute to how good you feel about yourself?" Both Gender $(p=.00)$ and Grade $(p=.01)$ were found to be significant factors in this study. Table 4.16 shows the probability of getting a positive response, that is, a "Some" response, was dependent on these factors $(p<.05)$.

Table 4.16

ANOVA table for survey question 6

Df Df Residual $\operatorname{Pr}(\mathrm{Chi})$

$\begin{array}{llll}\text { Null } & & 7 & \\ \text { Gender } & 1 & 6 & 0.00 \\ \text { Grade } & 3 & 3 & 0.01 \\ \text { Grade:Gender } & 3 & 0 & 0.54\end{array}$

Table 4.17 summarizes the responses to this question. It appears the relationship between getting good grades and how good a student feels about him- or herself was the strongest at the Grade 6 level, which is consistent with the findings in the first part of this 
Chapter. Almost 84 percent (58/69) of the Grade 6 students surveyed reported getting good grades made them generally feel good, as compared to 68.4 percent $(52 / 76)$ of the Grade 8 students and approximately 67.1 percent $(49 / 73,45 / 67)$ of both the Grade 10 and Grade 12 students.

Table 4.17

Number of responses according to gender to the survey question 6

\begin{tabular}{cccccc}
\hline $\begin{array}{c}\text { Grade } \\
\text { level }\end{array}$ & $\mathrm{N}$ & \multicolumn{2}{c}{ Some } & \multicolumn{2}{c}{ Not much } \\
\hline & & $\mathrm{M}$ & $\mathrm{F}$ & $\mathrm{M}$ & $\mathrm{F}$ \\
& & 28 & 30 & 10 & 1 \\
6 & 69 & 23 & 29 & 16 & 8 \\
8 & 76 & 23 & 16 & 8 \\
10 & 73 & 14 & 35 & 16 & 5 \\
12 & 67 & 17 & 28 & 17 & 5 \\
Total & 285 & 82 & 122 & 62 & 22 \\
\hline
\end{tabular}

The relationship between getting good grades and feeling good about one's self was also found to be stronger for the girls, than it was for the boys. Almost 85 percent (122/144) of the girls reported that getting good grades made them feel good about themselves, as compared to slightly less that 57 percent (82/144) of the boys.

"Feeling good" was generally defined from the perspective of the school experience, rather than the more global experience. For the majority of students in this sample, good grades felt good, often resulting in a sense of pride or accomplishment, feelings of prestige or being accepted (especially by parents or teachers), and the belief that they were smart or the effort was worth it. Bad grades, on the other hand, usually resulted in feelings of disappointment, sadness, shame, or even fear. Despite the ratings given to this question, the feelings of the majority of the students are probably summed 
up by the words of one Grade 6 student who wrote, "Good grades, good; bad grades, bad."

Like Questions 5 and 6, Question 7 also referred to the importance of getting good grades, this time, in terms of the total school experience. Question 7 asked the students, "As part of your total school experience how important are good grades to you?" Table 4.18 shows Gender $(p=.00)$ and Grade $(p=.00)$ were significant factors.

Table 4.18

ANOVA table for survey question 7

\begin{tabular}{lccc}
\hline & Df & Df Residual & $\operatorname{Pr}$ (Chi) \\
\hline Null & & 7 & \\
Gender & 1 & 6 & 0.00 \\
Grade & 3 & 3 & 0.00 \\
Grade:Gender & 3 & 0 & 0.10 \\
& & & \\
\hline
\end{tabular}

Table 4.19 shows the aggregated responses to the survey question according to gender and grade level.

Table 4.19

Number of responses according to gender and grade to the survey question 7

\begin{tabular}{cccccc}
\hline $\begin{array}{c}\text { Grade } \\
\text { level }\end{array}$ & N & Important & \multicolumn{2}{c}{$\begin{array}{c}\text { Not all that } \\
\text { important }\end{array}$} \\
\hline & & M & F & M & F \\
\hline & & & & & \\
6 & 73 & 35 & 35 & 3 & 0 \\
8 & 72 & 26 & 31 & 13 & 2 \\
10 & 69 & 26 & 37 & 2 & 4 \\
12 & 67 & 24 & 32 & 9 & 2 \\
Total & 281 & 121 & 135 & 27 & 8 \\
& & & & & \\
\hline
\end{tabular}


Over 94 percent (135/143) of the girls, reported getting good grades was a very important part of the total school experience. In comparison, only 81.7 percent $(121 / 148)$ of the boys reported that getting good grades was important to them. It should also be noted that 33.3 percent (13/39) of the Grade 8 boys and 27.3 percent $(9 / 33)$ of the Grade 12 boys reported that good grades are not important to them, as compared to 7.9 percent (3/38) of the Grade 6 boys and 7.1 percent $(2 / 28)$ of the Grade 10 boys.

It is difficult to speculate why the students in this sample might have reported getting good grades was an important part of the school experience. For some it seemed to be a sense of acceptance or reality, and while a few seemed somewhat cynical about it, most conceded that good grades were probably necessary for entry into college or university. For others, they repeated their earlier response that good grades made them feel good. One student responded by asking the rhetorical question: "Isn't that why we are here?" At least one student seemed to experience some difficulty answering this question and wrote, "I don't know, this is the first time that I have actually thought about it." At least a couple of students from each grade level offered there was more to life than getting good grades and reported an appreciation for the social aspects of their school experience. Friendships and having fun were often typical responses from the students who were less convinced about the primary importance of good grades. As one Grade 8 boy put it, "I think getting good grades is important, but there a few things that come first." Another Grade 8 girl added, "Of course it is my main focus at school, but friends are incredibly important too." Jobs and post-secondary entry were also common themes for many of the students reporting that good grades were important. So were parental and 
teacher approval. One of the grade 6 students commented, "I like people to see my report cards and say, Wow... what a smart kid!"

Questions 8,9 and 10 shifted the focus from grades and academic achievement to the importance of participating in school activities. Question 8, for example, asked the students: "How important is participating in school activities, such as sports, service, or the arts, to your future success after graduation?" Table 4.20 summarizes the combined responses of the students to this question according to grade.

\section{Table 4.20}

Student responses according to grade for survey question 8

\begin{tabular}{cccc}
\hline Grade level & N & Important & Not that important \\
\hline 6 & 66 & 56 & 10 \\
8 & 69 & 61 & 8 \\
10 & 66 & 52 & 14 \\
12 & 64 & 44 & 20 \\
\hline
\end{tabular}

The logistical regression analysis of the aggregated "Important" response and "Not that Important" response revealed that none of the factors were significant in this case. In other words, the probability of getting an "Important" response was not dependent on Gender, Grade or their interaction. Although not statistically significant the most noticeable difference in these ratings is the relatively large percentage (31\%) of Grade 12 students who reported that participation in school activities was not that important to their future success.

Of the 20 Grade 12 students who responded that participating was not that important, the most typical responses included feelings of stress or exhaustion, lack of interest, or lack of time to devote to these activities. Three students simply reported they 
preferred to be alone. The general responses of the students who reported that participation in school activities was very important to them were quite different and included following their passions, having fun, and adding meaning to their educational experience. Of the 52 Grade 10 students who saw participation in school activities as enriching, many echoed these themes. One student summed up these sentiments when he suggested, "Participation in these activities is the reason I stay in school." Other typical responses included the need to develop skills, the love of an activity, having fun and being with friends. For the Grade 10 students who reported that participation was not important, the common responses included a preference for solitary activities, a perceived lack of relevance in school activities, and negative attitudes about school in general. A connection between school activities and the job market seemed to be important to a number of Grade 8 students and resulted in both positive and negative responses. Recurring themes for Grade 6 students included the desire to be involved and learning to do things well. So was having something to do. As one Grade 6 student wrote, "It is fun." Another student added, "I don't like to go home." Still another Grade 6 contributed, "It keeps you busy, so that you don't screw your brain [playing] video games."

Question 9 asked the students: "How much does participating in these school activities contribute to how good you feel about yourself?" The responses, "Very much" and "Quite a bit" were combined as the positive response. The probability of getting this positive response was not dependent on Gender, Grade, or their interaction.

Table 4.21 shows the number of responses to the combined variables according to gender and grade level. Although not statistically significant, a review of Table 4.21 implies an apparent decline in the perceived importance of participating in school 
activities for the boys in this sample between Grade 6 and Grade 12. The percentage of boys reporting that participation was important to them dropped from 81percent (30/37) in Grade 6, to a little over 44 percent (15/34) in Grade 12. The percentages for the girls, on the other hand, remain relatively constant across the four grade levels, ranging from a low of 59.5 percent (25/42) in Grade 10 to 69.7 percent (23/33) in Grade 12.

\section{Table 4.21}

Number of responses according to gender to the survey question 9

\begin{tabular}{cccccc}
\hline $\begin{array}{c}\text { Grade } \\
\text { level }\end{array}$ & N & Some & \multicolumn{2}{c}{ Not much } \\
& & M & F & M & F \\
\hline & & & & & \\
6 & 69 & 30 & 21 & 7 & 11 \\
8 & 75 & 24 & 24 & 15 & 12 \\
10 & 72 & 15 & 25 & 15 & 17 \\
12 & 67 & 15 & 23 & 19 & 10 \\
Total & 283 & 84 & 93 & 56 & 50 \\
& & & & & \\
\hline
\end{tabular}

Common responses from the 38 Grade 12 students, who reported that participation in school activities made them feel good about themselves, included the joy associated with being part of something, the ability to make a contribution to the school in some way, or doing something they loved doing. Four students reported that it motivated them to do other things better. A sense of pride or accomplishment was also a common response. Perhaps these sentiments are best summarized by one of the Grade 12 girls who wrote, "I found myself enjoying myself and life so much when I was involved in sports. I was contributing to school spirit and it allowed me to be a leader! I was with my friends, doing things I loved to do." Contrast this view with a student who found no personal attachment to being involved, "I only want to do things that will benefit me." 
For the students that enjoyed participating in activities it seemed to be a very positive experience, for example, one Grade 10 dancer wrote, "When I dance, I feel on top of the world. It is so much fun!" For other students, however, this was not always the case. A Grade 10 student, who felt they were not very good at sports, reported. "It's hard for me to fit in."

Question 10 asked the students, "How much does participating in these school activities contribute to how valuable you think your school experience is to you?" The factors, Gender, Grade, and the Gender:Grade interaction, were not statistically significant in this study. In other words, the probability of getting a "Valuable" response did not depend on these factors. The aggregated responses to this question are summarized in Table 4.22.

\section{Table 4.22}

Student responses recorded as percentages to the survey question 10

\begin{tabular}{ccc}
\hline Grade level & Valuable & Not valuable \\
\hline 6 & 76.0 & 24.0 \\
8 & 60.6 & 39.4 \\
10 & 62.3 & 37.7 \\
12 & 63.2 & 36.8 \\
\hline
\end{tabular}

A review of the responses to the open-ended question offered little new information. The responses of the students that valued the experience reported the joy of being part of the something they enjoyed and the sense of pride and accomplishment that was associated with the experience. One Grade 8 girl suggested, "It makes me feel better about school". Another Grade 8 student seemed to interpret participation as classroom involvement, and responded, "It makes me understand the subject better". Several 
students, especially in the younger grades, responded that it gave them something to do. Health, fitmess, and team involvement were common themes related to participation in sports. Contribution was a typical response for several of the secondary students. Other responses included relief from stress and boredom.

The final question of the eleven survey questions asked the students, "What makes you feel better about yourself, getting good grades or participating in school activities?" Two different analyses were done for Question 11 . The first analysis compared "Good grades" and "School activities" and addressed the question, "Do these students feel better about themselves because of good grades or school activities?" Table 4.23 shows that Gender was found to be significant factor in this case $(p=.01)$. Grade and the interaction of Gender $(p=.82)$ and Grade $(p=.59)$ were not significant factors.

\section{Table 4.23}

ANOVA table for survey question 11A

Df Df Residual $\operatorname{Pr}($ Chi)

$\begin{array}{llll}\text { Null } & & 7 & \\ \text { Gender } & 1 & 6 & 0.01 \\ \text { Grade } & 3 & 3 & 0.82 \\ \text { Grade:Gender } & 3 & 0 & 0.59\end{array}$

Table 4.24 summarizes the student responses according to gender. It can be seen from the table that good grades are more important to the girls than they are to the boys. Over 72 percent $(55 / 76)$ of the girls reported good grades were being more important that participation in school activities to how good they felt about themselves. The boys, on the other hand, were relatively evenly split on the issue, with approximately 51 percent (40/78) selecting good grades over school activities. 


\section{Table 4.24}

Number of responses according to gender to the survey question $11 \mathrm{~A}$

\begin{tabular}{cccccc}
\hline $\begin{array}{c}\text { Grade } \\
\text { level }\end{array}$ & $\mathrm{N}$ & \multicolumn{2}{c}{$\begin{array}{c}\text { Good } \\
\text { grades }\end{array}$} & \multicolumn{3}{c}{$\begin{array}{c}\text { School } \\
\text { activities }\end{array}$} \\
\hline & & $\mathrm{M}$ & $\mathrm{F}$ & $\mathrm{M}$ & $\mathrm{F}$ \\
\hline & & & & & \\
6 & 36 & 11 & 13 & 9 & 3 \\
8 & 42 & 9 & 16 & 11 & 6 \\
10 & 43 & 8 & 20 & 8 & 7 \\
12 & 33 & 12 & 6 & 10 & 5 \\
Total & 154 & 40 & 55 & 38 & 21 \\
& & & & & \\
\hline
\end{tabular}

For the students who chose good grades, a common response, regardless of grade level, was the belief that good grades were necessary for entry into university or college, the goal most of them associated with going to school. Other responses included good grades made them feel good as summarized by one student who offered, "Good grades make me feel smart." Other typical responses included the connection between good grades and a brighter future, being accepted or appreciated, especially by parents, career opportunities and a sense of accomplishment

For those students who choose school activities over good grades, typical responses across the grades included feeling good and having fun. Perhaps these sentiments are better summarized by the comments of two of the 33 students sampled in Grade 12. The first student wrote, "Getting good grades makes me feel good about myself for a short while. School activities make me feel good about myself and my peers for a very long time." The other Grade 12 student added, "Grades are what you see, school activities are what everyone else sees." Other typical observations included the thought that school activities, rather than grades, seemed to allow some students to 
experience success at school and provided a choice of whether or not the students wished to participate.

The second analysis compared the sum of "Good grades," "School activities," and "Both about the same" with "Neither one." None of the factors were significant in this case. Although not statistically significant, it is of interest to note that Table 4.26 shows almost 14.5 percent (10/69) of the Grade 12 students appear to find minimal value in the school experience, at least from the perspective of getting good grades or participating in school activities. This compares with approximately 4.4 percent of the Grade 6 students, 5.3 percent of the Grade 8 students, and 5.6 percent of the Grade 10 students. Table 4.25 also implies, however, that the vast majority of the students from the four grade levels appear to find some value in either getting good grades or participating in school activities.

Table 4.25

Number of responses according to grade to question $11 \mathrm{~B}$

\begin{tabular}{cccc}
\hline Grade level & N & Positive Response & Negative Response \\
\hline & & & \\
6 & 67 & 64 & 3 \\
8 & 75 & 71 & 4 \\
10 & 71 & 67 & 4 \\
12 & 69 & 59 & 10 \\
Total & 282 & 261 & 21 \\
\hline
\end{tabular}

The last part of the survey asked three reflective questions. The first question asked the students: "What are the things or circumstances that you have experienced in school so far that make you feel good about yourself?" Of the 58 students in Grade 6 who responded to this question typical responses included getting good grades (30), socializing and being with friends (12), fun electives (10), and participating in sports 
(10). The common Grade 8 responses tended to be much the same. In this case, 62 students responded with 23 students reporting good grades. Other recurring responses included friends (19), sports (22), and the performing arts (10). Of the 60 Grade 10 students who responded to this question, having friends (30), good grades (27), good courses (15), sports (13), fun teachers (10), and lots of things to do (14) were the most common responses. Although the 63 Grade 12 students who responded to this question offered a wide range of possibilities, their most typical responses were friendships (39), perhaps best summarized by the student who described his school experience as "being part of a close family school." Other common Grade 12 responses included seeing the school as a place where they had lots of opportunities to get involved or just be themselves (27), getting good grades (21), sports (16), great elective programs (16), and supportive teachers (7).

Question Two asked the students: "What are the things that you have experienced in school that give you confidence in your future after you graduate?" Only half the Grade 6 students (35) responded to this question. The most typical responses from these students included grades (25), followed by a distant sports (5) and friends (4). The typical Grade 8 responses were much the same with good grades (21) being the most popular response, followed by sports (9). Many of the 45 Grade 10 students agreed, but some added the skills they had developed (13) and the support they have received (9). The most common themes for the Grade 10 students included grades (20) and the variety of elective programs (19) the school had to offer, especially in the area of computer technology, the performing arts, and the Leadership and Peer Tutoring programs. Only a small number of the 60 Grade 12 students reported good grades (9) as something that 
gave them confidence in their future. Their responses were quite diverse, but typical responses included the development of a broad range of skills (18), applied programs like the work experience program and the "hands-on" elective courses (14), a supportive learning environment (10), caring teachers (8), and of course, close relationships and friends (12).

The final question in the survey asked the students: What are the best things about school and what are the worst things? Included on the list of best things for the 58 Grade 6 students were sports (21), favorite classes (19), friends (19), activity days (4), and favorite teachers (4). The most common worst things for these students included boring classes (19), doing too much work (15), cranky teachers (5), bullies (5), and the Lunch Club, better known as the detention hall (4). The Grade 8 students listed friends (20), sports (15), and learning opportunities (10) as their best things, while the worst things were much the same as the Grade 6 responses. For the 65 Grade 10 students, typical best things responses included being with friends (30), the variety of classes and activities that were available to them (9), having good teachers (8), and being in a positive environment (6). On the negative side, uninspiring or uncaring teachers (16), too much homework (9), boring classes (5), and cliques (4) were the most frequent responses. The 64 Grade 12 students who responded to this questions provided the widest range of responses, but like the Grade 10 students, most reported being with friends (37) as one of the best things about school. Other typical responses included socializing (20), the diversity of programs and learning opportunities (13), some great teachers (9), and interesting courses (9). Uncaring teachers (14), the heavy workload (9), and uninspiring teachers (8) were generally seen as the worst things about school. 


\section{Summary of Survey Analysis}

A review of the ratings and written responses to the Student Survey revealed a wide range of views and perceptions, which often varied according to grade and gender. As a group, the Grade 6 students appeared to be very optimistic about the future, regarded getting good grades as very important, and were generally positive about their school experience. Many of the Grade 12 students, on the other hand, seemed to be less optimistic about the future, were not as sure about the importance of good grades, and sometimes tended to be quite cynical about their school experience. Although these data are only exploratory, the general themes are often consistent with some of the findings in the first part of the study, more specifically that relationship between academic achievement and student self-esteem seemed to be the strongest at the Grade 6 level and GPA appears to be of decreasing importance to self-esteem as the students get older. In the first analysis the relationship between the level of involvement and self-esteem was reported as being the strongest when students were heavily involved in school activities, yet many of the students reported in this survey that they did not value participation in these activities. The students who do not value involvement may not participate, but these same students may have lower self-esteem than those students who do participate. It is important to remember that the number of students who participate is unrelated to the effect of participation on student self-esteem and just because these students may not value participation in activities does not mean that their level of self-esteem is independent of their level of involvement. Further study is recommended. One has to wonder what the implications are for the educated citizen. The implications will be discussed in Chapter V. 


\section{Summary of Analysis of Data}

A review of the statistical analysis in the first part of this study shows a relationship exists between grade point average, the level of student involvement in school-related or extra-curricular activities, grade level, and the interaction of GPA and grade level, and the four types of self-esteem reported in this study: Total Self, SchoolAcademic, General Self and Social Self-Peers. All the predictor variables, with the exception of gender, were significantly related to the four measures of self-esteem. It appears, however, that the relationship between GPA and self-esteem was the strongest at the Grade 6 level and that GPA was of less importance to the self-esteem of the students in the other grades. Multiple comparison analysis found significant differences in the means of the interactions of GPA and Grade between Grade 6 and Grades 10 and 12 for all cases of self-esteem, except School-Academic self-esteem. A review of the parameter estimates shows that a change in GPAnew, or GPA, results in the greatest difference in the self-esteem scores at the Grade 6 level (the slope was the steepest in Grade 6). The relationship between the level of involvement and self-esteem was the strongest at Level 3, which indicates being actively involved in school-related or extra-curricular activities appears to be associated with higher levels of self-esteem. Once again, the largest increase in self-esteem scores was associated with a heavy level of involvement in these activities. Although not found to be statistically significant, the positive gender coefficients in the cases of Total self-esteem, School-Academic self-esteem, and General Self self-esteem, suggest the boys had higher self-esteem, on average, than the girls in this sample. Only in the case of Social Self-Peers self-esteem did it appear the girls had higher self-esteem scores than the boys. Finally, the self-esteem scores for Grade 6 were 
higher, on average, than the scores for the other grades with the exception of the scores on the Social Self-Peers self-esteem measure. In this case, the scores, on average, were higher for the Grade 10 and 12 students than they were for the Grade 6 students.

The second part of this study was designed primarily to add some depth to the findings associated with the first analysis and to support any recommendations that might be made regarding this analysis. From the logistical analysis and the coding of descriptive data it seems the responses to the survey questions, especially those associated with getting good grades and participating in school activities, often vary according to grade and gender. It seems academic achievement is more important to Grade 6 students than it is to Grade 12 students. This finding supports the analysis of the first part of the study. While all the participating students tended to be optimistic about their future, many Grade 12 students did not appear to give much of the credit for this optimism to their school experience. While most of the Grade 6 students were very supportive about their school experience, many of the Grade 12 students seemed to be quite cynical about it. Getting good grades was found to be significantly more important to the girls, than it was for the boys. It seems the association between getting good grades and feeling good about one's self is the strongest at Grade 6, a finding that supports the first analysis. Chapter V will address these findings in more detail and offer recommendations for future study. 
CHAPTER V: SUMMARY, CONCLUSIONS, AND RECOMMENDATIONS

\author{
Introduction
}

The British Columbia Graduation Program Policy (1993) states that students... "should leave the public school system with the knowledge, skills and attitudes needed to become educated citizens" (p.1). An educated citizen is one who possesses both the intellectual and human and social skills needed to succeed in the $21^{\text {st }}$ century. The problem that needs to be addressed is how to develop these human and social dimensions within a school system that defines intellectual development as its primary purpose. Will a focus on academic achievement help students develop self-esteem and positive attitudes regarding change? This chapter will attempt to answer this question by reviewing the findings associated with the statistical and survey analysis in Chapter IV, which will be discussed within the context of the research questions. In addition, recommendations for further study will be presented based on the statistical and survey analysis. Finally, the limitations of this study will be discussed and acknowledged.

Findings and Discussion

Self-esteem scores were calculated for each of the four measures of self-esteem: Total self-esteem, Academic-School self-esteem, General Self self-esteem, and Social Self-Peers self-esteem. These scores were used as the dependent variables in Research Questions 1, 1a, 1b and 1c:

1. To what extent does academic achievement influence the Total self-esteem of students in grades 6,8,10 and 12 in a small, semi-rural school district in British Columbia? 
a. To what extent does academic achievement influence the AcademicSchool self-esteem of the students?

b. To what extent does academic achievement influence the General Self self-esteem of the students?

c. To what extent does academic achievement influence the Social Self-Peers self-esteem of the students?

Grade point averages were calculated using a 4-point scale for each student and reported as the measurement of academic achievement. Dummy variables were created for gender, grade level, and level of involvement to answer Research Question 2:

2. Do these relationships vary by gender, grade level and participation in nonacademic and extra-curricular activities in school?

As reported in Chapter IV, the model included all four of the independent variables and the interaction between GPA and Grade, GPA and Involvement, and GPA and Gender. When GPA was used, high correlations were noted when the interactions were added to the model. In other words, the effect of one factor is dependent on which other factors are in the model. This conditional type of statement is not useful, so GPA was centred to reduce the correlation among the variables. As a result, each effect could be looked at independently and the interactions between GPAnew and Involvement and GPAnew and Gender could be removed from the model without introducing any bias into the estimated coefficients. F-tests were used to test the significance of effects simultaneously, while parameter estimates were used to calculate the individual t-tests of significance. Multiple comparison analysis was conducted to investigate mean 
differences between the different levels of the factors deemed significant to the study. Significant findings will be shown in italics in the following sections.

\section{$\underline{\text { Statistical Analysis }}$}

Multiple regression procedures determined gender was not a significant factor in this study. Theory, however, dictates that factors deemed important to the study based on prior information should be retained in the model. The final model contained the terms GPAnew, Grade level, Involvement, Gender, and the interaction of GPAnew and Grade.

It is interesting that gender was not a significant factor in this study because this finding is not consistent with much of the literature. The research literature suggests girls often score significantly lower than boys on self-esteem measures, even though they tend to earn better grades (Segal, 1980; Levinson, 1996; Kolenik, 1993; Wu, 1990). It should be noted, however, that while not statistically significant, the positive coefficients reported for gender, in all cases except Social Self-Peers self-esteem, imply the selfesteem scores were higher for the boys than they were for the girls. As reported in Chapter One, context-bound measures, such as the Coopersmith Self-Esteem Inventory, contain statements that limit the respondents to a given context. According to Skaalvik (1986), these measures tend to mask gender differences. It would be difficult, however, for the Coopersmith Self-Esteem Inventory, which reports five different self-esteem scales, not to be context-bound. The use of this popular self-esteem measure may explain the apparent inconsistency associated with gender in this study. It is also important to recognize that the results of this study are functions of the particular sample of the population from which it was taken. Although differences were observed in this sample, 
there is no statistical evidence to show that a difference exists in the population. While the theory generally suggests boys tend to score higher on self-esteem measures than girls, it seems that in this sample no statistical difference is evident. This is interesting and may be worthy of further study.

The relatively low $R^{2}$ values in all cases showed that the factors studied were weak indicators of self-esteem and there was a great deal of unexplained variation associated with the data, especially in the case of General-Self self-esteem. In all the four cases of Self-Esteem, GPA, level of involvement, grade level, and the interaction between GPAnew and grade were found to be significant factors $(p<.05)$.

Although the relatively low $R^{2}$ values indicated that the predictor variables did not explain much of the variation in the four Self-Esteem scores, regression analysis revealed GPA, grade level, level of involvement in school-related and extra-curricular activities, and the interaction between GPAnew and grade level to be statistically significant $(p<.05)$. As previously reported, gender was found not to be significant in this study. The $R^{2}$ values ranged from .36 in the case of School-Academic self-esteem to .20 in the case of General-Self self-esteem. The $R^{2}$ values in the cases of Social Self-Esteem and Total Self-Esteem were .22 and .24 respectively.

The relationship between GPA and student self-esteem was the strongest for the Grade 6 students and self-esteem was highest for the students who were heavily involved in school activities.

Multiple comparison analysis showed the relationship between GPA and selfesteem to be the strongest at the Grade 6 level and self-esteem was found to be significantly higher for those students who were heavily involved (spending at least three 
hours per week) in school activities. In the case of Social Self-Esteem, self-esteem was also significantly higher for students reporting a moderate level of involvement (more than one hour, but less than three hours) engaged in school-related or extra-curricular activities. It might be concluded, then, at least in the context of this particular study, that the relationship between GPA and self-esteem was not as strong for students in the higher grades, as it was for students in Grade 6. If this is so, one might logically question whether the focus on intellectual development in schools is having the desired effect on human and social development, especially on the development of self-esteem. From the perspective of the educated citizen, who by definition possesses a positive self-image, it seems unlikely that this primary focus on academic achievement, as measured by GPA, contributes much to development of self-esteem in students.

Seligman (1995) was highly critical of the California Task Force to Promote Selfesteem and Personal and Social Responsibility because of its focus on the feeling good side of self-esteem. He wrote, "The reason the California report is so flabby on the feeling good side is because there is no effective technology for teaching feeling good which does not first teach doing well" (p.33). "What California (and presumably every other state [and province]) needs is not children who are encouraged to feel good, but children who are taught the skills of doing well" (p.35). One might reasonably conclude from Seligman's comments that teaching students to do something well should predict high levels of self-esteem, but according to the findings of this study the relationship between academic achievement and self-esteem appears to be weak at best. As reported in Chapter II, the Final Report of the California Task Force to Promote Self-esteem and Personal and Social Responsibility (1990) concludes, 
"Education and the school-experience greatly influence a child's psychology and social well-being, character, and productive potential as an adult" (p.64). Assuming a child's psychology, social well-being, character, and productive potential include having a healthy self-esteem, it might be concluded that there must be more to the school experience than academic achievement. The multiple comparison analysis showed a significant relationship between high levels of involvement in school activities and healthy self-esteem. This relationship did not appear to be grade specific. A review of the descriptive data, which were collected from the Student Surveys, revealed that students who reported being involved in school activities found these activities enjoyable. They liked the social experience, the challenge, the praise, and sense of accomplishment they felt when they did something well. In this case, they chose the activity in which they did well. Confidence and competence were consistent themes in these surveys, both of which are often associated with positive levels of self-esteem.

Low (2000) suggests in the process of learning, many young people simply go through the motions. They are compliers, rather than adaptive learners. Learning is passive, rather than active. The students are not actively engaged in the process. Learning often lacks relevance and meaning. Caine and Caine (1991) agree and state further, "The overwhelming need for learners is meaningfulness" (p.7). Glasser (1992) adds, "Although quality may be a hard concept to define, most of us recognize it when we see it, and most students do not see it in the work they are asked to do in their academic classes, [but] they easily see the quality inherent in most of their extracurricular activities" (p.89). As educators, we might find the study of the relationship between 
active involvement in school activities and student self-esteem useful, especially if we take what we learn and apply it to the learning process.

Logistical regression procedures were used to analyze the ratings given by the students to each survey question. Additional data were collected and grouped according to theme in a effort to answer Research Question 3, which asked, "What attitudes, if any, do the participants in this study have with regard to their school experience, more specifically towards getting good grades, participating in school activities, and preparing for the future." Research Question 4 asked further, "Do these attitudes vary according to gender and grade level?" The primary purposes for collecting these data were to add depth to the findings of the study and to generate recommendations for further study. A brief summary of the findings associated with the survey questions is reported in the next section of this chapter.

Survey Analysis

Over $80 \%$ of the students are relatively optimistic about their future, reporting that they were either "very sure" or "somewhat sure" of a bright future.

Generally the students were optimistic about their future, although the collective percentage was more conservative than the $91 \%$ reported in the 1994 National Youth Survey reported in Chapter II.

The vast majority of students, especially Grade 12 students, believe they will have control over their lives after they graduate from school.

When asked how much control they thought they would have over their lives after they graduated from school, all Grade 12 students reported they would have either “a great deal" or "some control" over their lives. Believing something is important often 
makes the task more meaningful and relevant. As reported earlier in this study, people often do what they believe they can do and what is worth doing, both functions of healthy self-esteem.

Over $81 \%$ of the students anticipate, after they become adults, being at least as well off, if not better off, financially than their parents.

The collective response that students anticipated being "better off" or "about the same" financially as their parents was considerably lower than the response reported in the 1994 National Youth Survey. In this study, only $81.8 \%$ of students, as compared to $99 \%$ of the respondents in the 1994 National Youth Survey study, offered this optimistic prediction.

As the grade levels increase, the students' belief that school is adequately preparing them for their life after graduation seems to decrease.

The Student Survey shifted the focus to the school experience when the students were asked how well they thought school prepared them for life after graduation. Grade level was determined to be significant to this question. The student responses revealed quite different views at each grade level regarding the value of the school experience. As reported in Chapter IV, the combined positive responses seemed to show a decline at each grade level. Over 85 percent of Grade 6 students reported that school was adequately preparing them for the future, as compared to 70.8 percent of Grade 8 students, 56.2 percent of Grade 10 students, and 37.6 percent of Grade 12 students. According to Year 2000: A Framework for Learning (1999), "The purpose of education in British Columbia is to enable learners to develop their individual potential and to acquire the knowledge, skills, and attitudes needed to contribute to a healthy 
society and a prosperous and sustainable economy" (p.3). When almost a third of Grade 12 students report that they do not think the schools are adequately preparing them for the future one might conclude that the schools are doing a poor job of helping these students develop the knowledge, skills, and attitudes, which collectively define the educated citizen. On the other hand, most of Grade 6 students seemed to be very positive about the school experience. It appears this trust in the school experience begins to erode with grade level, ultimately resulting in a high level of cynicism at Grade 12 . The apparent lack of cynicism at the Grade 6 level possibly explains why the relationship between GPA and self-esteem appears to be the strongest at that grade level.

Most students, especially the girls, think getting good grades is important to future success in life.

The school experience was narrowed down to getting good grades and students were asked how important they thought getting good grades was in terms of their future success. Given the results of the previous question, one might reasonably expect that the value of good grades would decline with grade level, but statistical analysis determined grade level was not significant in this question. Gender was the significant factor. A review of the responses showed getting good grades was more important to the girls than it was to the boys, which is consistent with the literature that suggests girls are more successful academically than boys. If this is true, and the primary focus in schools is on intellectual development, then one has to wonder what the implications are for boys.

Good grades are more important to the self-esteem of girls, than they are to the selfesteem of boys. 
One of the questions in the Student Survey was designed to specifically link academic achievement with self-esteem. Students were asked how much getting good grades contributed to how good they felt about themselves. In this case, both grade and gender were found to be significant factors. A review of the student responses to this question showed more girls than boys reported that good grades contributed either " $\mathrm{a}$ great deal" or "quite a bit" to their self-esteem. It appears the self-esteem needs of the boys, especially in terms of the school experience, might be different from those of the girls. According to the data, the relationship between getting good grades and how good the students feel about themselves was the strongest at Grade 6. In this case, $83 \%$ of Grade 6 students indicated that getting good grades contributed either "a great deal" or "quite a bit" to how good they felt about themselves, as compared to $67.1 \%$ for the secondary students. These findings are consistent with earlier findings, which reported the relationship between self-esteem and GPA was the strongest at Grade 6. Once again, one has to wonder what the implications are for a school system that defines intellectual development as its primary goal.

More girls than boys think grades are important to the total school experience.

The students were asked how important they thought grades were in terms of the total school experience. Statistical analysis determined gender was significant in this question. A review of the responses showed getting good grades was more important to girls than it was to boys. Once again, these findings support the literature that suggests boys are less inclined to value academic success. Clearly more research is warranted in this area, especially in light of the focus on academic achievement in education. 
Participation in school activities appears to be less important to Grade 12 students than it is to students in the other grades.

The focus of the Student Survey now shifted from academic achievement to participation in school activities. The students were first asked how important participating in school activities was to their future success. Grade level was found to be a significant factor in this case. As reported in Chapter IV, participation in school activities was not that important for a relatively large number of Grade 12 students. A review of the survey data found that almost 22 percent of these students had rated themselves as "no involvement" during the collection of the data. This compares to 12.5 percent of the Grade 6 students, 7.6 percent of the Grade 8 students, and 15.8 percent of the Grade 10 students.

Participation in school activities appears to be more important to student self-esteem for middle school students than it is for secondary students.

Participation in school activities was connected with self-esteem in one of the survey questions. Students were asked how much participating in school activities contributed to how good they felt about themselves. Although Grade, Gender, and their interaction were not significant to this question, given the responses to the preceding question, it was perhaps not too surprising to find that over 43 percent of Grade 12 students reported that participating in school activities had very little to do with how good they felt about themselves. This compared to 26 percent of Grade 6 students. The apparent decline in the importance of participating in school-related activities between Grade 6 and Grade 12 might be troubling to many educators, especially given the earlier findings that a high level of involvement is related to higher self-esteem scores. 
Good grades are more important to the self-esteem of girls than school activities.

School activities, on the other hand, are more important to the self-esteem of boys than are good grades.

The students were asked what made them feel better about themselves, good grades or school activities. Other possible responses included "both about the same" or "neither one." In the first case, only the responses "good grades" and "school activities" were compared. In this case, gender was significant. Good grades were found to be more important to the self-esteem of the girls than they were to the boys. School activities, however, were more important to the self-esteem of the boys than they were to the girls. These findings are of interest for a number of reasons. First of all, they support the findings of the B.C Teachers Association (2001) that reports girls as being more academically successful than boys. As pointed out earlier in this chapter, people tend to do better at the things that are important to them. The findings also suggest that the selfesteem of the girls is specifically associated with academic achievement, which is not supported by the earlier findings, which found gender was not a significant factor in this study. Thirdly, the findings suggest there might be value in engaging young people, especially boys, in school activities. This is consistent with the earlier findings that heavy involvement in school-related or extracurricular activities was associated with selfesteem. Given the growing concern over the self-esteem of boys in schools, these findings might be important considerations.

Good grades and/or participating in school activities may be associated with student self-esteem, but less so for Grade 12 students. 
In the second case, "good grades", "school activities", and "both about the same" were combined together as a positive response and compared with "neither one" as a negative response. Finding value in grades and/or school activities was associated with the students feeling good about themselves or student self-esteem. Although none of the factors studied were found to be significant, it is important to note that almost 15 percent of the Grade 12 students reported a negative response to this question, which is almost triple the figure for the other grades.

Although no statistical significance is implied, the student responses to the reflective question, "What are the things or circumstances that you have experienced so far that make you feel good about yourself?" reveal getting good grades is the most common response ( 52 percent) for the Grade 6 students. This compares with 37 percent for the Grade 8 students, 45 percent for the Grade 10 students, and 33 percent for the Grade 12 students. The most common response for the Grade 12 students (62 percent) was friendship and other social aspects of their school experience. This compares with 50 percent at Grade 10,31 percent at Grade 8, and 21 percent at Grade 6. These figures imply a shift in the relationship between feeling good (self-esteem) and good grades from Grade 6 to Grade 12, when the social experience seems to be a more important factor. Further study of the relative importance of this social dimension might be worthwhile.

The second reflective question asked the students, "What are the things that you have experienced in school that give you confidence in your future (optimism) after you graduate?" While only half the Grade 6 students responded, over 71 percent of them reported getting good grades was most important to the Grade 6 students. Only 15 percent of the 60 Grade 12 students who responded to this question seemed to share this 
view. Skill development ( 30 percent), practical experience ( 23 percent), close relationships ( 20 percent), and a supportive learning environment (17 percent) were more important to these students.

The final reflective question asked the students, "What are the best things and worst things about school?" The top three best things for the 58 Grade 6 students who responded to this question were sports ( 36 percent), favorite classes ( 33 percent), and friends ( 33 percent). For the 64 Grade 8 students, friends ( 31 percent), sports ( 23 percent), and learning opportunities (16 percent) topped their list. The 65 Grade 10 students ranked friends ( 46 percent) first, followed by a distant variety of classes and opportunities (14 percent) and having good teachers (12 percent). Friends (58 percent), socializing ( 31 percent), and the diversity of learning opportunities ( 20 percent) rounded out the list of the 64 Grade 12 students who responded to this question. It is clear that the social aspects of school are important to most students, especially the Grade 12 students. All four grades reported boring classes, workload, and uncaring teachers as their top three worst things about school choices. Bullying and cliques were also of concern to the junior students. Good grades was only reported by one Grade 6 student, five Grade 8 students, three Grade 10 students, and three Grade 12 students as being one of the best things about school. This is interesting given the responses to the two previous questions.

It seems that fostering a caring and supportive learning environment, one that recognizes the human and social needs, as well as the academic and intellectual needs, of the students appears to be important to the development of self-esteem in students. With the exception of gender, the survey analysis generally supports the findings of this study. GPA and level of involvement are both related to student self-esteem. The relationship 
between GPA and self-esteem is the strongest in Grade 6, while self-esteem seems to be significantly higher for those students who are heavily involved in school-related or extra-curricular activities.

\section{Implications for Future Research}

The educated citizen has been defined as the purpose of education in this study, but the development of the educated citizen goes well beyond academic achievement or intellectual development. Equally important is human and social development, which includes the development of a good self-image and healthy self-esteem. The students reported that the social side of schooling was very important to them and it was shown that active participation in school-related or extra-curricular activities was associated with higher levels of self-esteem. Although some may disagree, most educators and students now recognize schools are more than institutions of academic learning. They are also very complex social institutions. An editorial in the Association for Supervision and Curriculum Development: Curriculum Update (1999) observed, "The human relationships among students and educators play as crucial a role in school life as curriculum or instruction and may have as powerful an effect on learning [and] the school's role in fostering positive social behavior is its most important role" (p.1). When the students were asked what they liked best about school a typical answer was they liked the social aspects of the experience, the friendships, and caring and inspiring teachers. Two of the most basic human psychological needs are feeling secure and having a sense of belonging. Creating a social environment that is safe and supportive should be the first priority of every school. A primary focus on intellectual development would seem somewhat naïve if the learning environment is perceived as 
hostile or uncaring. Educators need to focus on the human and social development needs, not only of their students, but also of the entire school culture. Simply implementing what Seligman (1995) labels a "feeling good" program would be short-sighted.

This study has clearly demonstrated that doing things or being involved in things, in this case, active participation in school activities, was associated with higher levels of self-esteem. As reported by Finn (1989), "Participation [in extracurricular activities] is correlated with a range of desirable outcomes including higher levels of self-esteem and feelings of control over one's life, higher educational aspirations, higher academic ability and grades among males, lower delinquency rates, and greater involvement in political and social activity as young adults" (p.128). Not only should educators create safe and caring school environments, they should also develop and promote opportunities for more students to become involved in school activities. For many teachers this will be a very contentious issue. Many academic teachers, for example, already complain that their students are too involved in things outside the classroom that takes time away from learning. Professional development programs need to be developed to heip these teachers understand the importance of developing the whole child. Finn (1989) agrees, but reminds us, "There is little research to help us design interventions to increase participation" (p.133).

\section{Recommendations for Future Study}

The $R^{2}$ values were low in all cases, which indicated the factors studied were poor indicators of self-esteem and that there was a great deal of unexplained variation associated with the data. Further research needs to be conducted using additional predicator variables, which are associated with the school experience, such as measures 
of belonging or course relevance. GPA was the only measure of academic achievement in this study. Given the current interest in other measurements of learning, such as multiple intelligence, learning styles, or emotional intelligence, it is recommended other measures of academic achievement be considered for inclusion in the new model. It is important to remember that many other non-school related factors are important determinants of the self-esteem of boys and girls. For example, family dynamics, body image, perceptions of personal popularity, athletic or artistic ability, involvement in hobbies, support networks, and numerous other factors are likely to influence the $R^{2}$ values associated with selfesteem. In addition, both the review of the literature and the Student Survey show gender as a significant factor, thus additional measures of self-esteem might be investigated for further study.

The reported high levels of optimism and the apparent cynicism of the senior students towards their school experience are intriguing. While it is generally conceded that the teenage years are turbulent and confusing times for many young people, it is interesting and worthy of further investigation that the relationship between GPA and self-esteem was found to be the strongest in Grade 6. It is recommended that additional research be conducted into the apparent decline in this relationship during the subsequent grades, ultimately resulting in the cynicism Grade 12 students expressed towards the value of the school experience.

Finally more meaningful results might emerge from a longitudinal study that traces the same class of students from Grade 6 through to their graduating year. Although statistical analysis found there were no significant differences between the GPA, gender, and grade level of the participating and non-participating students in this study, the 
collection of data was dependent on a student population in a small, somewhat unique, school district in southwestern British Columbia. This study should be replicated with other student populations, both urban and rural, before any statements of generalizability can be made.

\section{Limitations of the Study}

This study is limited to the population surveyed, that is, the students in a small, somewhat unique district in the southwestern Canada. Although a well-accepted measurement of self-esteem, the Coopersmith Self-Esteem Inventory is generally considered to be a context-bound instrument, which may impact on the results associated with gender differences (Osbourne \& Le Gette, 1982; Skaalvik, 1986). Grade point averages (GPA) are commonly used as a measurement of academic achievement in schools, but like grades and percentages, they are often imprecise measurements of actual student learning. In addition, because different teachers determine them, often using different criteria, it is especially difficult to resolve this imprecision problem. Self-reporting is also subject to lack of precision. The self-reported level of involvement in school-based or extra-curricular activities should only be considered as an estimate. While a relationship between being actively involved and high self-esteem was reported, it is possible the involvement parameters which were established for a minimal or moderate level of involvement were too close to one another to detect significant differences between them. Finally, a review of the survey analysis reveals that many of the middle school students often appeared to lack the ability or willingness to articulate a full written response to the open-ended questions, which were associated with each survey question. Although this generally made establishing themes a 
relatively easy task for this age group, it may have been at the expense of accuracy and/or depth of response.

\section{Summary and Conclusions}

Recent tragic events in schools across North America are a poignant signal that educators everywhere need to reassess what they are doing, how they are doing it, and why they are doing it. Despite the relatively optimistic views expressed by the students in this study and others, it is clear that many young people are suffering from low levels of self-esteem. It also appears many students find the learning experience boring and irrelevant. Unless these problems are adequately addressed the reliance on intellectual development as it currently exists is unlikely to help these young people develop the important human and social skills deemed critically essential for survival in today's complex society and the changing workplace of the $21^{\text {st }}$ century.

Much of the research linking self-esteem to academic achievement has been based on the assumption that healthy self-esteem predicts academic success. Certainly low levels of seif-esteem have been associated with poor scholastic achievement. But, as Frase and Streshly (2000) point out, it is a myth to think..."students must feel good about themselves before they can learn" (p.58). First of all, there has to be the will to learn and this is contingent on the belief that what is learned is worthwhile. Many students are no longer willing to accept that something is worth learning simply because someone talls them it is, especially given the virtual explosion of information now available to them. Adding to the confusion is the question, "What is learning?" Further complicating the situation is the current demand for standards and accountably in the school system. Fortunately for all concerned, it seems most students, at least the students in this study, 
value good grades, but not without the cost of cynicism and disappointment, especially for those about to graduate. This should be of concern to all educators and clearly more effort must be expended making curriculum more relevant, especially for the senior students.

It is important to note, however, that the responsibility for learning should not fall exclusively on the shoulders of the educator. Too often schools or teachers have been blamed for the reported malaise students have towards learning. As Branden (1994) so aptly points out, "The aim must be to teach children how to think, how to recognize logical fallacies, how to be creative, and how to learn" (p.208). Once these important skills have been taught, students should be expected to share the responsibility for their own learning. While most students report good grades are important, many of them fall into the category of what Low (2000) refers to as compliers. Complying students do little more than necessary when it comes to learning and too many of them even earn good grades without really becoming involved in the learning process.

In conclusion, it is the hope of this researcher that this study has positively contributed to the literature on self-esteem, optimism, and academic achievement. More specifically, it is hoped that educators, parents, and politicians will take time to reexamine the current focus on intellectual development in the schools and pay more attention to the human and social development needs of the students. In a recent Business Week article, How to Fix America's Schools, the author lists seven ideas that work: performance pay, smaller schools, accountability, more variety, adequate funding, increased school time, and the effective use of technology. One has to wonder where the social and human needs of the students fit into this list. Perhaps these needs are being 
partially met, but it seems from the evidence that academic achievement only plays a minor role in this process. Finally, it is the hope of this researcher that all stakeholders will truly reflect on what it means to be an educated citizen and work together to fulfill this worthy goal. In the introduction to this study reference was made to the use of the SAT 9 as a standardized measure of academic achievement in the San Diego area. More recently the newspapers in the San Diego area report yet two more tragic school shootings. Clearly something is missing in our schools. 


\section{REFERENCES}

Aalborg, A. E. (1998). Parental participation and healthy adolescent development: An empowerment approach for inner-city schools. (Doctoral dissertation, University of California, Berkeley, 1998). Dissertation Abstracts International, 59(08B), 4048.

Adler, A. (1969). The science of living. New York: Anchor Books, Doubleday.

Adler, N. (1997). Self-esteem. http://www.macses.ucsf.edu/Research/Psychosocial/notebook/

Alloy, L. B. \& Abramson, L. Y. (as cited in Seligman, M. (1990). Learned optimism: How to change your mind and your life. New York: Pocket Books (Simon and Schuster, Inc.)

Aspinwall, L. and Taylor, S. (1992). Modeling cognitive adaptation: A longitudinal investigation of the impact of individual differences and coping on college adjustment and performance. Journal of Personality and Social Psychology, 63(6). 9891003.

Bandura, A. (1997). Self-efficacy: The exercise in control. New York: W.H. Freeman and Company.

Bao, C. (1996). Academic achievement of Chinese-American immigrant adolescents with limited English proficiency as related to family socioeconomic status, student's self-concept, and years of schooling. (Doctoral dissertation, New York University, 1996). Dissertation Abstracts International, 57(03A), 0981.

Beane, J. \& Lipka, R. (1984). Self-concept, self-esteem and the curriculum. New York: Teachers College Press.

Bennis, W. (1989). On becoming a leader. Reading, MA: Addison-Wesley.

Billings, S. (1997). Resiliency of successful high-risk females in an alternative setting. (Doctoral dissertation, University of Connecticut, 1997). Dissertation Abstracts International, 58(04A), 1240.

Blascovich, J., \& Tomaka, J. (1991). Measures of self-esteem. In J. P. Robinson, P. R. Shaver, \& L. S. Wrightsman (Eds.) Measures of personality and social psychological attitudes, Volume I. San Diego, CA: Academic Press.

Borba, M. (1989). Esteem Builders. Torrence, CA: Jalmar Press

Borba, M. (1989). Self-esteem skill builders. Los Angeles, CA: Jalmar Press 
Bottenfield, T.C. (1999). Self-esteem maintenance: The selective-valuing of a memory-enhancement technique. (Doctoral dissertation, Wayne State University, 1999). Dissertation Abstracts International, 60(06A), 1900.

Branden, N. (1994). The six pillars of self-esteem. New York: Bantam Books.

British Columbia Teachers' Federation. (2000). G.I. Joe meets Barbie, software engineer meets caregiver: Males and females in B.C.'s public schools and beyond. Vancouver.

Brock, B., Bialozor, R. C., \& McLaughlin, T. F. (1993). Effects of nongradedness on pupils' self-esteem. The Canadian School Executive. Vol. 12(7), 11-14.

Brookover, W. (1965). Self-concept of ability and school achievement. East Lansing, MI: Office of Research and Public Information, Michigan State University.

Bumbary, S. (1991). A course on social dynamics for urban junior high school students. (Doctoral dissertation, University of Massachusetts, 1991). Dissertation Abstracts International, 52(09A), 3239.

Caine, R., Caine, G., \& Crowell, S. (1994). Mindshifts: A brain-based process for restructuring schools and renewing education. Tucson, AZ: Zephyr Press.

Canfield, J. \& Wells, H. (1976). 100 ways to enhance self-concept in the classroom. Inglewood Cliffs, NJ: Prentice-Hall.

Carvajal, S.C. (1997). Global expectancies of the self as distal determinants of adolescent substance abuse: $\mathrm{A}$ test of mediating and moderating effects. (Doctoral dissertation, University of Houston, 1997). Dissertation Abstracts International, 58(3-B), 1591.

Castro, C. (1998). Predicting high school disengagement from early adolescent self-esteem and academic achievement. (Doctoral dissertation, University of Oregon, 1998). Dissertation Abstracts International, 59(09A), 3345.

Cazenave, A. (1993). The effects of self-concept, school atmosphere, motivation, locus-of-control and attendance on African-American adolescents' reading achievement. (Doctoral dissertation, Temple University, 1993). Dissertation Abstracts International, 54(02A), 0470.

Chickering, A. W. (1983). Quality from the students' point of view. Paper presented at the 22nd Annual Meeting of the American Association of State Colleges and Universities Nashville, TN, November 2, 1982. (ERIC Document Reproduction Service No. ED235765.

“Column One", Education Week 11, 11 (November 13, 1991), p. 1. 

Freeman.

Coopersmith, S. R. (1967). The antecedents of self-esteem. San Francisco: W.H.

Conference Board of Canada. (1992). Employability skills profile: What employers are looking for. Ottawa.

Covey, S. (1989). Seven habits of highly effective people. New York: Simon and Schuster Publishing.

Csikszentmihalyi, M. (1997). Finding flow: The psychology of engagement with everyday life. New York: Basic Books.

Daggy, P. P. (1994). Factors related to maintaining adolescent females in a gifted program. (Doctoral dissertation, Indiana University, 1994). Dissertation Abstracts International, 55(12A), 3746.

Egger, S. (1998). Optimism as a factor that promotes resilience in inner-city middle-school students exposed to high levels of community violence. (Doctoral dissertation, University of California, Los Angeles, 1998). Dissertation Abstracts International, 59(09), 5078.

Erickson, C.D. (1994). Developmental and gender differences in predicting career aspirations among adolescents. (Doctoral dissertation, Arizona State University, 1994). Dissertation Abstracts International, 56(01A), 0094.

Erikson, E. \& Erikson, J. (1997). The life cycle completed. New York: W.W. Norton and Co.

Faltz, C. J. (1996). Toward a better understanding of the achievement-attitude paradox of African-American students: Identifying a model of student beliefs and behaviors for achieving versus underachieving African-American adolescents. (Doctoral dissertation, University of Wisconsin - Milwaukee, 1996). Dissertation Abstracts International, 57(04A), 1482.

Finn, J. D. (1989). Withdrawing from school. Review of Educational Research. $59(2), 117-142$.

Fischer, M. \& Leitenberg, H. (1986). A comparison of aggressive and withdrawn children's self-esteem, optimism and pessimism, and casual attributions for success and failure. Journal of Abnormal Child Psychology, 17(2), 133-144.

Forsythe, L. K. (1994). A cross-case analysis in two transforming middle level schools of the effects of school, adult, and student factors on the protective factors which promote resiliency. (Doctoral dissertation, Iowa State University, 1994). Dissertation Abstracts International. 55(09A), 2657. 
Frankl, V. $(1946,1984)$. Man's search for meaning. New York: Simon and Schuster Publishing.

Frase, L. E. \& Streshly, W. (2000). Top ten myths in education: Fantasies Americans love to believe. Lanham, MD: The Scarecrow Press, Inc.

Frost, M. D. (1996). Talented students, academic achievement and self-esteem: Longitudinal comparisons of gifted versus non-gifted program placement. (Doctoral dissertation, University of Missouri - Columbia, 1996). Dissertation Abstracts International, 58(10A), 3784 .

Gardner, H. (1993). Multiple intelligences: The theory in practice. New York: Basic Books.

Geocaris, C. \& Ross, M. (1999). A test worth taking. Educational Leadership 57(1), 29-33.

Gleason, A. E. (1998). Changing explanatory style in middle-school children. Dissertation Abstracts International, 59(1-B), 0440.

Goleman, D. (1995). Emotional intelligence: Why it can matter more than I.Q. New York: Doubleday-Dell Publishing.

Hair, E. C. (1999). Longitudinal analysis of the self and personality. (Doctoral dissertation, Texas A and M University, 1999). Dissertation Abstracts International, 60(06B), 2984.

Huck, S. W., Cormier, W. H., and Bounds Jr., W. G. (1974). Reading statistics and research. New York: Harper \& Row, Publishers, Inc.

Huck, S. W. \& Cormier, W. H. (1996). Reading statistics and research. New York: HarperCollins College Publishers.

James, J. (1996). Thinking in the future tense: Leadership skills for a new age. New York: Simon and Schuster Publishing.

James, W. (1890). Principles of psychology. New York: Henry Holt.

Jeffers, S. (1987). Feel the fear and do it anyway. New York: Ballantine Books.

Jones, J. G. \& Grieneeks, L. (1970). Measures of self-perception and predictors of scholastic achievement. Journal of Educational Research, 63(5). 201-203. 57.

Keiner, R. (2000). What teens really think. Reader's Digest, Vol. 156 (938), 50- 
Kennedy, E. M. (1994). On the common core of learning. In J. M. Noll (Ed.), Taking sides: Clashing views on controversial educational issues, $9^{\text {th }}$ Ed. (pp. 120-124). Guilford, CT: Dushkin/McGraw Press.

Kirk, R. H. (1995). A study of academic resiliency in African-American children. (Doctoral dissertation, University of Southern California, 1995). Dissertation Abstracts International, 57(01A), 0078.

Kohn, A. (1993). Choices for children: Why and how to let students decide. Phi Delta Kappan, 75(1).

Kolenik, C. T. (1993). Attitudes of male and female adolescents toward academic ability, scholastic effort, and athleticism. (Doctoral dissertation, Columbia University Teacher College, 1993). Dissertation Abstracts International, 54(03A), 0886.

LaMeres, C. (1990). The winner's circle: Yes, I can. Notes from a self-esteem seminar in Vancouver, BC.

Levinson, S. H. (1996). The short-term effects of adolescent competence training of self-esteem and social skills in an upper middle-class, suburban middle school. (Doctoral dissertation, Columbia University Teachers College, 1996). Dissertation Abstracts International, 57(02A), 0535.

Litten, K. G. (1998). A prevention program design for inner-city, high school adolescents to combat learned helplessness and depression. (Doctoral dissertation, Miami Institute of Psychology of the Caribbean Center for Advanced Studies, 1998). Dissertation Abstracts International, 60(03), 1306.

Long, C. A. (1995). The development of self-esteem in young adolescents with mild mental retardation. (Doctoral dissertation, University of Missouri, 1995). Dissertation Abstracts International, 57(09A), 3892.

Low, K. (2000). The leaming process and strategic adaptive learning. Paper presented at a meeting of the Learning Ecologists, Victoria, BC., April, 2000.

Lowery, L. (1998), as cited in Geocaris, C. \& Ross, M. (1999). A test worth taking. Educational Leadership 57(1), 29-33.

Lynch, M. E. (1998). Self-handicapping and overachievement: Two strategies to cope with self-doubt. (Doctoral dissertation, Ohio State University, 1998). Dissertation Abstracts International, 59(10), 5621.

Maehr, M. L. \& Braskamp, L. A. (1986). The motivation factor: A theory of personal investment. Lexington, MA: Lexington Books. 
Marshall, C. \& Rossman, G. B. (1989). Designing qualitative research. Newbury Park, CA: Sage Publications, Inc.

McGill, C. L (1999). At-risk adolescents: Demographic and personal factors that affect their success in a military-style intervention. Dissertation Abstracts International, 60(3-A), 0649.

Menard, S. (1995). Applied Logistical Regression Analysis. Sage University Paper series on Quantitative Applications in the Social Sciences, 07-106. Thousand Oaks, CA: Sage

Ministry of Education. (1993). The graduation program policy: Grades 11 and 12. Province of British Columbia.

Ministry of Education. (1995). Policy curricular: Number 95-04. Province of British Columbia, June 15, 1995.

Ministry of Education. (1995). Policy curricular: Number 97-04. Province of British Columbia, June 10, 1997.

Ministry of Education. (1998). 1998 provincial assessment of reading and writing: Interpreting your school's assessment results. Province of British Columbia.

Ministry of Education. (1999). Student information profile for the school year 1998/1999. Province of British Columbia.

Ministry of Education. (1999). Year 2000: A framework for learning. Province of British Columbia.

Mouton, S. G. (1995). Assessing school attachment: A qualitative investigation of low-attached high school students. (Doctoral dissertation, University of Houston, 1995). Dissertation Abstracts International, 56(08A), 3006.

Mruk, C. (1995). Self-esteem: Research, theory and practice. New York: Springer Publishing Company.

$\mathrm{Mu}, \mathrm{X}$. (1999). The psychological adjustment of vocational high school students: A study of Chinese adolescents. (Doctoral dissertation, University of Washington, 1999). Dissertation Abstracts International, 59(7-A), 2346.

Mullin, M. J. (1998). The study of the relationship between self-esteem in ninthgrade students and the environment in a Catholic high school. (Doctoral dissertation, Seton Hall University, College of Education and Human Services, 1998). Dissertation Abstracts International, 59(01A), 1241. 
Nieto, S. (1994). Lessons from students on creating a chance to dream. Harvard Educational Review, 64(4), 392-426.

Noll, J. M. (1997). Taking sides: Clashing views on controversial education issues. (9 ${ }^{\text {th }}$ Ed.) Guilford, CT: Dushkin/McGraw.

Nurmi, J. E. (1990). Adolescent's orientation to the future: Development of interests and plans, and related attributions and affects, in the life span context. (Doctoral dissertation, Helsingin Yliopisto (Finland), 1990). Dissertation Abstracts International, $\underline{51(02 \mathrm{C})}, 0322$.

Osborne, L. W. \& H. R. LeGette. 1982. Sex, race, grade level, and social class differences in self-concept. Measurement and Evaluation in Guidance 14(4):195-201.

Patton, M. Q. (1990). Qualitative evaluations and research methods. Newbury Park, CA: Sages Publications, Inc.

Pereda, S., del-Carmen-Menendez, M., Mori, A., \& Meneez, J. (1990). Achievement motive, locus of control, FTO, and academic performance. Revista de Psicologia Generaly Aplicada, 43, 217-224.

Pollina, A. (1995). Gender balance: Lessons from girls in science and mathematics. Educational Leadership 53(1), 30-33.

Pugh, J. (1985). The eternal optimist. St. Petersburg Times, Religion section. June 8.

Quinn, R. (1996). Deep change: Discovering the leader within. San Francisco: Jossey-Bass Publishing.

Rabbin, R. (1998). Invisible leadership: Igniting the soul at work. Lakewood, CO: Acropolis Books.

Raffini, J. P. (1988) as cited in Renchler, R. (1992). School motivation, school culture, and academic achievement. (Report No. EA 023 593). Eugene, OR: ERIC Clearinghouse on Educational Management.

Rambo-Chroniak, K. M. (1998). Coping and adjustment in the freshman year transition. (Doctoral dissertation, Northwestern University, 1998). Dissertation Abstracts International, 59(12-A), 4378.

Rawlins, R. (1991). The relationship among hope/hopelessness, self-esteem, perceived social support, and life events in adolescents. (Doctoral dissertation, University of Alabama at Birmingham, 1991). Dissertation Abstracts International, 52(06A), 2987. 
Reasoner, R. \& Dusa, G. (1991). Building self-esteem in secondary school: A comprehensive school program. Palo Alto, CA: Consulting Psychologists Press, Inc.

Renchler, R. (1992). School motivation, school culture, and academic achievement. (Report No. EA 023 593). Eugene, OR: ERIC Clearinghouse on Educational Management.

Riddle, M. W. (1986). The transition to junior high school: Patterns of change in children's perception of competence and control, motivational orientation, anxiety, and self-esteem. (Doctoral dissertation, University of Denver, 1986). Dissertation Abstracts International, 47(10-A), 3615.

Riley, H. J. \& Others (1992). Current Trends in Grades and Grading Practices in Undergraduate Higher Education. Results of the 1992 AACRAO Survey. American Association of Collegiate Registrars and Admissions Officers, Washington, D.C. 1994 (ERIC Document Reproduction Service No. ED378893).

Rizza, M. (1997). Exploring successful learning with talented female adolescents (girls). (Doctoral dissertation, University of Connecticut, 1997). Dissertation Abstracts International. 58(08A), 3003.

Rosario, J. (1999). Puerto Rican youth "at risk": Impact of ethnic identity and self-esteem on academic success. (Doctoral dissertation, Pace University, 1999). Dissertation Abstracts International, 60(04-B), 1870.

Satir, V. (1988). The new peoplemaking. Mountain View, CA: Science and Behavior Books, Inc.

Scherer, M. (2000). Perspective: not by tests alone. Educational Leadership. 57(5), 5 .

Schlecty, P. (1994) as cited in Geocaris, C. \& Ross, M. (1999). A test worth taking. Educational Leadership 57(1), 29-33.

Schroeder, L. D., Sjoquist, D. L. \& Stephan, P. E. (1986). Understanding multiple analysis: An introductory guide. Beverly Hills, CA: Sage Publications, Inc.

Segal, M. S. (1980). The influence of a mainstream vocational placement on achievement, self-esteem and behavior. (Doctoral dissertation, Lehigh University). Dissertation Abstracts International, 41(03A), 1023.

Seligman, M. (1990). Learned optimism: How to change your mind and your life. New York: Pocket Books (Simon and Schuster, Inc.)

Seligman, M. (1995). The optimistic child: A proven program to safeguard children against depression and build lifelong resilience. New York: Houghton Mifflin. 
Shih, T. A. (1998). Against the odds: College-bound at-risk minority students. (Doctoral dissertation, University of Washington, 1998). Dissertation Abstracts International, 59(06A), 1910.

Sizer, T. (1999). No two are quite alike. Educational Leadership 57(1). 6-11.

Smith, L.T. (1997). A middle school alternative program for the at risk student: Reversing the effects of grade repetition. (Doctoral dissertation, Georgia State Univeristy, 1997). Dissertation Abstracts International, 58(08A), 2948.

Spradley, J. P. (1979). The enthnographic interview. New York: Holt, Rinehart and Winston.

Stein, N. (1999). Listening to - and learning from - girls. Educational Leadership, 57(3), 18-20.

Steinem, G. (1993). Revolution from within: A book of self-esteem. Boston: Little, Brown and Co.

Stephens, D. (1997). Relationship between learned helplessness and urban adolescent problem behavior. (Doctoral dissertation, Rutgers the State University of New Jersey - New Brunswick, 1996). Dissertation Abstracts International, 57(11-B), 7237.

Sternberg, R. J. (1997). Successful intelligence: How practical and creative intelligence determine success in life. New York: Penguin-Putnam, Inc.

Stevenson, H. (1992) as cited in Frase, L. E. \& Streshly, W. (2000). Top ten myths in education: Fantasies Americans love to believe. Lanham, MD: The Scarecrow Press, Inc.

Stipek, D.J. (1984), as cited in Renchler, R. (1992). School motivation, school culture, and academic achievement. (Report No. EA 023 593). Eugene, OR: ERIC Clearinghouse on Educational Management. 2001.

Symonds, W.C. (2001). How to fix America's schools. Business Week, March 19,

The California Task Force to Promote Self-esteem and Personal and Social Responsibility. (1990). Toward a state of self-esteem. Sacramento, CA: Bureau of Publications, California State Department of Education.

The New Lexicon Webster's Encyclopedic Dictionary of the English Language, (1998). Canadian Edition, New York: Lexican Publications, Inc.

Training for What? British Columbia Labour Force Development Board, 1995. 
Valenzuela, A. (1990). Familism and academic achievement among Mexicanorigin high school students. (Doctoral dissertation, Stanford University, 1993).

Dissertation Abstracts International, 51(08A), 2700.

Van Scotter, R. (1994). What young people think about school and society. Educational Leadership, 53(3), 72-78.

Walker, D. (1995). Women and self-esteem. http://www.crusade.org/wto/esteem/esteem/html.

Weiner, B. $(1979,1983,1984)$ as cited in Renchler, R. (1992). School motivation. school culture, and academic achievement. (Report No. EA 023 593). Eugene, OR: ERIC Clearinghouse on Educational Management.

Weisman, N. C. (1998). The self-concept of learning-disabled adults. Dissertation Abstracts International, 58(9-B), 5157.

Wiggins, G. \& McTighe, J. (1998) as cited in Geocaris, C. \& Ross, M. (1999). A test worth taking. Educational Leadership 57(1), 29-33.

Wiggins, J. D., Schatz, E. L. \& West, R. W. (1994). The relationship of selfesteem to grades, achievement scores, and other factors critical to school success. The School Counsellor, 41(1), 239-244.

Witty, J. P. (1992). Academic success and resiliency among low-income AfricanAmerican male students. (Doctoral dissertation, University of North Carolina at Greensboro, 1992). Dissertation Abstracts International, 54(03A), 1110.

Wu, C. F. (1990). The relationships between self-esteem and educational outcomes with elementary and junior high school students in Taiwan. (Doctoral dissertation, United States International University, 1990). Dissertation Abstracts International, 51(07A), 2327. Press.

Wylie, R. C. (1974). The self-concept. Lincoln, NE: University of Nebraska

Younger, M. S. (1985). A first course in linear regression. Boston, MA: Duxbury Press. 


\section{APPENDIX A \\ Coopersmith Self-Esteem Inventory}

On the next pages, you will find a list of statements about feelings. If a statement describes how you usually feel, put a X in the column "Like Me." If the statement does not describe how you usually feel, put an X in the column "Unlike Me." There are no right or wrong answers.

Like Me Unlike Me

1. Things usually don't bother me.

2. I find it ver hard to talk in front of the class.

3. There are lots of things about myself I'd if I could.

4. I can make up my mind without too much trouble.

5. I'm a lot of fun to be with.

6. I get upset easily at home.

7. It takes me a long time to get used of anything new.

8. I'm popular with the kids my own age.

9. My parents usually consider my feelings.

10. I give in very easily.

11. My parents expect too much of me.

12. It's pretty tough to be me.

13. Things are all mixed up in my life.

14. Kids usually follow my ideas.

15. I have a low opinion of myself.

16. There are many times when I would like to leave home.

17. I often feel upset I school.

18. I'm not as nice looking as most people.

19. If I have something to say, I usually say it.

20. My parents understand me.

21. Most people are better liked than me.

22. I usually feel as if my parents are pushing me.

23. I often get discouraged at school.

24. I often wish I were someone else.

25. I can't be depended on.

26. I never worry about anything.

27. I'm pretty sure of myself.

28. I'm easy to like.

29. My parents and $I$ have a lot of fun together.

30. I spend a lot of time daydreaming.

31. I wish I were younger.

32. I always do the right thing.

33. I'm proud of my schoolwork.

34. Someone always has to tell me what to do. 
35. I'm often sorry for the things that I do.

36. I'm never happy.

37. I'm doing the best that I can.

38. I can usually take care of myself.

39. I'm pretty happy.

40. I would rather play with children younger than I am.

41. I like everyone I know.

42. I like to be called on in class.

43. I understand myself.

44. No one pays much attention to me at home.

45. I never get scolded.

46. I'm not doing as well as I would like in school.

47. I can make up my mind and stick to it.

48. I really don't like being a [boy] [girl].

49. I don't like being with other people.

50. I'm never shy.

51. I often feel ashamed of myself.

52. Kids pick on me often.

53. I always tell the truth.

54. My teachers make me feel I'm not good enough.

55. I don't care what happens to me.

56. I'm a failure

57. I get upset when I'm scolded.

58. I always know what to say to people. 


\section{APPENDIX B}

Student Survey

Name:

Grade:

As part of your Career and Personal Planning program you will be asked to complete the following survey:

\section{Part One: Participation in School-Related Activities}

As you are probably aware, many employers value student participation in school activities outside the classroom, such as membership in school clubs; involvement in school politics, leadership and tutoring programs; participation in the performing or fine arts; and involvement in recreation and sports. In the space below, list the school activities that you participate in and carefully estimate the number of hours on average that you spend per week engaged in these activities.

$\underline{\text { School Activities }}$

\section{Average Number of Hours Per Week Spent on These Activities}

\section{Part Two: View of the Future}

Several year ago a survey was conducted in the United States that asked young people a number of questions about the future. Several of these questions are listed below. Please read each of these questions, then circle the response that is most like you.

1. How sure are you that you will have a promising future?

Very sure Somewhat sure Not too sure Not sure at all

Please explain the rating you gave yourself. 
2. How sure are you that you will be able to control your life in the future?

Very sure Somewhat sure Not too sure Not sure at all

Please explain the rating you gave yourself.

3. How well off financially do you expect to be as an adult compared to your family?

Better off About the same Worse off Don't know

On what is this expectation based?

4. How well does school prepare you for life after graduation?

Very well Quite a bit Not very much Not at all

Please explain your rating in more detail, specifically what is was about your school experience that either has or has not prepared you for the future.

5. How important are getting good grades to your future success?

Very important Somewhat important Not important Not sure

Please explain your response to this question. 
6. How much does getting good grades contribute to how good you feel about yourself?

Very much

A little bit

Not very much

Not at all

Please explain the rating you gave yourself.

7. How important are good grades to you in terms of your total school experience?

Very important Somewhat important Not important Not sure

Please explain your answer.

8. How important is participating in school activities, such as sports, the performing arts, or clubs to your future success after graduation?

Very important Somewhat important Not important Not sure

Why is participating in school activities either important or not important to you? Please try to explain the rating you gave yourself.

9. How much does participating in these school activities contribute to how good you feel about yourself?

Very much Quite a bit A little bit Not that much

In what ways does participating or not participating influence how good you feel about yourself? 
10. How much does participating in these school activities contribute to how valuable you think your total school experience is to you?

Very valuable Somewhat valuable A little bit valuable Not that valuable

In what ways does participating or not participating in school activities contribute to the value of your total school experience? Explain.

11. What makes you feel better about yourself, getting good grades or participating in school activities?

Good grades School activities Both about the same Neither one

Please explain your answer.

Part Three: Reflecting on the School Experience

Take a few moments to think about your school experience to date, then to the best of your ability try to describe in a paragraph, or in point form if you prefer, the following:

What are the things or circumstances that you have experienced in school that have made you feel good about yourself as a person?

What are things or circumstances that you have experienced so far that give you confidence in the future?

What are the best things and worst things about school?

Thank you for your participation in this survey. 


\section{APPENDIX C \\ Request for Mission to Conduct the Study}

Date

Name

Superintendent of Schools

Address

Dear,

The Career and Personal Planning curriculum stresses importance of the three provincial goals of education:

- Intellectual Development

- Human and Social Development

- Career Development

While the Year 2000: A Framework for Learning document provides numerous strategies for Intellectual Development and certain aspects of Career Development, it is much less clear about Human and Social Development should be facilitated.

As part of my doctoral work at the University of San Diego I would like to conduct a study that investigates the effectiveness of the schools in the district in addressing these important personal management dimensions. More specifically, I would like to explore the relationship between academic achievement, school participation, grade level and gender, and how they influence student self-esteem. Additionally I would like to explore several themes of student optimism.

I plan to survey students in grades $6,8,10$ and 12 , using an instrument that measures selfesteem and a short student survey related to self-worth and positive views of the future, as part of their Career and Personal Planning program.

This study has been approved by the Committee for the Protection of Human Subjects at the University of San Diego, and as such, ensures student confidentiality and informed parental consent.

I would like to formally request your permission to conduct this study.

Yours truly, 


\title{
APPENDIX D
}

\author{
Parent Informed Consent Form
}

October 22,2000

Dear Parent(s):

As part of my doctoral studies in Educational Leadership at the University of San Diego, I am investigating the relationship between student self-esteem, ácademic achievement, and the attitudes of the grades $6,8,10$ and 12 students toward their school experience, with a particular focus on how these attitudes influence their view of the future. This information will assist staff at the (Name) Middle School and (Name) Secondary School to assess their effectiveness at developing the human and social skills of their students. Both the Ministry of Education and the Conference Board of Canada agree that our schools need to assist young people not only in the development of their intellectual skills, but also in the development of their human and social skills. These two goals are recognized as key to the Career and Personal Planning program, which is offered to the students in this School District.

I would like permission for your child to participate in a study that will be conducted as part of his or her Career and Personal Planning program. The study is titled "The Relative Importance of Academic Achievement in Determining the Self-Esteem of Students in Rural British Columbia”. The well-known Coopersmith Self-Esteem Inventory and a Student Survey will be administered to participating students as part of a Career and Personal Planning seminar on attitudes. There will be no additional obligation beyond this seminar to participate in this study. Generally the Coopersmith Self-Esteem Inventory only takes about 10 minutes to complete. The student survey may take a little longer to complete depending on the age and the amount of detail the students wish to include. It is estimates that the entire exercise should take no more than 40 minutes.

Individual confidentiality will be assured and your right to access information respected. Student data will be anonymous and reported only as collective data. Your child will not be identified by name at any time during this research. Should either you or your son or daughter choose at any time not to participate in this study, this choice will be honored. It is not anticipated that this study will cause any risk or discomfort whatsoever to any of the participating students, but the counselors at both schools have agreed to be available to any student who might wish to discuss any part of it.

As the results of this study are completed, I will provide the principals of all the schools participating in this study with a summary of findings, which will be available to you upon request. Please contact me at (phone number) if you have any questions or concerns. 
Please sign and return this form as soon as possible. I have enclosed a stamped envelope for your convenience. Please note that there is no agreement, written or verbal, beyond that expressed in the consent form.

I, the undersigned, understand the above explanations and on that basis, I give my consent for my son or daughter to participate in this research, which will be conducted as part of the Career and Personal Planning program. My signature indicates that $I$ have read the information above. My child's signature indicates that he or she understands that a study will be conducted in class and agrees to participate. I realize that I may withdraw my child or my child may withdraw without prejudice at any time after signing this form should either one of us decide to do so.

Child's Name:

Grade Level (circle one): $\quad \begin{array}{llll}6 & 8 & 10 & 12\end{array}$

Signature of Parent/Guardian ___ Date

Signature of the Student ___ Date 


\section{APPENDIX E}

Scatter Plots

Total Self-Esteem vs. GPA




School-Academic Self-Esteem vs. GPA

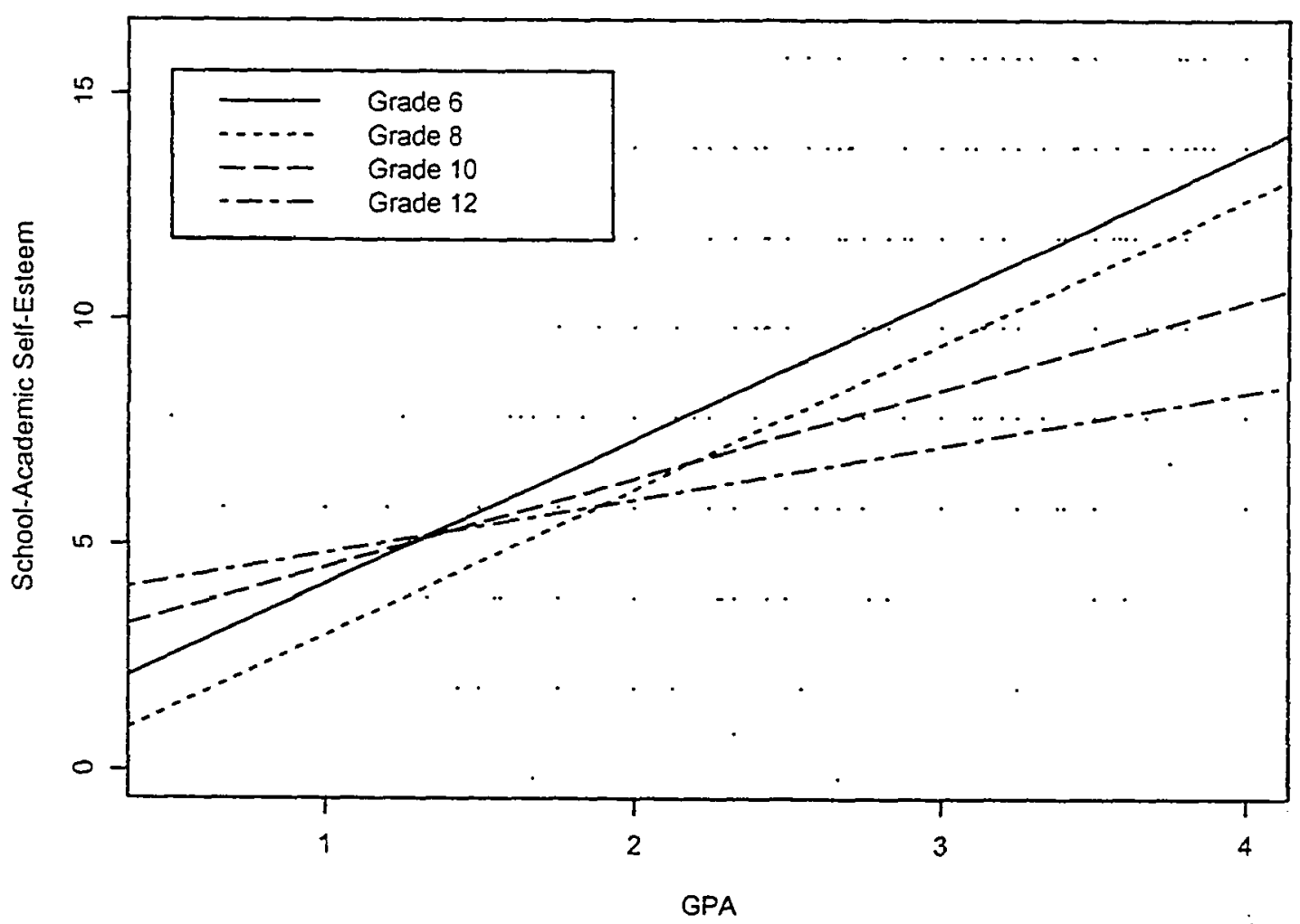


General Self Self-Esteem vs. GPA

$\hat{4}$

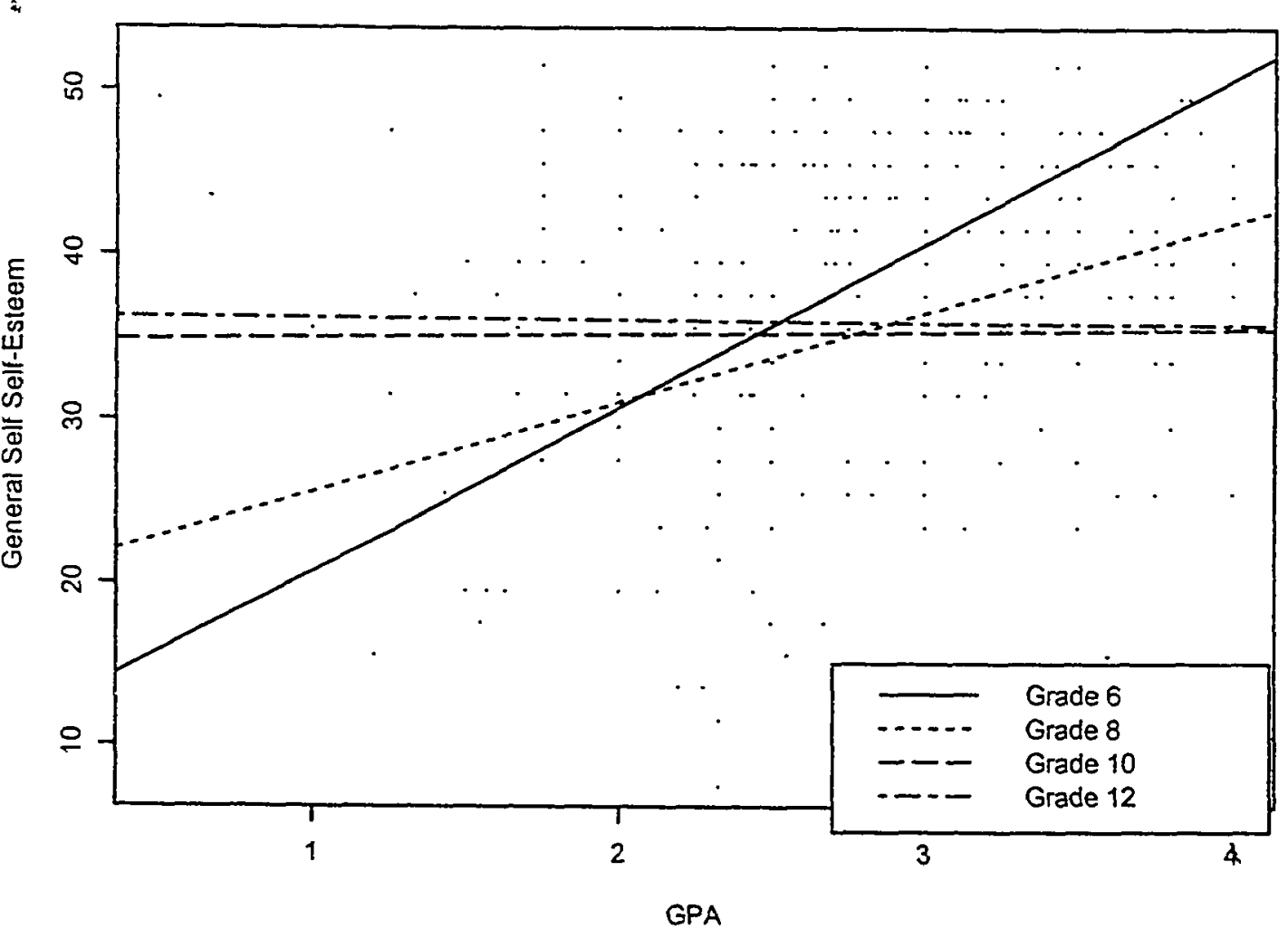


Social Self-Peers Self-Esteem vs. GPA

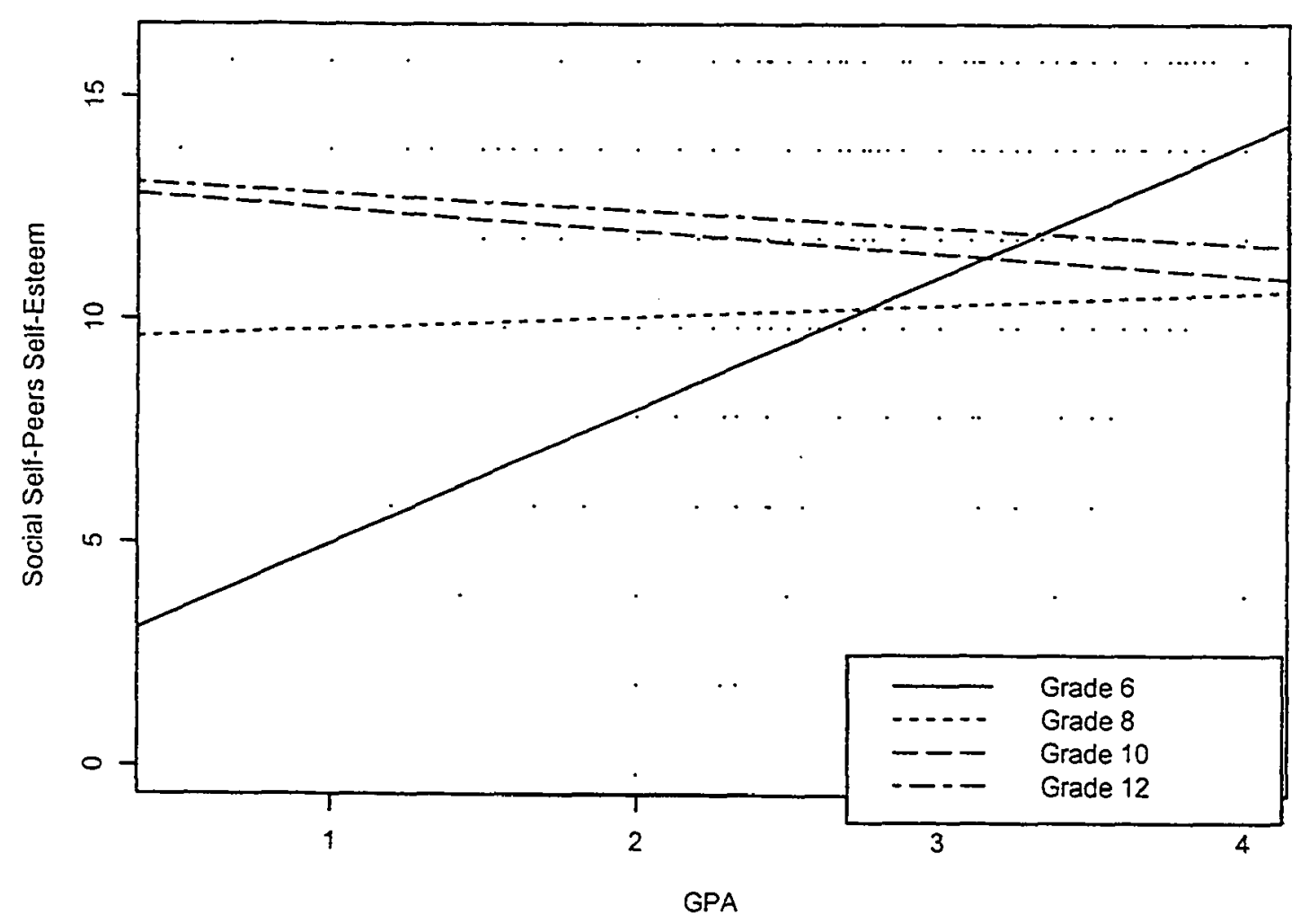




\section{APPENDLX F}

\section{Analysis of Self-Esteem Data (New GPA's, Full Model) Using S-PLUS}

\section{Analysis of Total Self-Esteem}

This is the most general model:

$>$ yfit4_Im(Total GPAnew*Involve+GPAnew*Grade+GPAnew*Gender, data $=y$, subset $=$ Lie $<5$ )

This is the Type 3 SS ANOVA table:

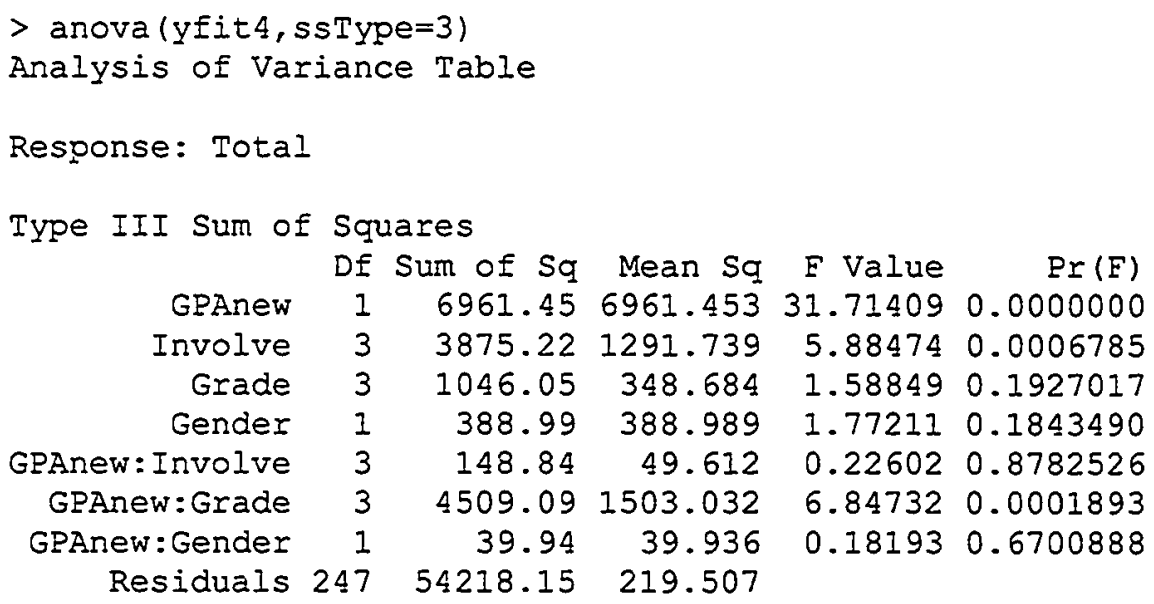

This is the Type 1 SS ANOVA table:



This is the reduced model:

$>$ ytest4_update (yfit4, School Involve+GPAnew*Grade+Gender)

This is the Type 3 SS ANOVA table for the reduced model: 




These are the parameter estimates for the reduced model:

$>\operatorname{summary}($ ytest 4$)$

Coefficients:

$\begin{array}{rrrrr} & \text { Value Std. Error } & t \text { value } & \text { Pr }(>|t|) \\ \text { (Intercept) } & 70.6707 & 3.3412 & 21.1511 & 0.0000 \\ \text { Involve2 } & 1.7020 & 3.3215 & 0.5124 & 0.6088 \\ \text { Involve3 } & 2.0511 & 3.0644 & 0.6693 & 0.5039 \\ \text { Involve4 } & 10.1916 & 3.1150 & 3.2718 & 0.0012 \\ \text { GPAnew } & 19.1481 & 3.3865 & 5.6543 & 0.0000 \\ \text { Grade2 } & -5.0651 & 2.6333 & -1.9235 & 0.0556 \\ \text { Grade3 } & -5.2766 & 2.6529 & -1.9890 & 0.0478 \\ \text { Grade4 } & -4.4019 & 2.7679 & -1.5904 & 0.1130 \\ \text { Gender } & 2.4266 & 1.9110 & 1.2698 & 0.2053 \\ \text { GPAnewGrade2 } & -7.8556 & 4.6358 & -1.6946 & 0.0914 \\ \text { GPAnewGrade3 } & -15.8998 & 4.0723 & -3.9044 & 0.0001 \\ \text { GPAnewGrade4 } & -17.2718 & 4.0344 & -4.2811 & 0.0000\end{array}$

Residual standard error: 14.73 on 251 degrees of freedom Muj.tiple R-Squared: 0.2416

E-statistic: 7.269 on 11 and 251 degrees of freedom, the p-value is $9.296 e-11$

These are the multiple comparisons for Involve:

$>$ multicomp.lm(ytest4, 'Involve')

95 s simultaneous confidence intervals for specified linear combinations, by the Sidak method critical point: 2.651 , response variable: Total

intervals excluding 0 are flagged by

Estimate Std.Error Lower Bound Upper Bound

$\begin{array}{rrrrr}0-1 & -1.700 & 3.32 & -10.50 & 7.10 \\ 0-2 & -2.050 & 3.06 & -10.20 & 6.07 \\ 0-3 & -10.200 & 3.11 & -18.40 & -1.93 * * * * \\ 1-2 & -0.349 & 2.57 & -7.16 & 6.49 \\ 1-3 & -8.490 & 2.69 & -15.60 & -1.36 * \star * \star \\ 2-3 & -8.140 & 2.36 & -14.40 & -1.87 * * \star *\end{array}$


These are the multiple comparisons for Grade:



These are the multiple comparisons for GPA:Grade:

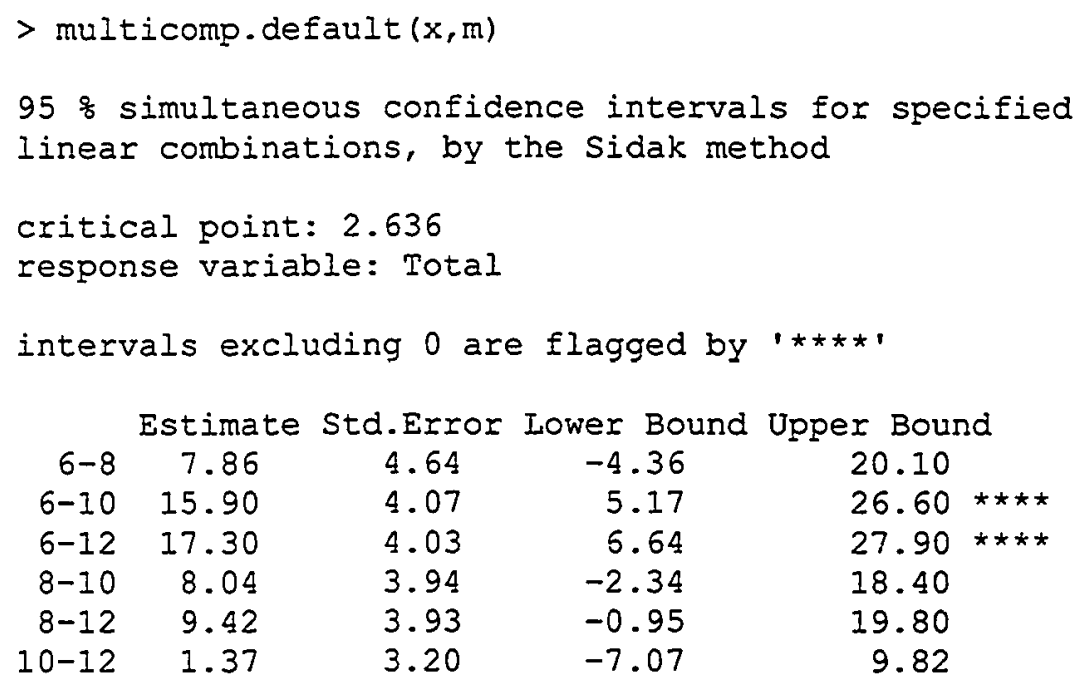




\section{Analysis of School Self-Esteem}

This is the most general model:

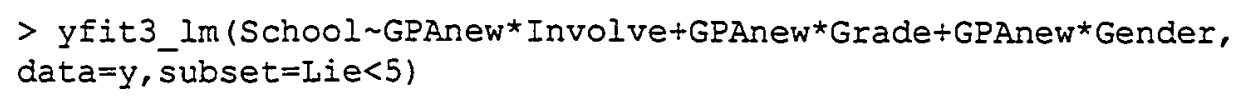

This is the Type 3 SS ANOVA table:

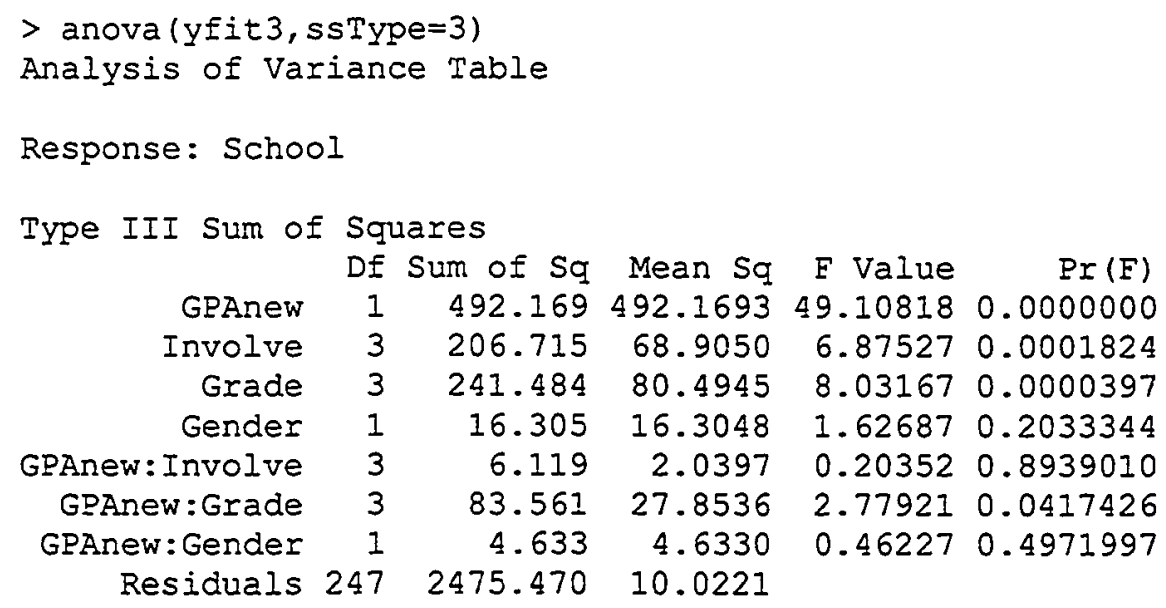

This is the Type 1 SS ANOVA table:

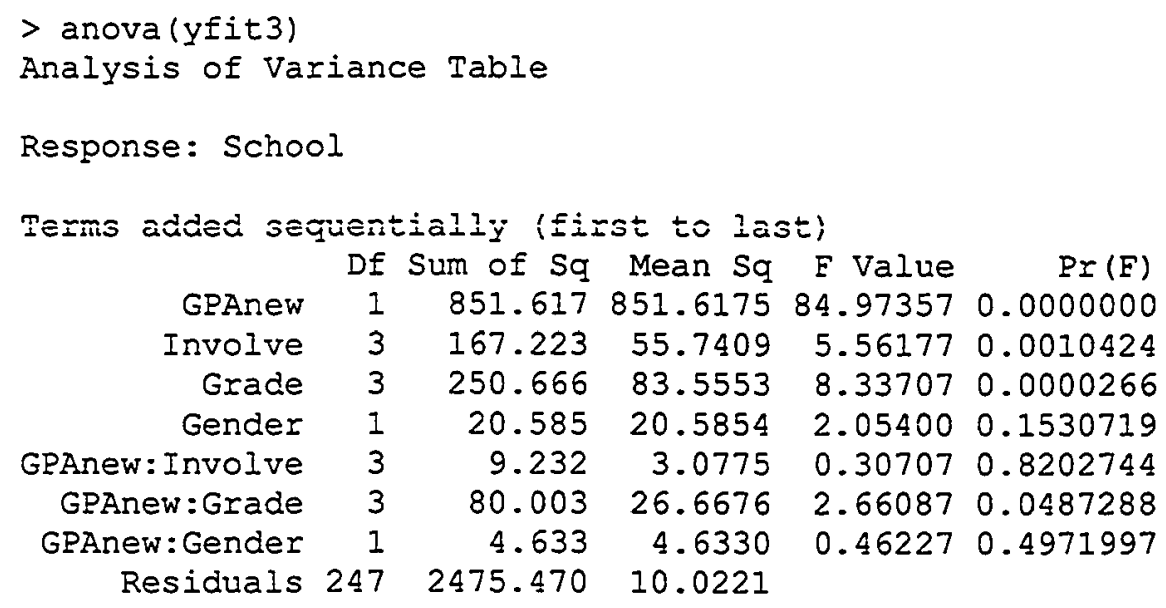

This is the reduced model:

> ytest3_update (yfit3,School Involve+GPAnew*Grade+Gender)

This is the Type 3 SS ANOVA table for the reduced model:

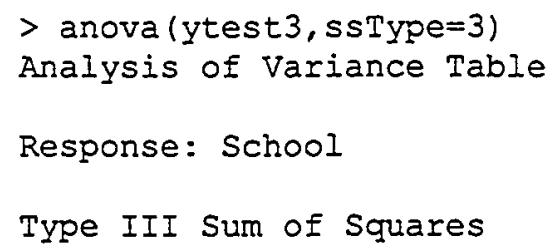




$\begin{array}{rrrrrr} & \text { Df } & \text { Sum of Sq } & \text { Mean Sq } & \text { F Value } & \operatorname{Pr}(F) \\ \text { Involve } & 3 & 238.383 & 79.4610 & 8.02757 & 0.0000396 \\ \text { GPAnew } & 1 & 558.340 & 558.3397 & 56.40649 & 0.0000000 \\ \text { Grade } & 3 & 242.268 & 80.7559 & 8.15839 & 0.0000333 \\ \text { Gender } & 1 & 18.990 & 18.9898 & 1.91845 & 0.1672572 \\ \text { GPAnew:Grade } & 3 & 84.814 & 28.2714 & 2.85613 & 0.0377063 \\ \text { Residuals } 251 & 2484.524 & 9.8985 & & \end{array}$

These are the parameter estimates for the reduced model:

$>$ summary (ytest 3 )

Coefficients:

$\begin{array}{rrcrr} & \text { Value } & \text { Std. Error } & t \text { value } & \text { Pr }(>|t|) \\ \text { (Intercept) } & 9.7244 & 0.7137 & 13.6247 & 0.0000 \\ \text { Involve2 } & 0.3496 & 0.7095 & 0.4927 & 0.6227 \\ \text { Involve3 } & 1.0027 & 0.6546 & 1.5318 & 0.1268 \\ \text { Involve4 } & 2.6459 & 0.6654 & 3.9765 & 0.0001 \\ \text { GPAnew } & 3.1768 & 0.7234 & 4.3915 & 0.0000 \\ \text { Grade2 } & -1.0677 & 0.5625 & -1.8980 & 0.0588 \\ \text { Grade3 } & -1.7874 & 0.5667 & -3.1540 & 0.0018 \\ \text { Grade4 } & -2.8411 & 0.5913 & -4.8051 & 0.0000 \\ \text { Gender } & 0.5654 & 0.4082 & 1.3851 & 0.1673 \\ \text { GPAnewGrade2 } & 0.0348 & 0.9903 & 0.0352 & 0.9720 \\ \text { GPAnewGrade3 } & -1.2190 & 0.8699 & -1.4013 & 0.1624 \\ \text { GPAnewGrade4 } & -1.9947 & 0.8618 & -2.3146 & 0.0214\end{array}$

Residual standard error: 3.146 on 251 degrees of freedom Multiple R-Squared: 0.3562

F-statistic: 12.63 on 11 and 251 degrees of freedom, the p-value is 0

These are the multiple comparisons for Involve:

$>$ multicomp. Im(ytest3, 'Involve')

95 simultaneous confidence intervals for specified

Iinear combinations, by the Sidak method

critical point: 2.651

response variable: School

intervals excluding 0 are flagged by $' * \star * *$ '

$\begin{array}{lrrrr} & \text { Estimate Std. Error } & \text { Lower Bound Upper Bound } \\ 0-1 & -0.350 & 0.710 & -2.23 & 1.530 \\ 0-2 & -1.000 & 0.655 & -2.74 & 0.733 \\ 0-3 & -2.650 & 0.665 & -4.41 & -0.882 \\ 1-2 & -0.653 & 0.549 & -2.11 & 0.801 \\ 1-3 & -2.300 & 0.574 & -3.82 & -0.774 * * * * \\ 2-3 & -1.640 & 0.505 & -2.98 & -0.304 * \star * *\end{array}$

These are the multiple comparisons for Grade:

$>$ multicomp.default $(x, m)$

$95 \%$ simultaneous confidence intervals for specified 


\begin{tabular}{|c|c|c|c|c|c|c|}
\hline \multicolumn{7}{|c|}{$\begin{array}{l}\text { critical point: } 2.636 \\
\text { response variable: School } \\
\text { intervals excluding } 0 \text { are flagged by }, * * * * \text { ' }\end{array}$} \\
\hline & Estimate & Std.Error & Lower Bound & Upper & Bound & \\
\hline $6-8$ & 1.07 & 0.563 & -0.415 & & 2.55 & \\
\hline $6-10$ & 1.79 & 0.567 & 0.294 & & 3.28 & $\star \star \star \star$ \\
\hline $6-12$ & 2.84 & 0.591 & 1.280 & & 4.40 & $\star \star \star \star *$ \\
\hline $8-10$ & 0.72 & 0.546 & -0.720 & & 2.16 & \\
\hline $8-12$ & 1.77 & 0.570 & 0.270 & & 3.28 & $\star \star \star \star$ \\
\hline $10-12$ & 1.05 & 0.558 & -0.417 & & 2.52 & \\
\hline
\end{tabular}

These are the multiple comparisons for GPA:Grade:






\section{Analysis of General Self-Esteem}

This is the most general model:

$>$ yfitl_Im(General GPAnew*Involve+GPAnew*Grade+GPAnew*Gender, data $=y, \overline{s u b s e t}=$ Lie<5)

This is the Type 3 SS ANOVA table:

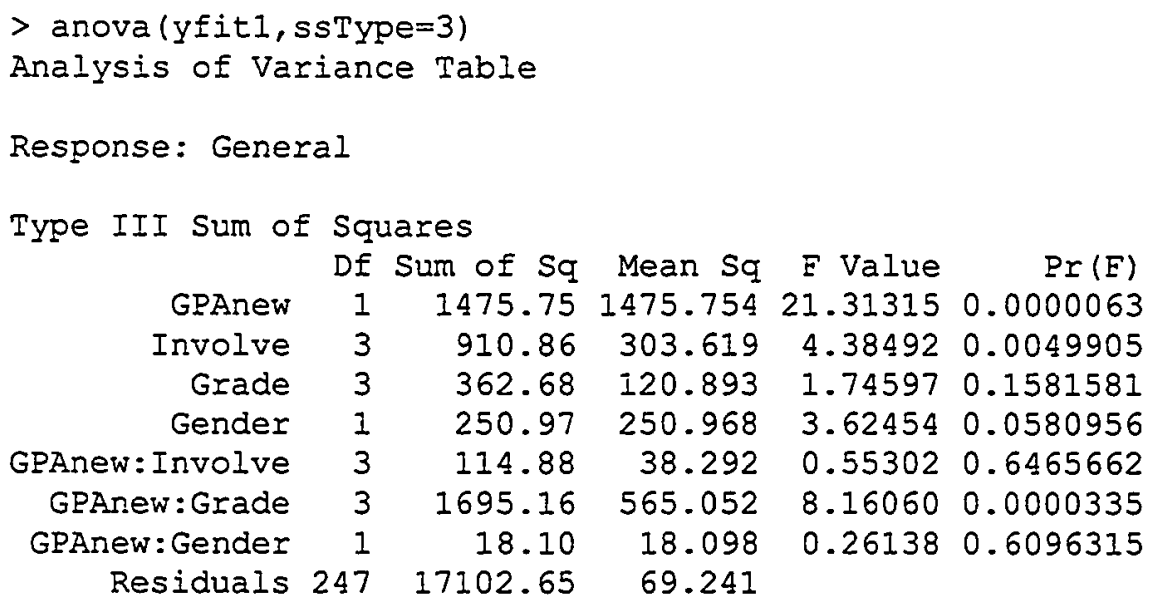

This is the Type 1 SS ANOVA table:

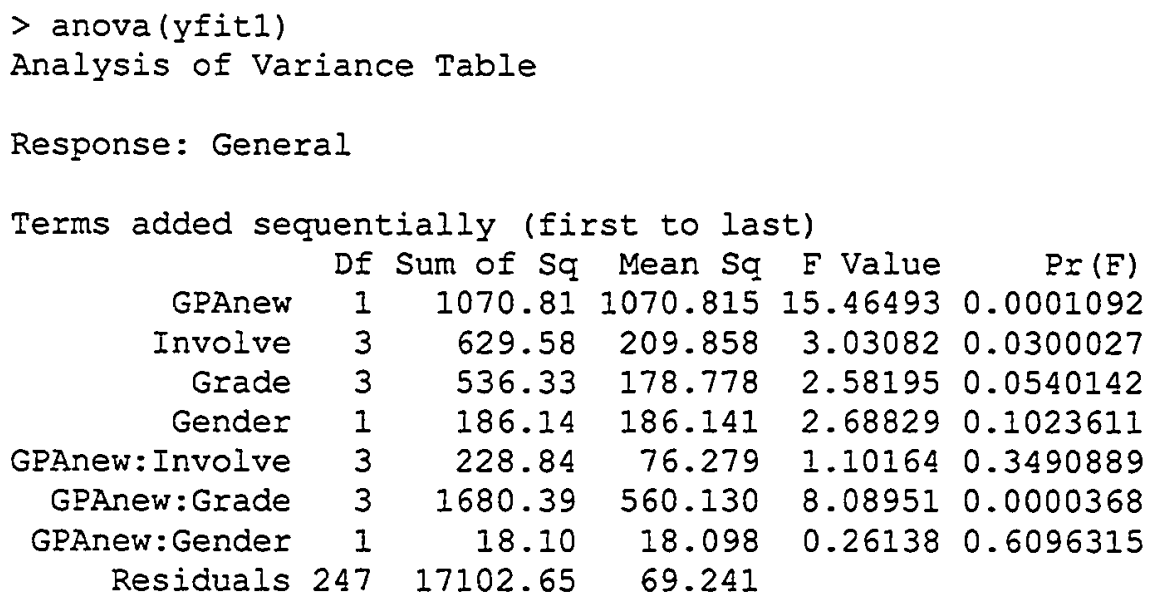

This is the reduced model:

> ytestI_update (yfitl, General Involve+GPAnew*Grade+Gender)

This is the Type 3 SS ANOVA table for the reduced model:

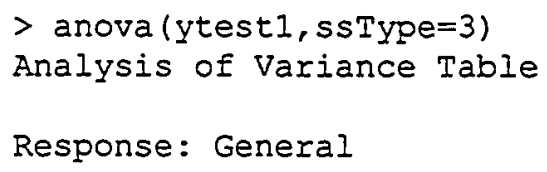


Type III Sum of Squares

$\begin{array}{rrrrrr} & \text { Df } & \text { Sum of Sq } & \text { Mean Sq } & \text { F Value } & \operatorname{Pr}(F) \\ \text { Involve } & 3 & 888.23 & 296.076 & 4.30586 & 0.0055319 \\ \text { GPAnew } & 1 & 1467.61 & 1467.611 & 21.34358 & 0.0000061 \\ \text { Grade } & 3 & 395.40 & 131.799 & 1.91677 & 0.1273351 \\ \text { Gender } & 1 & 226.78 & 226.784 & 3.29813 & 0.0705517 \\ \text { E:Grade } & 3 & 1770.90 & 590.300 & 8.58477 & 0.0000190 \\ \text { Residuals } 251 & 17259.07 & 68.751 & & \end{array}$

These are the parameter estimates for the reduced model:

$>\operatorname{summary}(y \operatorname{test} 1)$

Coefficients:

$\begin{array}{rrrrr} & \text { Value Std. Error } & t \text { value } & \text { Pr }(>|t|) \\ \text { (Intercept) } & 38.2841 & 1.8812 & 20.3514 & 0.0000 \\ \text { Involve2 } & -0.2688 & 1.8701 & -0.1437 & 0.8858 \\ \text { Involve3 } & -0.1916 & 1.7253 & -0.1111 & 0.9116 \\ \text { Involve4 } & 4.0232 & 1.7538 & 2.2941 & 0.0226 \\ \text { GPAnew } & 9.9790 & 1.9066 & 5.2338 & 0.0000 \\ \text { Grade2 } & -3.1488 & 1.4826 & -2.1239 & 0.0347 \\ \text { Grade3 } & -3.0802 & 1.4936 & -2.0622 & 0.0402 \\ \text { Grade4 } & -2.4331 & 1.5583 & -1.5613 & 0.1197 \\ \text { Gender } & 1.9539 & 1.0759 & 1.8161 & 0.0706 \\ \text { GPAnewGrade2 } & -4.5476 & 2.6100 & -1.7424 & 0.0827 \\ \text { GPAnewGrade3 } & -9.8098 & 2.2928 & -4.2786 & 0.0000 \\ \text { GPAnewGrade4 } & -10.1104 & 2.2714 & -4.4511 & 0.0000\end{array}$

Residual standard error: 8.292 on 251 degrees of freedom Multiple R-Squared: 0.1955

F-statistic: 5.545 on 11 and 251 degrees of freedom, the p-value is $6.134 e-08$

These are the multiple comparisons for Involve:

$>$ multicomp.Im(ytestI, 'Involve')

95 s simultaneous confidence intervals for specified

linear combinations, by the Sidak method

critical point: 2.651

response variable: General

intervals excluding 0 are flagged by ' $* \star \star \star * '$

$\begin{array}{rrrrr} & \text { Estimate } & \text { Std.Error Lower } & \text { Bound Upper Bound } \\ 0-1 & 0.2690 & 1.87 & -4.69 & 5.230 \\ 0-2 & 0.1920 & 1.73 & -4.38 & 4.770 \\ 0-3 & -4.0200 & 1.75 & -8.67 & 0.626 \\ 1-2 & -0.0771 & 1.45 & -3.91 & 3.760 \\ 1-3 & -4.2900 & 1.51 & -8.30 & -0.280 * \star \star * \\ 2-3 & -4.2100 & 1.33 & -7.74 & -0.685 * \star * *\end{array}$


These are the multiple comparisons for GPA:Grade:

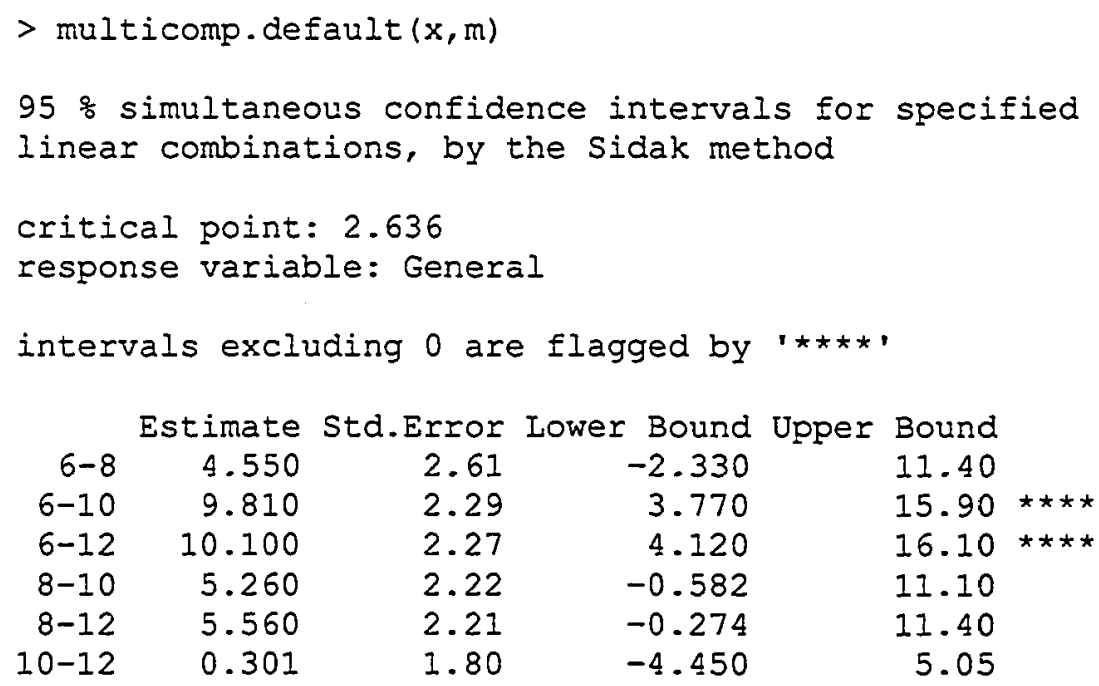




\section{Analysis of Social Self-Esteem}

This is the most general model:

$>$ yfit2_Im(Social $\sim$ GPAnew*Involve+GPAnew*Grade+GPAnew*Gender, data $=y, \overline{s u b s e t}=$ Lie $<5$ )

This is the Type 3 SS ANOVA table:

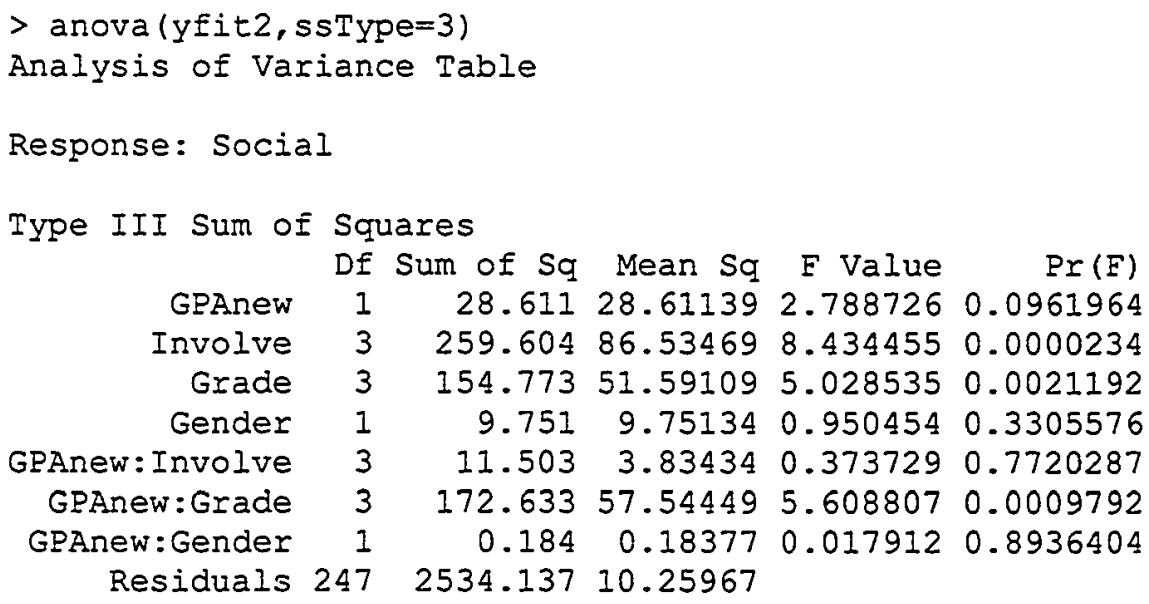

This is the Type 1 SS ANOVA table:

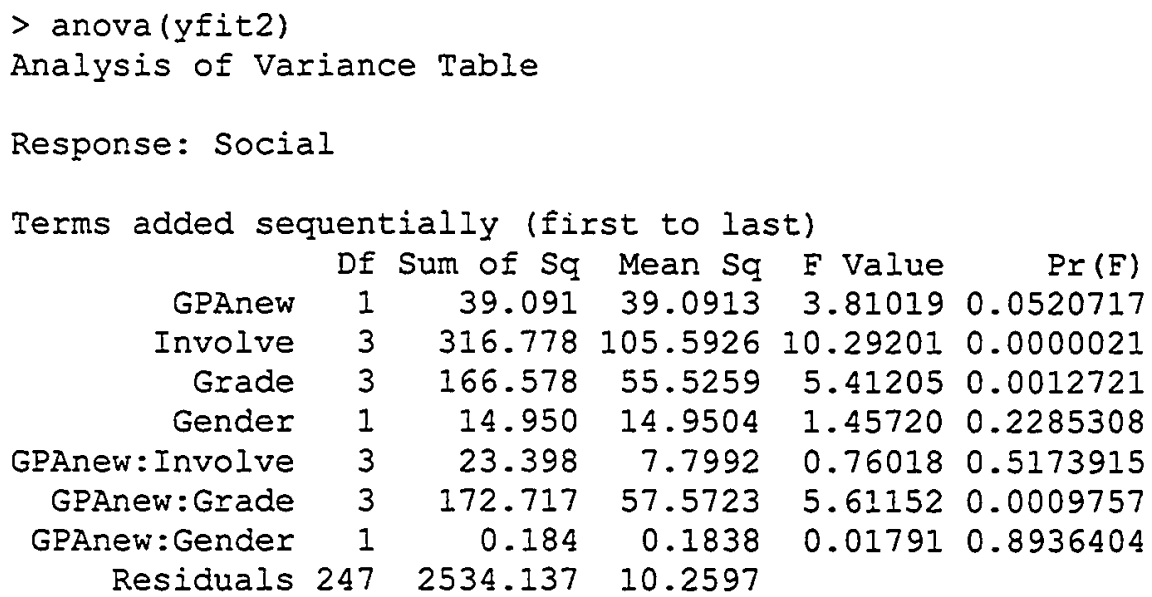

This is the reduced model:

> ytest2_update (yfit2, Social Involve+GPAnew*Grade+Gender)

This is the Type 3 SS ANOVA table for the reduced model:

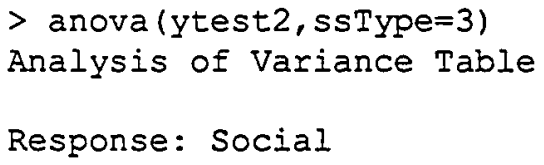




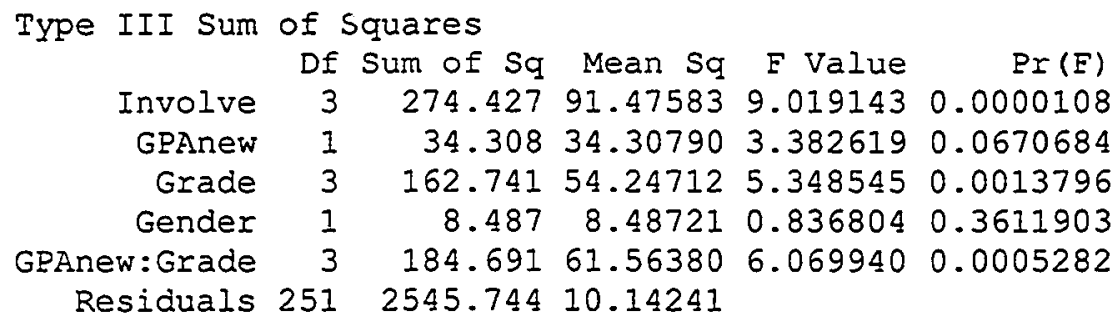

These are the parameter estimates for the reduced model:

$\begin{array}{rrcrr}\text { summary(ytest2) } & & & \\ \text { Coefficients: } & & & & \\ & \text { Value } & \text { Std. Error } & t \text { value } & \text { Pr }(>|t| \text { ) } \\ \text { (Intercept) } & 10.2503 & 0.7225 & 14.1878 & 0.0000 \\ \text { Involve2 } & 0.7863 & 0.7182 & 1.0948 & 0.2746 \\ \text { Involve3 } & 1.8659 & 0.6626 & 2.8160 & 0.0052 \\ \text { Involve4 } & 3.0644 & 0.6735 & 4.5496 & 0.0000 \\ \text { GPAnew } & 2.9883 & 0.7323 & 4.0810 & 0.0001 \\ \text { Grade2 } & -0.0034 & 0.5694 & -0.0059 & 0.9953 \\ \text { Grade3 } & 1.3421 & 0.5736 & 2.3397 & 0.0201 \\ \text { Grade4 } & 1.9023 & 0.5985 & 3.1784 & 0.0017 \\ \text { Gender } & -0.3780 & 0.4132 & -0.9148 & 0.3612 \\ \text { GPAnewGrade2 } & -2.7236 & 1.0024 & -2.7171 & 0.0070 \\ \text { GPAnewGrade3 } & -3.4968 & 0.8806 & -3.9711 & 0.0001 \\ \text { GPAnewGrade4 } & -3.3709 & 0.8724 & -3.8641 & 0.0001\end{array}$

Residual standard error: 3.185 on 251 degrees of freedom Multiple R-Squared: 0.221

F-statistic: 6.472 on 11 and 251 degrees of freedom, the p-value is $1.833 e-09$

These are the multiple comparisons for Involve:

$>$ multicomp.lm(ytest2, 'Involve')

95 s simultaneous confidence intervals for specified linear combinations, by the sidak method

critical point: 2.651

response variable: Social

intervals excluding 0 are flagged by ' $* \star \star \star *$ '

$\begin{array}{rrrrr} & \text { Estimate std. Error } & \text { Lower Bound Upper Bound } \\ 0-1 & -0.786 & 0.718 & -2.69 & 1.120 \\ 0-2 & -1.870 & 0.663 & -3.62 & -0.109 * \star \star \star \\ 0-3 & -3.060 & 0.674 & -4.85 & -1.280 * \star \star \star \\ 1-2 & -1.080 & 0.555 & -2.55 & 0.393 \\ 1-3 & -2.280 & 0.581 & -3.82 & -0.737 \\ 2-3 & -1.200 & 0.511 & -2.55 & 0.157\end{array}$


These are the multiple comparisons for Grade:

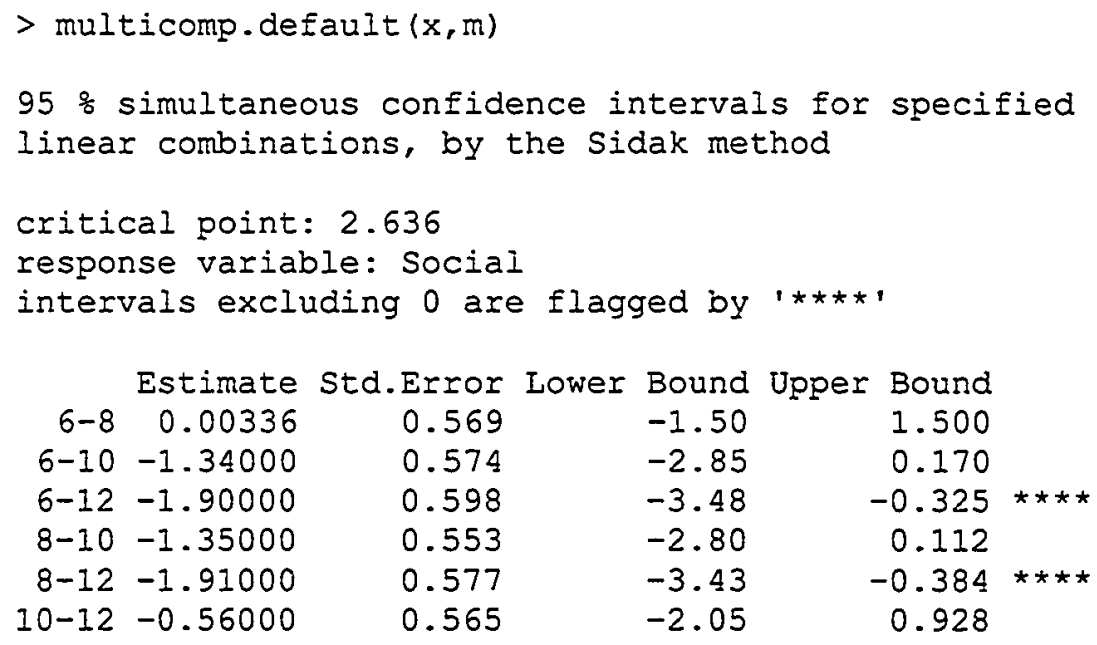

These are the multiple comparisons for GPA:Grade:






\section{APPENDIX G}

\section{Logistical Regression and Survey Analysis Using S-PLUS}

Logistical regression is the regression procedure used when there is one binary response variable, in the example above, a "Sure" or "Not sure" response. The standard multiple regression model assumes the response is normally distributed, but in this case, the data, which are binary, are not normally distributed.

We estimate the parameters using maximum likelihood estimation (as in the case of regular regression). The S-PLUS statistical analysis software uses MLE for parameter estimation in the models considered in this study. MLE is one of the most common methods used in statistics to fit models, that is, to obtain estimates of the unknown model parameters. The aim of MLE is to find the parameter value(s) that makes the observed data most likely. MLE reportedly has a lot of optimality properties, and is often used for that reason. Least-squares method is another (usually sub-optimal) method for fitting models. In the case of data analysis, all the data has been observed and there is no probabilistic part to them anymore (the word data is derived from the Latin word "given"). In MLE we are more interested in the likelihood of the model parameters that underlie the fixed data. However, in the case of regression, the same parameter estimates result from both methods. Note, however, that in this case the tests of the significance of these effects are approximate, but should be reliable given the relatively larges sample sizes involved. 
Tables for logistic regression analysis

$>$ anova(tl fit,test='Chisq')

Analysis of Deviance Table

Binomial model

Response: cbind $(A B, C D)$

Terms added sequentially (first to last)

NULL

Df Deviance

Gender

Grade 3

Gender:Grade 3

$>$ anova(t2fit,test='Chisq')

Analysis of Deviance Table

Binomial model

Response: $\operatorname{cbind}(A B, C D)$

Terms added sequentially (first to last)

NULL

Df

Deviance

Resid. Df

7

Gender 1

Grade 3

1.182365

5.895062

1.453079

Gender:Grade 3

$>$ anova(t3fit,test='Chisq')

Analysis of Deviance Table

Binomial model

Response: $\operatorname{cbind}(A B, C)$

Terms added sequentially (first to last)

$\begin{array}{ccclll} & \text { Df } & \text { Deviance } & \text { Resid. Df } & \begin{array}{l}\text { Resid. Dev } \\ 8.771392\end{array} & \operatorname{Pr}(\mathrm{Chi}) \\ \text { NULL } & & & 7 & 7.957386 & 0.3669384 \\ \text { Gender } & 1 & 0.814006 & 6 & 5.087416 & 0.4121108 \\ \text { Grade } & 3 & 2.869969 & 3 & 0.000000 & 0.1655069\end{array}$

$>$ anova(t4fit,test='Chisq')

Analysis of Deviance Table

Binomial model

Response: cbind(AB, $C D)$
$\operatorname{Pr}(\mathrm{Chi})$

8.249464

0.9271704

0.1200660

0.4919771 
Terms added sequentially (first to last)

NULL

Df Deviance Resid.

Gender $1 \quad 0.81020$

Grade $3 \quad 39.70083$

Gender:Grade $3 \quad 2.79450$

Df Resid. Dev

7

43.30553

$\operatorname{Pr}(\mathrm{Chi})$

$6 \quad 42.49533$

0.3680613

2.79450

0.0000000

$0 \quad 0.00000$

0.4244055

> anova(t5fit,test='Chisq')

Analysis of Deviance Table

Binomial model

Response: $\operatorname{cbind}(\mathrm{AB}, \mathrm{C})$

Terms added sequentially (first to last)

NULL

Df Deviance Resid.

Df Resid.

Dev

14.70136

Gender 1

9.516774

Grade 3

4.157816

7

5.18458

1.02677

0.00000

$\operatorname{Pr}(\mathrm{Chi})$

6

3

0

0.0020360

0.2449194

Gender:Grade $3 \quad 1.026766$

$>$ anova(t6fit,test='Chisq')

Analysis of Deviance Table

Binomial model

Response: $\operatorname{cbind}(\mathrm{AB}, \mathrm{CD})$

Terms added sequentially (first to last)

NULL

Df Deviance Resid.

Gender $\quad 125.40697$

Grade $\quad 310.58434$

Gender:Grade 32.18225

Df Resid. Dev

7

38.17356

$\operatorname{Pr}(\mathrm{Chi})$

6

12.76659

0.0000005

3

2.18225

0.0141996

0

0.00000

0.5354522

$>$ anova(t7fit,test='Chisq')

Analysis of Deviance Table

Binomial model

Response: $\operatorname{cbind}(\mathrm{AB}, \mathrm{C})$

Terms added sequentially (first to last)

NULL

Df Deviance Resid.

Gender

13.14841

Df Resid.

7

Dev

31.01935

$\operatorname{Pr}(\mathrm{Chi})$

Grade $3 \quad 11.61860$

6

17.87094

0.00028776

3

6.25234

0.00881072 
$\begin{array}{lllll}\text { Gender:Grade } 3 & 6.25234 & 0 & 0.00000 & 0.09995825\end{array}$

$>$ anova(t8fit,test $=$ 'Chisq')

Analysis of Deviance Table

Binomial model

Response: cbind $(A B, C)$

Terms added sequentially (first to last)

$\begin{array}{ccllll} & \text { Df } & \text { Deviance Resid. } & \text { Df Resid. } & \text { Dev } & \operatorname{Pr}(\mathrm{Chi}) \\ \text { NULL } & & & 7 & 9.605006 & \\ \text { Gender } & 1 & 0.026814 & 6 & 9.578192 & 0.8699286 \\ \text { Grade } & 3 & 9.027308 & 3 & 0.550884 & 0.0289300 \\ \text { Gder:Grade } & 3 & 0.550884 & 0 & 0.000000 & 0.9075784\end{array}$

$>$ anova(t9fit,test ${ }^{\prime}$ 'Chisq')

Analysis of Deviance Table

Binomial model

Response: cbind( $A B, C D)$

Terms added sequentially (first to last)

NULL

Df Deviance Resid.

Gender $\quad 1 \quad 0.765826$

6.870639

Grade 3

6.377421

Df Resid. Dev

7

14.01389

$\operatorname{Pr}$ (Chi)

6

13.24806

0.3815114

$3 \quad 6.37742$

0.0761373

Gender:Grade 3

0

0.00000

0.0946241

$>$ anova(t10fit,test='Chisq')

Analysis of Deviance Table

Binomial model

Response: $\operatorname{cbind}(\mathrm{AB}, \mathrm{CD})$

Terms added sequentially (first to last)

NULL

Df Deviance Resid.

Df Resid. Dev

Gender

7

12.68205

Grade $3 \quad 4.760424$

6

12.31668

7.55625

0.00000

$\operatorname{Pr}$ (Chi)

Gender:Grade 37.556252

3

0.5455380

0.1902044

0

0.0561306

$>$ anova(t1 1 fita,test='Chisq')

Analysis of Deviance Table

Binomial model

Response: cbind(A, B) 
Terms added sequentially (first to last)

$\begin{array}{ccllll} & \text { Df } & \text { Deviance Resid. } & \text { Df Resid. } & \text { Dev } & \operatorname{Pr}(\mathrm{Chi}) \\ \text { NULL } & & & 7 & 10.16139 & \\ \text { Gender } & 1 & 7.320826 & 6 & 2.84057 & 0.0068160 \\ \text { Grade } & 3 & 0.935691 & 3 & 1.90488 & 0.8168074 \\ \text { nder:Grade } & 3 & 1.904877 & 0 & 0.00000 & 0.5923826\end{array}$

$>$ anova(t1 lfitb,test='Chisq')

Analysis of Deviance Table

Binomial model

Response: $\operatorname{cbind}(\mathrm{ABC}, \mathrm{D})$

Terms added sequentially (first to last)

NULL

Df Deviance Resid.

Gender

1.709847

Grade 3

5.884717

Gender:Grade 34.345782

Df Resid.

Dev

11.94035

10.23050

$\operatorname{Pr}($ Chi)

6

4.34578

0.1910052

3

$0 \quad 0.00000$

0.1173557

0.2264656 
Correlation of coefficients for the original model



\begin{tabular}{|c|c|c|c|c|c|c|c|c|c|c|c|c|c|c|c|}
\hline & $\begin{array}{l}\text { Inter- } \\
\text { cept }\end{array}$ & GPA & $\ln v 1$ & $\ln v 2$ & $\ln v 3$ & Gr 8 & Gr 10 & Gr 12 & Gen & $\begin{array}{l}\text { GPA: } \\
\text { Invl }\end{array}$ & $\begin{array}{l}\text { GPA: } \\
\text { Inv2 }\end{array}$ & $\begin{array}{l}\text { GPA: } \\
\text { Inv3 }\end{array}$ & $\begin{array}{l}\text { GPA: } \\
\text { Gr8 }\end{array}$ & $\begin{array}{l}\text { GPA: } \\
\text { Grlo }\end{array}$ & $\begin{array}{l}\text { GPA: } \\
\text { Gr12 }\end{array}$ \\
\hline$\overline{G P A}$ & -.0927 & & & & & & & & & & & & & & \\
\hline $\ln v 1$ & -.5573 & .5613 & & & & & & & & & & & & & \\
\hline $\ln v 2$ & -.6134 & .6246 & .6264 & & & & & & & & & & & & \\
\hline $\ln 43$ & -.5706 & .5734 & .5521 & .6079 & & & & & & & & & & & \\
\hline Gr 8 & -.4993 & .4745 & -.0464 & .0101 & .0189 & & & & & & & & & & \\
\hline Gr 10 & .6424 & .6031 & .1605 & .1107 & .0728 & .5780 & & & & & & & & & \\
\hline $\mathrm{Gr} 12$ & -.6469 & .6208 & .1669 & .1946 & .0752 & .5780 & .6966 & & & & & & & & \\
\hline Gen & -.3635 & .3342 & .0012 & .0269 & .1944 & .1078 & .0536 & -.0518 & & & & & & & \\
\hline GPA:Invl & .5214 & $-.564 \overline{4}$ & -.9642 & -.6037 &. .5355 & .0531 & -.1244 & -.1425 & .0055 & & & & & & \\
\hline GPA:Inv2 & .5896 & -.6479 & -.61115 & -.9617 & -.5980 & -.0066 & -.0849 & -.1745 & -.0286 & .6395 & & & & & \\
\hline GPA:Inv3 & .5656 & -.6096 & -.5664 & -.6247 & -.9656 & -.0066 & -.0502 & -.0709 & -.1709 & .5956 & .6658 & & & & \\
\hline GPA:Gr8 & .4823 & -.4742 & .0549 & -.0061 & -.0123 & -.9807 & -.5685 & -.5686 & -.0941 & .0658 & .0021 & -.0050 & & & \\
\hline GPA:Grl0 & .6117 & -.5937 & -.1302 & -.0900 & -.0427 & -.5716 & -.9740 & -.6840 &. .0464 & .0922 & .0674 & .0152 & .5861 & & \\
\hline GPA:Grl2 & .6166 &. .6169 & -.1555 & -.1824 & -.0700 & -.5585 & -.6699 & -.9714 & .0513 & .1376 & .1725 & .0639 & .5729 & .6858 & \\
\hline GPA:Gen & .3221 & -.3097 & .0110 & -.0239 & -.1730 & -.0853 & -.0299 & .0686 & -.9705 & -.0207 & .0255 & .1528 & .0733 & .0285 & \\
\hline
\end{tabular}

Correlation of coefficients for the reduced model

\begin{tabular}{|l|l|l|l|l|l|l|l|l|l|l|l|l|}
\hline & $\begin{array}{l}\text { Inter- } \\
\text { cept }\end{array}$ & GPA & Inv 1 & Inv 2 & Inv 3 & Gr 8 & Gr 10 & Gr 12 & Gen & $\begin{array}{l}\text { GPA: } \\
\text { Gr8 }\end{array}$ & $\begin{array}{l}\text { GPA: } \\
\text { Gr 10 }\end{array}$ \\
\hline GPA & -.9481 & & & & & & & & & & \\
\hline $\operatorname{Inv} 1$ & -.2937 & .1036 & & & & & & & & & \\
\hline $\operatorname{Inv} 2$ & -.2671 & .0388 & .6791 & & & & & & & & \\
\hline $\operatorname{Inv} 3$ & -.2269 & .0202 & .6528 & .7072 & & & & & & & \\
\hline Gr 8 & -.6850 & .7013 & .0170 & .0101 & .0370 & & & & & & \\
\hline Gr 10 & -.8128 & .8071 & .1519 & .1095 & .1230 & .5913 & & & & & \\
\hline Gr 12 & -.8168 & .8216 & .1168 & .0977 & .0799 & .6024 & .6985 & & & & \\
\hline Gen & -.2513 & .1574 & -.0317 & .0094 & .0699 & .1091 & .1007 & .0641 & & & \\
\hline GPA:Gr8 & .6746 & -.7161 & -.0314 & -.0109 & -.0563 & -.9806 & -.5832 & -.5928 & -.1017 & & \\
\hline GPA:Gr10 & .7945 & -.8224 & -.1536 & -.0920 & -.1367 & -.5819 & -.9744 & -.0865 & -.0806 & .5977 & \\
\hline GPA:Gr12 & .7746 & -.8177 & -.0907 & -.0585 & -.0864 & -.5815 & -.6707 & -.9703 & -.0448 & .5962 & .6878 \\
\hline
\end{tabular}




\begin{tabular}{|c|c|c|c|c|c|c|c|c|c|c|c|c|c|c|c|}
\hline & $\begin{array}{l}\text { Inter- } \\
\text { cept }\end{array}$ & GPAn & $\ln v 1$ & $\ln 22$ & $\ln v 3$ & Gr 8 & Gr 10 & Gr 12 & Gen & $\begin{array}{l}\text { GPAn* } \\
\text { InvI }\end{array}$ & $\begin{array}{l}\text { GPAn* } \\
\text { Inv2 }\end{array}$ & $\begin{array}{l}\text { GPAn* } \\
\text { Inv3 }\end{array}$ & $\begin{array}{l}\text { GPAn* } \\
\text { Gr } 8\end{array}$ & $\begin{array}{l}\text { GPAn* } \\
\text { Gr10 }\end{array}$ & $\begin{array}{l}\text { GPAn } \\
\mathrm{Gr} 12\end{array}$ \\
\hline GPAn & -.0146 & & & & & & & & & & & & & & \\
\hline Inv I & -.6232 & -.1016 & & & & & & & & & & & & & \\
\hline Inv 2 & -.7262 & .1461 & .6892 & & & & & & & & & & & & \\
\hline $\ln v 3$ & -.6574 & .1052 & .6597 & .7081 & & & & & & & & & & & \\
\hline Gr 8 &. .3873 & .0987 & -.0760 & -.0074 & -.0810 & & & & & & & & & & \\
\hline Gr 10 & -.4429 & .1592 & -.0282 & .0570 & -.0511 & .5324 & & & & & & & & & \\
\hline Gr 12 & -.4912 & .0803 & .0995 & .1538 & -.0249 & .5091 & .5337 & & & & & & & & \\
\hline Gen & -.3296 & .1467 & -.0494 & -.0043 & .0712 & .0660 & .1215 & .0873 & & & & & & & \\
\hline GPAn*Inv! & .5214 & -.5644 & .2897 & .1892 & .1978 & -.0506 & -.1600 & -.0349 & -.0602 & & & & & & \\
\hline GPAn:Inv2 & .5896 & -.6479 & .2036 & .2335 & .2232 & -.0230 & -.0906 & -.0262 & -.0166 & .6395 & & & & & \\
\hline GPAn:Inv3 & .5656 & -.6096 & .2010 & .2108 & .0766 & -.0582 & -.1567 & -.0359 & -.0972 & .5956 & .6658 & & & & \\
\hline GPAn:Gr8 & .4823 & -.4742 & -.0497 & -.0140 & -.0661 & -.1074 & -.0390 & -.0413 & -.0969 & -.0658 & .0021 & .0050 & & & \\
\hline GPAn:Grlo & .6117 & -.5937 & -.1222 & -.0735 & -.1062 & -.0467 & -.0846 & -.0636 & -.0788 & .0922 & .0674 & .0152 & .5861 & & \\
\hline GPAn:Grl2 & .6165 & -.6169 & .0427 & -.0180 & -.0270 & -.0448 & -.0665 & .0168 & -.0401 & .1376 & .1725 & .0639 & .5729 & .6858 & \\
\hline GPAn:Gen & .3221 & -.3097 & -.0384 & .0081 & -.0857 & -.0758 & -.0120 & .0296 & -.0232 & -.0207 & .0255 & .1528 & .0733 & .0285 & -.06 \\
\hline
\end{tabular}

Correlation of coefficients for the reduced centred model

\begin{tabular}{|c|c|c|c|c|c|c|c|c|c|c|c|}
\hline & $\begin{array}{l}\text { Inter- } \\
\text { cept }\end{array}$ & $\overline{\text { GPAn }}$ & $\ln v 1$ & $\ln v 2$ & $\ln v 3$ & Gr 8 & Gr 10 & Gr 12 & Gen & $\begin{array}{l}\text { GPAn } \\
\text { Gr8 }\end{array}$ & $\begin{array}{l}\text { GPAn } \\
\text { Grlo }\end{array}$ \\
\hline GPAn & -.1479 & & & & & & & & & & \\
\hline Inv 1 & -.6233 & .1036 & & & & & & & & & \\
\hline Inv 2 & -.7223 & .0388 & .6791 & & & & & & & & \\
\hline Inv 3 & -.6495 & .0202 & .6528 & .7072 & & & & & & & \\
\hline Gr 8 & -.3935 & .0721 & -.0665 & .0027 & -.0863 & & & & & & \\
\hline Gr 10 & -.4759 & .0891 & .0218 & .0954 & -.0347 & .5318 & & & & & \\
\hline Gr 12 & -.5093 & .0977 & .1169 & .1680 & -.0182 & .5120 & .6985 & & & & \\
\hline Gen & -.3407 & .1574 & -.0317 & .0094 & .0699 & .0584 & .1045 & .0844 & & & \\
\hline $\mathrm{GPAn}^{*} \mathrm{Gr} 8$ & .0926 & -.7161 & -.0314 & -.0109 & -.0563 & -.1071 & -.0501 & -.0455 & -.1017 & & \\
\hline GPAn ${ }^{*}$ Gr 10 & .1675 & -.8224 & -.1536 & -.0920 & -.1367 & -.0424 & -.0779 & -.0635 & -.0806 & .5977 & \\
\hline GPAn ${ }^{*} \mathrm{Gr} 12$ & .1189 & -.8177 & -.0907 & -.0585 & -.0864 & -.0476 & -.0558 & -.0228 & -.0448 & .5962 & .6878 \\
\hline
\end{tabular}




\section{APPENDIX I}

Testing for high correlations using Type 1 and Type 3 ANOVA tables

One way of detecting whether the parameter estimates are highly correlated is whether the Type 1 and Type 3 ANOVA tables are quite different. The two types of ANOVA tables for Total self-esteem are shown below. Table I.1 or the Type 3 Sum of Squares ANOVA table shows the tests of whether each effect is significant given that all the other effects are in the model.

Table I.1

Type 3 sum of squares ANOVA table with GPA for total self-esteem

\begin{tabular}{lccccc}
\hline & Df & Sum of Squares & $\begin{array}{c}\text { Mean } \\
\text { Square }\end{array}$ & F-value & $\operatorname{Pr}(\mathrm{F})$ \\
\hline GPA & 1 & 7895.57 & 6961.45 & 31.7141 & 0.0000 \\
Involvement & 3 & 2827.12 & 214.20 & 0.9758 & 0.4047 \\
Grade & 3 & 3556.08 & 1185.36 & 5.4001 & 0.0013 \\
Gender & 1 & 1.81 & 1.81 & 0.0082 & 0.9278 \\
GPA:Involvement & 3 & 148.84 & 49.61 & 0.2260 & 0.8783 \\
GPA:Grade & 3 & 4509.09 & 1503.03 & 6.8473 & 0.0002 \\
GPA: Gender & 1 & 39.94 & 39.936 & 0.1819 & 0.6701 \\
Residuals & 247 & 54218.15 & 219.507 & & \\
\hline p 05 & & & & &
\end{tabular}

The Type 1 Sum of Squares ANOVA table shown in Table 1.2 is read from the bottom to the top. The last $p$-value corresponds to the test of whether GPA:Gender is significant, given that all other effects are in the model. Not surprisingly this value is the same in both tables. The second last p-value corresponds to the test of whether GPA:Grade is significant given that all the other effects, except GPA:Gender, are in the model. The third last p-value corresponds to the test of whether GPA:Involvement is significant given that all the other effects, except GPA:Gender and GPA:Grade, are in the model, and so on. 
Table 1.2

Type 1 sum of squares ANOVA table with GPA for total self-esteem

\begin{tabular}{lccccc}
\hline & Df & $\begin{array}{c}\text { Sum of } \\
\text { Squares }\end{array}$ & Mean Square & F-value & $\operatorname{Pr}(\mathrm{F})$ \\
\hline GPA & 1 & 7895.57 & 7895.565 & 35.9696 & 0.0000 \\
Involvement & 3 & 2827.12 & 942.373 & 4.29314 & 0.0056 \\
Grade & 3 & 1458.60 & 486.201 & 2.21497 & 0.0869 \\
Gender & 1 & 268.87 & 268.874 & 1.22490 & 0.2695 \\
GPA:Involvement & 3 & 611.48 & 203.826 & 0.92856 & 0.4275 \\
GPA:Grade & 3 & 4474.07 & 1491.357 & 6.79413 & 0.0002 \\
GPA:Gender & 1 & 39.94 & 39.936 & 0.18193 & 0.6701 \\
Residuals & 247 & 54218.15 & 219.507 & & \\
\hline
\end{tabular}

Terms added sequentially (first to last); $p<.05$

In the Type 1 Sum of Squares ANOVA table, then, the order in which the effects are specified in the model matters if there is correlation among the factors. However, if there is no correlation, the order does not matter, and, in fact, the two ANOVA tables will be identical. This implies the significance of each effect can be assessed independently. It can be seen that the tables are quite different, therefore one can assume that unacceptable levels of correlation exist.

Centering GPA to get GPAnew substantially reduced the correlation among the parameter estimates. GPAnew was calculated by subtracting the mean (GPA) from the GPA scores, that is, the difference between a student's GPA and the overall mean GPA. By using GPAnew rather than GPA, it can be seen that the two ANOVA tables shown in Table I.3 and Table I.4 are nearly identical. In other words, the tables can be scanned to see which effects are significant, independent of which other effects are in the model. In each case of self-esteem, the comparison of the Type 1 and Type 3 ANOVA tables with GPA (see Appendix J) showed evidence of high correlations between the parameter 
estimates, which support the use of GPAnew. These results are consistent with those found in the correlation matrix comparisons.

Table I.3

Type 3 sum of squares ANOVA table with GPAnew for total self-esteem

\begin{tabular}{lccccc}
\hline & Df & Sum of Squares & $\begin{array}{c}\text { Mean } \\
\text { Square }\end{array}$ & F-value & $\operatorname{Pr}(\mathrm{F})$ \\
\hline GPAnew & 1 & 6961.45 & 6961.45 & 31.7141 & 0.0000 \\
Involvement & 3 & 3875.22 & 1291.74 & 5.8847 & 0.0007 \\
Grade & 3 & 1046.05 & 348.68 & 1.5885 & 0.1927 \\
Gender & 1 & 388.99 & 388.99 & 1.7721 & 0.1843 \\
GPAnew:Involvement & 3 & 148.84 & 49.61 & 0.2260 & 0.8783 \\
GPAnew:Grade & 3 & 4509.09 & 1503.03 & 6.8473 & 0.0002 \\
GPAnew: Gender & 1 & 39.94 & 39.94 & 0.1819 & 0.6701 \\
Residuals & 247 & 54218.15 & 219.51 & & \\
\hline
\end{tabular}
$\mathrm{p}<.05$

\section{Table I.4}

Type 1 sum of squares ANOVA table with GPAnew for total self-esteem

\begin{tabular}{lccccc}
\hline & Df & $\begin{array}{c}\text { Sum of } \\
\text { Squares }\end{array}$ & Mean Square & F-value & $\operatorname{Pr}(\mathrm{F})$ \\
\hline GPAnew & 1 & 7895.57 & 7895.565 & 35.96959 & 0.0000 \\
Involvement & 3 & 2827.12 & 942.373 & 4.29314 & 0.0057 \\
Grade & 3 & 1458.60 & 486.201 & 2.21497 & 0.0869 \\
Gender & 1 & 268.87 & 268.874 & 1.22490 & 0.2695 \\
GPAnew:Involvement & 3 & 611.48 & 203.826 & 0.92856 & 0.4275 \\
GPAnew:Grade & 3 & 4474.07 & 1491.357 & 6.79413 & 0.0002 \\
GPAnew:Gender & 1 & 39.94 & 39.936 & 0.18193 & 0.6701 \\
Residuals & 247 & 54218.15 & 219.507 & & \\
\hline
\end{tabular}

Terms added sequentially (first to last); $p<.05$ 


\section{APPENDIX J}

Comparison of Type 1 and Type 3 ANOVA Tables for GPA and GPAnew using S-PLUS

Results for Total Self-Esteem

$>$ anova(yf4,ssType $=3$ )

Analysis of Variance Table

Response: Total

Type III Sum of Squares

$\begin{array}{llllll} & \text { Df } & \text { Sum of Sq } & \text { Mean Sq } & \text { F Value } & \operatorname{Pr}(F) \\ \text { GPA } & 1 & 6961.45 & 6961.453 & 31.71409 & 0.0000000 \\ \text { Involve } & 3 & 642.61 & 214.204 & 0.97584 & 0.4047278 \\ \text { Grade } & 3 & 3556.08 & 1185.359 & 5.40010 & 0.0012925 \\ \text { Gender } & 1 & 1.81 & 1.807 & 0.00823 & 0.9277839 \\ \text { GPA:Involve } & 3 & 148.84 & 49.612 & 0.22602 & 0.8782526 \\ \text { GPA:Grade } & 3 & 4509.09 & 1503.032 & 6.84732 & 0.0001893 \\ \text { GPA:Gender } & 1 & 39.94 & 39.936 & 0.18193 & 0.6700888 \\ \text { Residuals } & 247 & 54218.15 & 219.507 & & \end{array}$

$>$ anova(yf4)

Analysis of Variance Table

Response: Total

Terms added sequentially (first to last)

$\begin{array}{llllll} & \text { Df } & \text { Sum of Sq } & \text { Mean Sq } & \text { F Value } & \operatorname{Pr}(\mathrm{F}) \\ \text { GPA } & 1 & 7895.57 & 7895.565 & 35.96959 & 0.0000000 \\ \text { Involve } & 3 & 2827.12 & 942.373 & 4.29314 & 0.0056384 \\ \text { Grade } & 3 & 1458.60 & 486.201 & 2.21497 & 0.0869299 \\ \text { Gender } & 1 & 268.87 & 268.874 & 1.22490 & 0.2694773 \\ \text { GPA:Involve } & 3 & 611.48 & 203.826 & 0.92856 & 0.4275175 \\ \text { GPA:Grade } & 3 & 4474.07 & 1491.357 & 6.79413 & 0.0002031 \\ \text { GPA:Gender } & 1 & 39.94 & 39.936 & 0.18193 & 0.6700888 \\ \text { Residuals } & 247 & 54218.15 & 219.507 & & \end{array}$


$>$ anova(yfit4,ssType $=3$ )

Analysis of Variance Table

Response: Total

Type III Sum of Squares

$\begin{array}{llllll} & \text { Df } & \text { Sum of Sq } & \text { Mean Sq } & \text { F Value } & \operatorname{Pr}(\mathrm{F}) \\ \text { GPAnew } & 1 & 6961.45 & 6961.453 & 31.71409 & 0.0000000 \\ \text { Involve } & 3 & 3875.22 & 1291.739 & 5.88474 & 0.0006785 \\ \text { Grade } & 3 & 1046.05 & 348.684 & 1.58849 & 0.1927017 \\ \text { Gender } & 1 & 388.99 & 388.989 & 1.77211 & 0.1843490 \\ \text { GPAnew:Involve } & 3 & 148.84 & 49.612 & 0.22602 & 0.8782526 \\ \text { GPAnew:Grade } & 3 & 4509.09 & 1503.032 & 6.84732 & 0.0001893 \\ \text { GPAnew:Gender } & 1 & 39.94 & 39.936 & 0.18193 & 0.6700888 \\ \text { Residuals } & 247 & 54218.15 & 219.507 & & \end{array}$

$>$ anova(yfit4)

Analysis of Variance Table

Response: Total

Terms added sequentially (first to last)

$\begin{array}{llllll} & \text { Df } & \text { Sum of Sq } & \text { Mean Sq } & \text { F Value } & \operatorname{Pr}(F) \\ \text { GPAnew } & 1 & 7895.57 & 7895.565 & 35.96959 & 0.0000000 \\ \text { Involve } & 3 & 2827.12 & 942.373 & 4.29314 & 0.0056384 \\ \text { Grade } & 3 & 1458.60 & 486.201 & 2.21497 & 0.0869299 \\ \text { Gender } & 1 & 268.87 & 268.874 & 1.22490 & 0.2694773 \\ \text { GPAnew:Involve } & 3 & 611.48 & 203.826 & 0.92856 & 0.4275175 \\ \text { GPAnew:Grade } & 3 & 4474.07 & 1491.357 & 6.79413 & 0.0002031 \\ \text { GPAnew:Gender } & 1 & 39.94 & 39.936 & 0.18193 & 0.6700888 \\ \text { Residuals } & 247 & 54218.15 & 219.507 & & \end{array}$

Results for School-Academic Self-Esteem

$>$ anova(yf3,ssType $=3$ )

Analysis of Variance Table

Response: School

Type III Sum of Squares

$\begin{array}{llllll} & \text { Df } & \text { Sum of Sq } & \text { Mean Sq } & \text { F Value } & \text { Pr(F) } \\ \text { GPA } & 1 & 492.169 & 492.1693 & 49.10818 & 0.0000000 \\ \text { Involve } & 3 & 2.667 & 0.8891 & 0.08871 & 0.9661960 \\ \text { Grade } & 3 & 31.209 & 10.4029 & 1.03799 & 0.3763487 \\ \text { Gender } & 1 & 1.218 & 1.2182 & 0.12155 & 0.7276536 \\ \text { GPA:Involve } & 3 & 6.119 & 2.0397 & 0.20352 & 0.8939010 \\ \text { GPA:Grade } & 3 & 83.561 & 27.8536 & 2.77921 & 0.0417426 \\ \text { GPA:Gender } & 1 & 4.633 & 4.6330 & 0.46227 & 0.4971997 \\ \text { Residuals } & 247 & 2475.470 & 10.0221 & & \end{array}$


$>$ anova(yf3)

Analysis of Yariance Table

Response: School

Terms added sequentially (first to last)

$\begin{array}{llllll} & \text { Df } & \text { Sum of Sq } & \text { Mean Sq } & \text { F Value } & \text { Pr(F) } \\ \text { GPA } & 1 & 851.617 & 851.6175 & 84.97357 & 0.0000000 \\ \text { Involve } & 3 & 167.223 & 55.7409 & 5.56177 & 0.0010424 \\ \text { Grade } & 3 & 250.666 & 83.5553 & 8.33707 & 0.0000266 \\ \text { Gender } & 1 & 20.585 & 20.5854 & 2.05400 & 0.1530719 \\ \text { GPA:Involve } & 3 & 9.232 & 3.0775 & 0.30707 & 0.8202744 \\ \text { GPA:Grade } & 3 & 80.003 & 26.6676 & 2.66087 & 0.0487288 \\ \text { GPA:Gender } & 1 & 4.633 & 4.6330 & 0.46227 & 0.4971997 \\ \text { Residuals } & 247 & 2475.470 & 10.0221 & & \end{array}$

$>$ anova(yfit3,ssType $=3$ )

Analysis of Variance Table

Response: School

Type III Sum of Squares

$\begin{array}{llllll} & \text { Df } & \text { Sum of Sq } & \text { Mean Sq } & \text { F Value } & \operatorname{Pr}(\mathrm{F}) \\ \text { GPAnew } & 1 & 492.169 & 492.1693 & 49.10818 & 0.0000000 \\ \text { Involve } & 3 & 206.715 & 68.9050 & 6.87527 & 0.0001824 \\ \text { Grade } & 3 & 241.484 & 80.4945 & 8.03167 & 0.0000397 \\ \text { Gender } & 1 & 16.305 & 16.3048 & 1.62687 & 0.2033344 \\ \text { GPAnew:Involve } & 3 & 6.119 & 2.0397 & 0.20352 & 0.8939010 \\ \text { GPAnew:Grade } & 3 & 83.561 & 27.8536 & 2.77921 & 0.0417426 \\ \text { GPAnew:Gender } & 1 & 4.633 & 4.6330 & 0.46227 & 0.4971997 \\ \text { Residuals } & 247 & 2475.470 & 10.0221 & & \end{array}$

$>$ anova(yfit3)

Analysis of Variance Table

Response: School

Terms added sequentially (first to last)

$\begin{array}{llllll} & \text { Df } & \text { Sum of Sq } & \text { Mean Sq } & \text { F Value } & \operatorname{Pr}(\mathrm{F}) \\ \text { GPAnew } & 1 & 851.617 & 851.6175 & 84.97357 & 0.0000000 \\ \text { Involve } & 3 & 167.223 & 55.7409 & 5.56177 & 0.0010424 \\ \text { Grade } & 3 & 250.666 & 83.5553 & 8.33707 & 0.0000266 \\ \text { Gender } & 1 & 20.585 & 20.5854 & 2.05400 & 0.1530719 \\ \text { GPAnew:Involve } & 3 & 9.232 & 3.0775 & 0.30707 & 0.8202744 \\ \text { GPAnew:Grade } & 3 & 80.003 & 26.6676 & 2.66087 & 0.0487288 \\ \text { GPAnew:Gender } & 1 & 4.633 & 4.6330 & 0.46227 & 0.4971997 \\ \text { Residuals } & 247 & 2475.470 & 10.0221 & & \end{array}$


Results for General Self-Esteem

$>$ anova(yfl,ssType=3)

Analysis of Variance Table

Response: General

Type III Sum of Squares

$\begin{array}{llllll} & \text { Df } & \text { Sum of Sq } & \text { Mean Sq } & \text { F Value } & \operatorname{Pr}(\mathrm{F}) \\ \text { GPA } & 1 & 1475.75 & 1475.754 & 21.31315 & 0.0000063 \\ \text { Involve } & 3 & 260.22 & 86.740 & 1.25272 & 0.2912526 \\ \text { Grade } & 3 & 1369.45 & 456.482 & 6.59261 & 0.0002652 \\ \text { Gender } & 1 & 0.08 & 0.082 & 0.00119 & 0.9725419 \\ \text { GPA:Involve } & 3 & 114.88 & 38.292 & 0.55302 & 0.6465662 \\ \text { GPA:Grade } & 3 & 1695.16 & 565.052 & 8.16060 & 0.0000335 \\ \text { GPA:Gender } & 1 & 18.10 & 18.098 & 0.26138 & 0.6096315\end{array}$

$\begin{array}{llll}\text { Residuals } \quad 247 \quad 17102.65 & 69.241\end{array}$

$>$ anova(yfl)

Analysis of Variance Table

Response: General

Terms added sequentially (first to last)

$\begin{array}{llllll} & \text { Df } & \text { Sum of Sq } & \text { Mean Sq } & \text { F Value } & \operatorname{Pr}(\mathrm{F}) \\ \text { GPA } & 1 & 1070.81 & 1070.815 & 15.46493 & 0.0001092 \\ \text { Involve } & 3 & 629.58 & 209.858 & 3.03082 & 0.0300027 \\ \text { Grade } & 3 & 536.33 & 178.778 & 2.58195 & 0.0540142 \\ \text { Gender } & 1 & 186.14 & 186.141 & 2.68829 & 0.1023611 \\ \text { GPA:Involve } & 3 & 228.84 & 76.279 & 1.10164 & 0.3490889 \\ \text { GPA:Grade } & 3 & 1680.39 & 560.130 & 8.08951 & 0.0000368 \\ \text { GPA:Gender } & 1 & 18.10 & 18.098 & 0.26138 & 0.6096315 \\ \text { Residuals } & 247 & 17102.65 & 69.241 & & \end{array}$

$>$ anova(yfitl,ssType=3)

Analysis of Variance Table

Response: General

Type III Sum of Squares

$\begin{array}{llllll} & \text { Df } & \text { Sum of Sq } & \text { Mean Sq } & \text { F Value } & \operatorname{Pr}(\mathrm{F}) \\ \text { GPAnew } & 1 & 1475.75 & 1475.754 & 21.31315 & 0.0000063 \\ \text { Involve } & 3 & 910.86 & 303.619 & 4.38492 & 0.0049905 \\ \text { Grade } & 3 & 362.68 & 120.893 & 1.74597 & 0.1581581 \\ \text { Gender } & 1 & 250.97 & 250.968 & 3.62454 & 0.0580956 \\ \text { GPAnew:Involve } & 3 & 114.88 & 38.292 & 0.55302 & 0.6465662 \\ \text { GPAnew:Grade } & 3 & 1695.16 & 565.052 & 8.16060 & 0.0000335 \\ \text { GPAnew:Gender } & 1 & 18.10 & 18.098 & 0.26138 & 0.6096315 \\ \text { Residuals } & 247 & 17102.65 & 9.241 & & \end{array}$


$>$ anova(yfit1)

Analysis of Variance Table

Response: General

Terms added sequentially (first to last)

$\begin{array}{llllll} & \text { Df } & \text { Sum of Sq } & \text { Mean Sq } & \text { F Value } & \operatorname{Pr}(\mathrm{F}) \\ \text { GPAnew } & 1 & 1070.81 & 1070.815 & 15.46493 & 0.0001092 \\ \text { Involve } & 3 & 629.58 & 209.858 & 3.03082 & 0.0300027 \\ \text { Grade } & 3 & 536.33 & 178.778 & 2.58195 & 0.0540142 \\ \text { Gender } & 1 & 186.14 & 186.141 & 2.68829 & 0.1023611 \\ \text { GPAnew:Involve } & 3 & 228.84 & 76.279 & 1.10164 & 0.3490889 \\ \text { GPAnew:Grade } & 3 & 1680.39 & 560.130 & 8.08951 & 0.0000368 \\ \text { GPAnew:Gender } & 1 & 18.10 & 18.098 & 0.26138 & 0.6096315 \\ \text { Residuals } & 247 & 17102.65 & 69.241 & & \end{array}$

$\underline{\text { Results for Social Self-Peers Self-Esteem }}$

$>$ anova(yf2,ssType=3)

Analysis of Variance Table

Response: Social

Type III Sum of Squares

$\begin{array}{llllll} & \text { Df } & \text { Sum of Sq } & \text { Mean Sq } & \text { F Value } & \operatorname{Pr}(\mathrm{F}) \\ \text { GPA } & 1 & 28.611 & 28.61139 & 2.788726 & 0.0961964 \\ \text { Involve } & 3 & 26.405 & 8.80162 & 0.857886 & 0.4635681 \\ \text { Grade } & 3 & 218.115 & 72.70516 & 7.086504 & 0.0001379 \\ \text { Gender } & 1 & 0.115 & 0.11492 & 0.011201 & 0.9157988 \\ \text { GPA:Involve } & 3 & 11.503 & 3.83434 & .373729 & 0.7720287 \\ \text { GPA:Grade } & 3 & 172.633 & 57.54449 & 5.608807 & 0.0009792 \\ \text { GPA:Gender } & 1 & 0.1840 . & 18377 & 0.017912 & 0.8936404\end{array}$

$\begin{array}{llll}\text { Residuals } & 247 \quad 2534.137 & 10.25967\end{array}$

$>$ anova(yf2)

Analysis of Variance Table

Response: Social

Terms added sequentially (first to last)

$\begin{array}{llllll} & \text { Df } & \text { Sum of Sq } & \text { Mean Sq } & \text { F Value } & \operatorname{Pr}(\mathrm{F}) \\ \text { GPA } & 1 & 39.091 & 39.0913 & 3.81019 & 0.0520717 \\ \text { Involve } & 3 & 316.778 & 105.5926 & 10.29201 & 0.0000021 \\ \text { Grade } & 3 & 166.578 & 55.5259 & 5.41205 & 0.0012721 \\ \text { Gender } & 1 & 14.950 & 14.9504 & 1.45720 & 0.2285308 \\ \text { GPA:Involve } & 3 & 23.398 & 7.7992 & 0.76018 & 0.5173915 \\ \text { GPA:Grade } & 3 & 172.717 & 57.5723 & 5.61152 & 0.0009757 \\ \text { GPA:Gender } & 1 & 0.184 & 0.1838 & 0.01791 & 0.8936404 \\ \text { Residuals } & 247 & 2534.137 & 10.2597 & & \end{array}$


$>$ anova(yfit2,ssType $=3$ )

Analysis of Variance Table

Response: Social

Type III Sum of Squares

$\begin{array}{llllll} & \text { Df } & \text { Sum of Sq } & \text { Mean Sq } & \text { F Value } & \operatorname{Pr}(F) \\ \text { GPAnew } & 1 & 28.611 & 28.61139 & 2.788726 & 0.0961964 \\ \text { Involve } & 3 & 259.604 & 86.53469 & 8.434455 & 0.0000234 \\ \text { Grade } & 3 & 154.773 & 51.59109 & 5.028535 & 0.0021192 \\ \text { Gender } & 1 & 9.751 & 9.75134 & 0.950454 & 0.3305576 \\ \text { GPAnew:Involve } & 3 & 11.503 & 3.83434 & 0.373729 & 0.7720287 \\ \text { GPAnew:Grade } & 3 & 172.633 & 57.54449 & 5.608807 & 0.0009792 \\ \text { GPAnew:Gender } & 1 & 0.184 & 0.18377 & 0.017912 & 0.8936404 \\ \text { Residuals } & 247 & 2534.137 & 10.25967 & & \end{array}$

$>$ anova(yfit2)

Analysis of Variance Table

Response: Social

Terms added sequentially (first to last)

$\begin{array}{llllll} & \text { Df } & \text { Sum of Sq } & \text { Mean Sq } & \text { F Value } & \operatorname{Pr}(\mathrm{F}) \\ \text { GPAnew } & 1 & 39.091 & 39.0913 & 3.81019 & 0.0520717 \\ \text { Involve } & 3 & 316.778 & 105.5926 & 10.29201 & 0.0000021 \\ \text { Grade } & 3 & 166.578 & 55.5259 & 5.41205 & 0.0012721 \\ \text { Gender } & 1 & 14.950 & 14.9504 & 1.45720 & 0.2285308 \\ \text { GPAnew:Involve } & 3 & 23.398 & 7.7992 & 0.76018 & 0.5173915 \\ \text { GPAnew:Grade } & 3 & 172.717 & 57.5723 & 5.61152 & 0.0009757 \\ \text { GPAnew:Gender } & 1 & 0.184 & 0.1838 & 0.01791 & 0.8936404 \\ \text { Residuals } & 247 & 2534.137 & 10.2597 & & \end{array}$




\begin{abstract}
APPENDIX K
Comparison of the Parameter Estimate Tables for the Models with GPA and GPAnew
\end{abstract}

Tables K. 1 and K.2 show the relationship between the parameters in the reduced model with GPA and GPAnew. Note that the interaction parameters are identical in both models, which explains why the interaction effects and associated p-values are the same in both analyses. The intercepts and main effects are different in the two models. It is important to note that in the model with GPAnew, the three Grade parameters represent the differences between Grades 8, 10 and 12 when GPA = mean GPA, that is, when GPAnew $=0$, not when GPA $=0$. In other words, these parameters no longer represent the changes in the intercept, rather they represent the changes in mean self-esteem when $\mathrm{GPA}=2.76$ or the mean GPA.

Table K.1

Parameter Estimates, $t$-values, and significance of the independent variables to total selfesteem using GPA

\begin{tabular}{lcccc}
\hline & Value & Standard Error & $t$ value & $\operatorname{Pr}(>|t|)$ \\
\hline Intercept & 17.73 & 10.40 & 1.71 & 0.09 \\
GPA & 19.15 & 3.39 & 5.65 & 0.00 \\
Involvement 1 & 1.70 & 3.32 & 0.51 & 0.61 \\
Involvement 2 & 2.05 & 3.06 & 0.67 & 0.50 \\
Involvement 3 & 10.19 & 3.12 & 3.27 & 0.00 \\
Gender & 2.43 & 1.91 & 1.27 & 0.21 \\
Grade 8 & 16.65 & 13.36 & 1.25 & 0.21 \\
Grade 10 & 38.68 & 11.77 & 3.29 & 0.00 \\
Grade 12 & 43.35 & 11.43 & 3.79 & 0.00 \\
GPAnew:Grade 8 & -7.86 & 4.64 & -1.69 & 0.09 \\
GPAnew:Grade 10 & -15.90 & 4.07 & -3.90 & 0.00 \\
GPAnew:Grade 12 & -17.27 & 4.03 & -4.28 & 0.00 \\
\hline
\end{tabular}


Table K.2

Parameter Estimates, $t$-values, and significance of the independent variables to total selfesteem using GPAnew

\begin{tabular}{lcccc}
\hline & Value & Standard Error & t value & $\operatorname{Pr}(>|t|)$ \\
\hline Intercept & 70.67 & 3.34 & 21.15 & 0.00 \\
GPAnew & 19.15 & 3.39 & 5.65 & 0.00 \\
Involvement 1 & 1.70 & 3.32 & 0.51 & 0.61 \\
Involvement 2 & 2.05 & 3.06 & 0.67 & 0.50 \\
Involvement 3 & 10.19 & 3.12 & 3.27 & 0.00 \\
Gender & 2.43 & 1.91 & 1.27 & 0.21 \\
Grade 8 & -5.07 & 2.63 & -1.92 & 0.06 \\
Grade 10 & -5.28 & 2.65 & -1.99 & 0.05 \\
Grade 12 & -4.40 & 2.77 & -1.59 & 0.11 \\
GPAnew:Grade 8 & -7.86 & 4.64 & -1.69 & 0.09 \\
GPAnew:Grade 10 & -15.90 & 4.07 & -3.90 & 0.00 \\
GPAnew:Grade 12 & -17.27 & 4.03 & -4.28 & 0.00 \\
\hline
\end{tabular}

When Involvement and Gender were added to the model, the corresponding parameters and their interpretation are the same regardless of whether GPA or GI'Anew are used. These parameters correspond to a shift upward or downward on the line reiating self-esteem and GPA. Thus, they may be interpreted as the difference in mean selfesteem for any value of GPA, including GPA $=0$ or GPA $=2.76$ (the mean GPA). 